AUTARQUIA ASSOCIADA À UNIVERSIDADE DE SÃO PAULO

Efeitos da radiação gama nas propriedades de blendas de amido termoplástico e suas misturas com poli(butileno adipato-co-tereftalato)

\author{
DIONE PEREIRA DE CASTRO
}

Dissertação apresentada como parte dos requisitos para obtenção do título de Mestre em Ciências na Área de Tecnologia Nuclear - Aplicações

Orientador:

Prof. Dr. Leonardo Gondim de Andrade e Silva

São Paulo 
INSTITUTO DE PESQUISAS ENERGÉTICAS E NUCLEARES

Autarquia associada à Universidade de São Paulo

Efeitos da radiação gama nas propriedades de blendas de amido termoplástico e suas misturas com poli(butileno adipato-co-tereftalato)

DIONE PEREIRA DE CASTRO

Dissertação apresentada como parte dos requisitos para obtenção do título de Mestre em Ciências na Área de Tecnologia Nuclear - Aplicações

Orientador:

Prof. Dr. Leonardo Gondim de Andrade e Silva

Versão Corrigida

Versão Original disponível no IPEN

São Paulo

2019 
Autorizo a reprodução e divulgação total ou parcial deste trabalho, para fins de estudo e pesquisa, desde que citada a fonte.

Como citar:

CASTRO, Dione Pereira de. Efeitos da radiação gama nas propriedades de blendas de amido termoplástico e suas misturas com poli(butileno adipato-co-tereftalato). 2019. 103 p.

Dissertação (Mestrado em Tecnologia Nuclear - Aplicações), Instituto de Pesquisas Energéticas e Nucleares, Universidade de São Paulo, São Paulo, 2019. Disponível em: www.teses.usp.br (data da consulta no formato: $\mathrm{dd} / \mathrm{mm} / \mathrm{aaaa})$.

Ficha catalográfica elaborada pelo Sistema de geração automática da Biblioteca IPEN/USP, com os dados fornecidos pelo(a) autor(a).

Castro, Dione Pereira de

Efeitos da radiação gama nas propriedades de blendas de amido termoplástico e suas misturas com poli(butileno adipato- $c o$-tereftalato) / Dione Pereira de Castro; orientador Leonardo Gondim de Andrade e Silva. - - São Paulo, 2019.

$103 \mathrm{p}$.

Dissertação (Mestrado) - Programa de Pós-Graduação em Tecnologia Nuclear (Aplicações) - - Instituto de Pesquisas Energéticas e Nucleares, Universidade de São Paulo, São Paulo, 2019.

1. Radiação gama. 2. Blendas. 3. TPS. 4. PBAT. I. Andrade e Silva, Leonardo Gondim de, orient. II.

Título. 
Autor: Dione Pereira de Castro

Orientador: Prof. Dr. Leonardo Gondim de Andrade e Silva

Título: Efeitos da radiação gama nas propriedades de blendas de amido termoplástico e suas misturas com poli(butileno adipato-co-tereftalato)

Dissertação apresentada ao Programa de Pós-Graduação em Tecnologia Nuclear da Universidade de São Paulo para obtenção do título de Mestre em Ciências.

Área de Concentração:

Tecnologia Nuclear - Aplicações

Data: 29/04/2019

BANCA EXAMINADORA

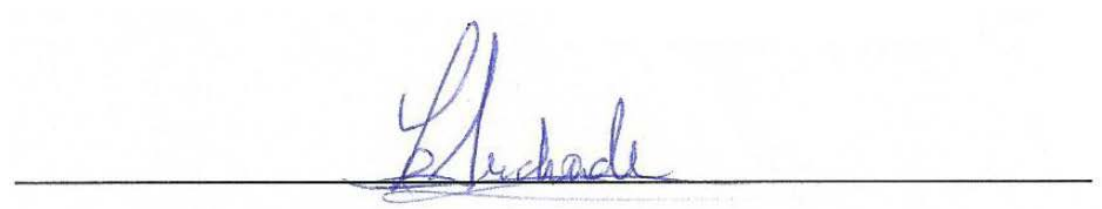

Prof. Dr. Leonardo Gondim de Andrade e Silva (Presidente)

Instituição: IPEN/USP Julgamento: APROVADO

Siciane Sanches Valura

Profa. Dra. Ticiane Sanches Valera

Instituição: POLI/USP Julgamento: APROVADO

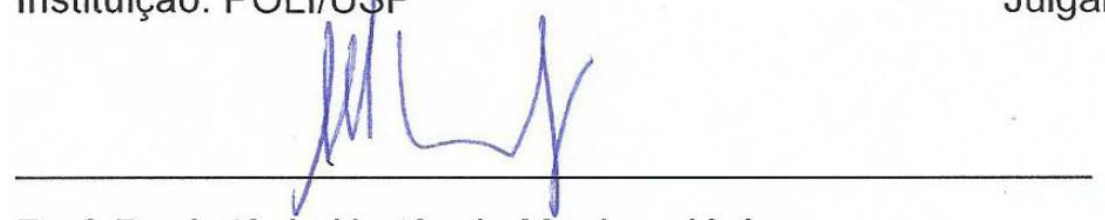

Prof. Dr. Antônio Hortêncio Munhoz Júnior

Instituição: Universidade Presbiteriana Mackenzie Julgamento: Aprovado 


\section{AGRADECIMENTOS}

Primeiramente ao Prof. Dr. Leonardo Gondim de Andrade e Silva pelo apoio, amizade, sabedoria, orientação e por acreditar que tudo é possível, assim contribuindo para minha formação como pessoa, profissional e pesquisador. Faltam palavras de agradecimento, sobra gratidão. Muito obrigado professor!

Ao Prof. Dr. Júlio Harada, pelo incentivo ao projeto, apoio e fornecimento das amostras.

Ao Prof. Dr. Alberto Saburo Todo, pelo conhecimento, sabedoria e apoio.

Ao Prof. Dr. Ademar Benévolo Lugão, pela oportunidade e contato com a ciência no início da minha carreira de pesquisador, no Centro de Química e Meio Ambiente.

Ao Prof. Dr. Luís Antônio Albiac Terremoto e Prof. Dr. Javier GonzálezMantecón do Centro de Engenharia Nuclear, pela oportunidade, convivência e aprendizado durante meu estágio em docência no Programa de Aperfeiçoamento de Ensino da Universidade de São Paulo.

À Profa. Dra. Martha Marques Ferreira Vieira e Prof. Dr. Afonso Rodrigues de Aquino do Centro de Ensino e Informação, pelas contribuições e ensinamentos na redação científica e apresentações.

À Ingredion e A. Azevedo Ind. e Comércio de Óleos, pelo fornecimento das amostras.

À Profa. Dra. Maria da Conceição Costa Pereira, pela ajuda, incentivo e contribuição no projeto.

Ao Prof. MSc. Djalma Batista Dias, pela ajuda, contribuição e incentivo ao projeto.

Ao Prof. Dr. Samir Luiz Somessari e Eng. Elizabeth S. Ribeiro Somessari, pela contribuição e irradiação das amostras.

Ao Dr. Pablo Antonio Vásquez Salvador, pelo apoio e contribuição na parte de irradiação.

À Profa. Dra. Luci Diva Brocardo Machado, pela paciência, ensinamentos, contribuição no projeto e análises térmicas.

Ao técnico Eduardo de Moura, pelas análises de FTIR. 
Ao Prof. Dr. René Ramos de Oliveira, Prof. Dr. Nelson Batista de Lima e Prof. Dr. Rafael H. Lazzari Garcia, pelas análises, contribuições e ensinamentos na difração de raios $X$.

Ao Prof. Rogério Aparecido Lopes da Silva da Universidade Presbiteriana Mackenzie, pelas análises morfológicas.

Ao Prof. MSc. Carlos Fernandes da Silva e a Fatec Mauá, pelo ensino, ajuda e contribuição no desenvolvimento desse projeto.

A MSc. Mariana do Nascimento Sartori, pelo apoio, incentivo e contribuição ao projeto.

À minha família e a todos aqueles que contribuíram para o desenvolvimento desse projeto.

Ao pessoal da secretaria, ao Paulo A. Balan Junior e especialmente à Bruna Roque da Silva, por me ajudar e auxiliar nos processos administrativos da pósgraduação.

A Profa. Dra. Ticiane Sanches Valera e a MSc. Carla Almêda Correia do Departamento de Engenharia Metalúrgica e de Materiais da POLI/USP, pela ajuda e contribuição no projeto.

Ao Instituto de Pesquisas Energéticas e Nucleares e ao Centro de Tecnologia das Radiações, pela disponibilização de equipamentos e possibilidade de desenvolvimento desse projeto.

À Universidade de São Paulo, pelo ensino e bolsa concedida no Programa de Aperfeiçoamento de Ensino.

Ao Pai do Céu, que permitiu pelos seus caminhos de luz, que esse projeto se encaminhasse até o final. 
"Faça as coisas o mais simples que você puder, porém não se restrinja às mais simples."

Albert Einstein 


\title{
EFEITOS DA RADIAÇÃO GAMA NAS PROPRIEDADES DE BLENDAS DE AMIDO TERMOPLÁSTICO E SUAS MISTURAS COM POLI(BUTILENO ADIPATO-CO-TEREFTALATO)
}

\author{
Dione Pereira de Castro
}

\section{RESUMO}

Diversas alternativas têm sido buscadas para minimizar o impacto ambiental causado pelos polímeros convencionais. Uma importante alternativa é o uso de polímeros biodegradáveis; no entanto, em razão do seu custo elevado quando comparados com polímeros convencionais, surgiu à necessidade de desenvolver misturas poliméricas biodegradáveis utilizando aditivos naturais degradáveis, menos agressivos ao meio ambiente; os quais podem ser degradados pela ação de micro-organismos ou enzimas. Este trabalho teve como objetivo preparar blendas de amido termoplástico (thermoplastic starch, TPS) obtidos com glicerol, óleo de mamona (OM) e TWEEN ${ }^{\circledR} 80$ com poli(butileno adipato-co-tereftalato) (PBAT), por extrusão. Posteriormente as blendas foram submetidas ao processo de irradiação com dose de 25 kGy e caracterizadas por análises termogravimétrica (TGA); calorimetria exploratória diferencial por fluxo de calor (DSC); espectroscopia vibracional de absorção no infravermelho por transformada de Fourier (FTIR); microscopia eletrônica de varredura (MEV); difração de raios X (DRX) e índice de cristalinidade (IC). Os resultados mostraram maior degradabilidade térmica para as blendas F2 (compostas por OM) e F3 (compostas por OM e TWEEN ${ }^{\circledR} 80$ ) em relação as blendas F0 (compostas por glicerol) e F1 (compostas por glicerol e TWEEN $^{\circledR} 80$ ). Observou-se uma boa interação química entre os componentes das misturas e a sua miscibilidade parcial para as misturas F0 e F1, comparadas com as demais. No entanto, as misturas F2 e F3 não tiveram fases co-contínuas; sendo que as curvas padrões de DRX das amostras não foram alteradas pela radiação gama. Os IC tiveram alterações antes e após a irradiação de acordo com o plastificante utilizado. Assim, as amostras irradiadas e não irradiadas não tiveram suas propriedades alteradas nos testes realizados. Pôde-se concluir que é viável a substituição do óleo de mamona por glicerol em blendas de TPS/PBAT.

Palavras-chave: Radiação gama, Blendas, TPS, PBAT. 


\title{
EFFECTS OF GAMMA RADIATION ON THE PROPERTIES OF THE THERMOPLASTIC STARCH/POLY(BUTYLENE ADIPATE-CO- TEREPHTHALATE) BLENDS
}

\author{
Dione Pereira de Castro
}

\section{ABSTRACT}

Several alternatives have been sought to minimize the environmental impact caused by conventional polymers. The use of biodegradable polymers is an important alternative for this; however, when compared to conventional polymers, the biodegradable ones have higher costs. Thus, the development of polymeric blends using matrices of biodegradable and synthetic polymers with natural additive, less environmentally aggressive materials that can be degraded by the action of microorganisms or enzymes, was considered. This work aimed to prepare blends of thermoplastic starch (TPS) obtained with glycerol, castor oil (OM) and TWEEN $^{\circledR} 80$ with poly(butylene adipate-co-terephthalate) (PBAT) by extrusion. Posteriorly, the blends were submitted to the irradiation process at a dose of $25 \mathrm{kGy}$ and characterized by thermogravimetric analysis (TGA); differential heat flow scanning calorimetry (DSC); Fourier transform infrared spectroscopy (FTIR); scanning electron microscopy (SEM); X-ray diffraction (XRD), and crystallinity index (Cl). The results demonstrated increased thermal degradation for the F2 (composed by $\mathrm{OM}$ ) and $\mathrm{F} 3$ (composed by OM and TWEEN ${ }^{\circledR} 80$ ) regarding F0 (composed by glycerol) e F1 (composed by glycerol and TWEEN ${ }^{\circledR} 80$ ) blends. A good blend component chemical interaction and partial miscibility for the blends F0 and F1 was observed and compared to the others. However, F2 and F3 blends did not present co-continuous phases; being that the XRD curve patterns were not altered by the gamma radiation. Changes in the crystallinity indexes $(\mathrm{Cl})$ were observed before and after irradiation according to the plasticizer used. The tests performed demonstrated that the irradiated and non-irradiated samples did not have their properties significantly altered. Thus, it was concluded that it is feasible to replace castor oil with glycerol in TPS/PBAT blends.

Key words: Gamma radiation, Blends, TPS, PBAT. 


\section{LISTA DE TABELAS}

Tabela 1 - Principais interações da radiação ionizante e suas consequências ................... 25

Tabela 2 - Propriedades químicas gerais do PBAT $\left(\right.$ Ecoflex $\left.^{\circledR}\right)$.............................................. 30

Tabela 3 - Algumas fontes de amido e suas composições químicas ................................... 35

Tabela 4 - Propriedades físico-químicas do óleo de mamona industrializado ..................... 42

Tabela 5 - Propriedades físico-químicas do TWEEN ${ }^{\circledR} 80$ (P1754) ....................................... 46

Tabela 6 - Formulações e composições das blendas de TPS/PBAT adicionadas de

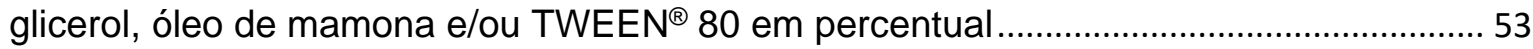

Tabela 7 - Tipos de vibrações moleculares e suas consequências ...................................... 60

Tabela 8 - Temperaturas (Tonset) dos componentes e das blendas, calculadas pelas curvas mostradas nas Figuras 33 e 34 e interpretadas pelo software TA Universal

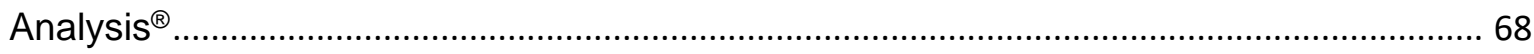

Tabela 9 - Bandas de absorção FTIR características das blendas F0-F1 ........................... 73

Tabela 10 - Bandas de absorção FTIR características das blendas F2-F3......................... 74

Tabela 11 - Valores de $2 \theta$ do amido tipo A e do PBAT $\left(\right.$ Ecoflex $\left.^{\circledR}\right)$.......................................... 80

Tabela 12 - Índices de cristalinidade (IC) das blendas, calculados por meio das curvas de

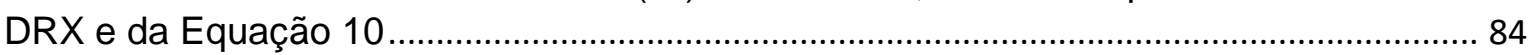

Tabela 15 - Micrografias das blendas F0 em diferentes magnificações (25x, 27x, 200x,

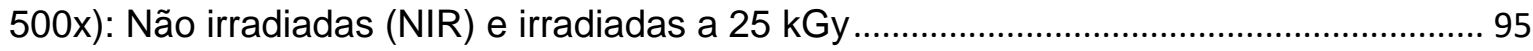

Tabela 16 - Micrografias das blendas F1 em diferentes magnificações (27x, 30x, 200x,

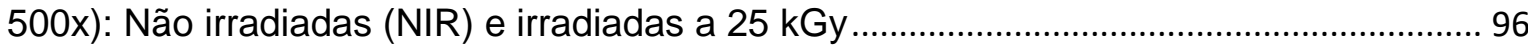

Tabela 17 - Micrografias das blendas F2 em diferentes magnificações (27x, 30x, 200x, 500x): Não irradiadas (NIR) e irradiadas a 25 kGy........................................................... 97

Tabela 18 - Micrografias das blendas F3 em diferentes magnificações (27x, 200x, 500x):

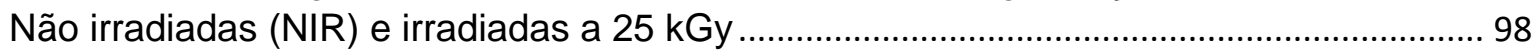

Tabela 19 - Área total de integração da curva de DRX da blenda F0 - (NIR/25 kGy) ...... 99

Tabela 20 - Área dos picos de integração da curva de DRX da blenda F0 - (NIR/25 kGy)

após correção de linha base

Tabela 21 - Área total de integração da curva de DRX da blenda F1 - (NIR/25 kGy) .... 100

Tabela 22 - Área dos picos de integração da curva de DRX da blenda F1 - (NIR/25 kGy)

após correção de linha base

Tabela 23 - Área total de integração da curva de DRX da blenda F2 - (NIR/25 kGy) .... 101

Tabela 24 - Área dos picos de integração da curva de DRX da blenda F2 - (NIR/25 kGy)

após correção de linha base

101

Tabela 25 - Área total de integração da curva de DRX da blenda F3 - (NIR/25 kGy) .... 102

Tabela 26 - Área dos picos de integração da curva de DRX da blenda F3 - (NIR/25 kGy) após correção de linha base 


\section{LISTA DE FIGURAS}

Figura 1 - Classificação dos polímeros biodegradáveis........................................................ 20

Figura 2 - llustração das estruturas químicas: a) PHB; b) PHB-HV ...................................... 21

Figura 3 - Ilustração da rota de obtenção do polietileno verde ............................................. 22

Figura 4 - Espectro eletromagnético das radiações ............................................................... 24

Figura 5 - Variação da intensidade do feixe em função da espessura................................. 26

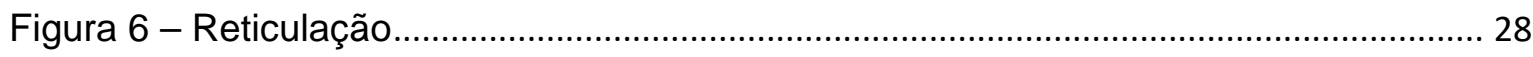

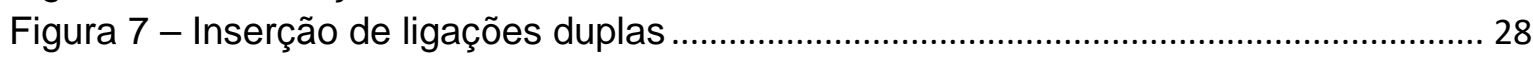

Figura 8 - Formação de radicais livres e moléculas-íons........................................................ 28

Figura 9 - llustração da estrutura química do PBAT ............................................................ 30

Figura 10: Filmes de PBAT excitados ao laser $(\lambda=405 \mathrm{~nm})$, após irradiação com fonte

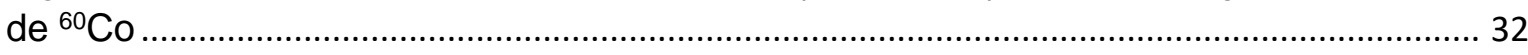

Figura 11 - llustração das estruturas químicas do amido: a) amilose; b) amilopectina .... 34 Figura 12 - Ilustração das estruturas químicas: a) glicerol; b) ácido oleico .......................... 38 Figura 13 - Ilustração da modificação química da amilose, induzida por feixe de elétrons

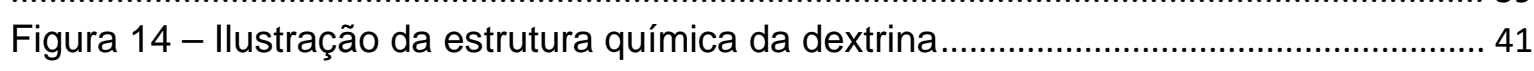

Figura 15 - Ilustração da estrutura química do triacilglicerol do ácido ricinoleico ............... 42

Figura 16 - Ilustração da reação de transesterificação de diácidos/poliois com o ácido ricinoleico

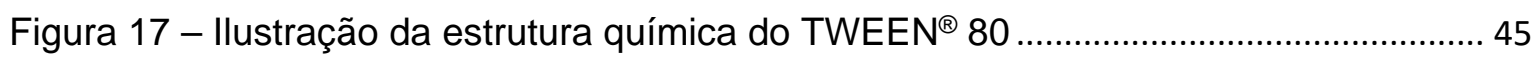

Figura 18 - Perfil longitudinal interno de uma extrusora ..................................................... 47

Figura 19 - Tipos de entrelaçamento e sentido das roscas de dupla extrusão ................... 48

Figura 20 - Perfil transversal de rosca com detalhamento (L/D) ....................................... 48

Figura 21 - Reação química entre o amido e o anidrido maleico por extrusão reativa..... 49

Figura 22 - Curvas termogravimétricas do amido in natura................................................ 54

Figura 23 - Representação esquemática para obtenção das blendas de TPS/PBAT ...... 55

Figura 24 - Mistura mecânica das formulações de blendas de TPS/PBAT ......................... 55

Figura 25 - Extrusora utilizada para obtenção de blendas de TPS/PBAT ............................ 56

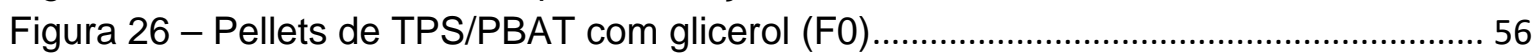

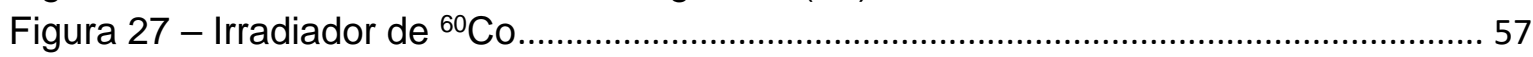

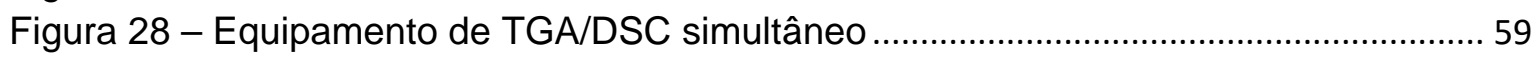

Figura 29 - Funcionamento típico de um dispositivo de ATR-FTIR ....................................... 61

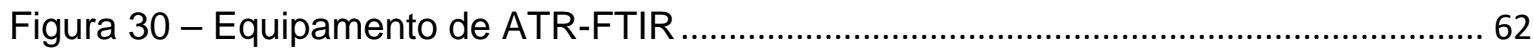

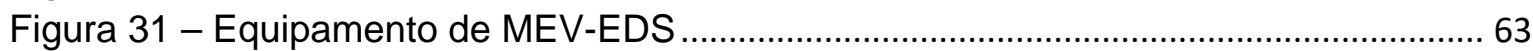

Figura 32 - Equipamento de difração de raios X com detalhe interno do difratometro ..... 64

Figura 33 - Curvas termogravimétricas das amostras NIR e seus componentes............... 66

Figura 34 - Curvas termogravimétricas das amostras irradiadas a 25 kGy e seus

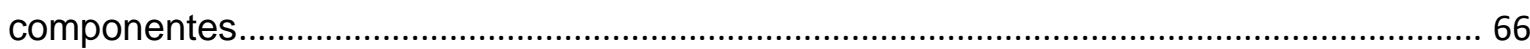

Figura 35 - Curvas termogravimétricas com destaque para a Tonset da formulação F2. 67

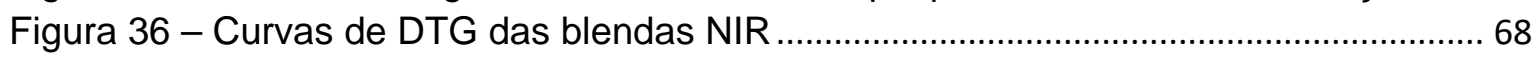

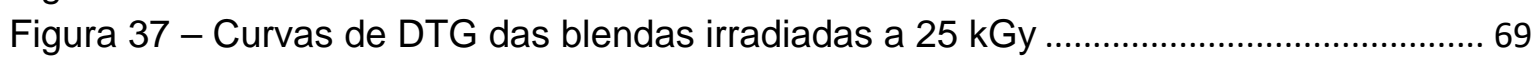

Figura 38 - Curvas de TGA/DSC das blendas não irradiadas (NIR) .................................. 71

Figura 39 - Curvas de TGA/DSC das blendas irradiadas a $25 \mathrm{kGy}$..................................... 71

Figura 40 - Espectros de ATR-FTIR das blendas F0 (NIR/25 kGy) ................................... 73

Figura 41 - Espectros de ATR-FTIR das blendas F1 (NIR/25 kGy) .................................. 73 
Figura 42 - Espectros de ATR-FTIR das blendas F2 (NIR/25 kGy) ….............................. 74

Figura 43 - Espectros de ATR-FTIR das blendas F3 (NIR/25 kGy) ................................... 74

Figura 44 - Espectros de FTIR (transmitância) do amido puro irradiado de 0 a 20 kGy .. 75

Figura 45 - Espectro de FTIR (absorbância) do PBAT ........................................................ 76

Figura 46 - Micrografias das blendas F0 (NIR/25 kGy) com magnificação de 200x ......... 78

Figura 47 - Micrografias das blendas F1 (NIR/25 kGy) com magnificação de 200x ......... 78

Figura 48 - Micrografias das blendas F2 (NIR/25 kGy) com magnificação de 200x ......... 79

Figura 49 - Micrografias das blendas F3 (NIR/25 kGy) com magnificação de 200x ......... 79

Figura 50 - Curvas de DRX das blendas F0 (NIR/25 kGy) ............................................... 81

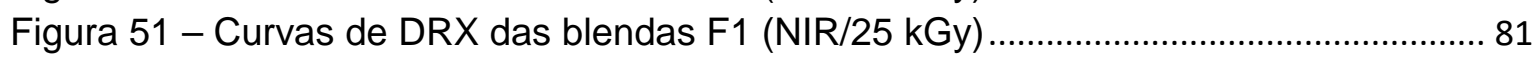

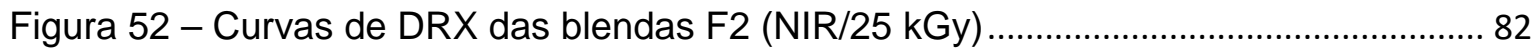

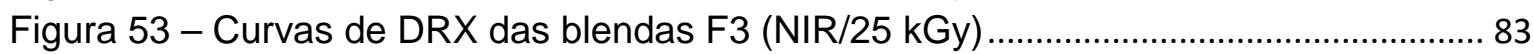

Figura 54 - Área total da região cristalina da blenda F0 - (NIR/25 kGy), após a correção

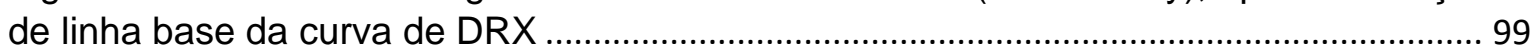

Figura 55 - Área total da região cristalina da blenda F1 - (NIR/25 kGy), após a correção

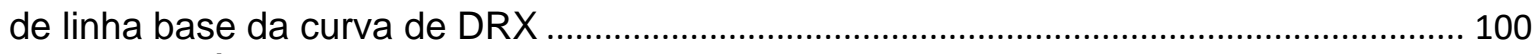

Figura 56 - Área total da região cristalina da blenda F2 - (NIR/25 kGy), após a correção

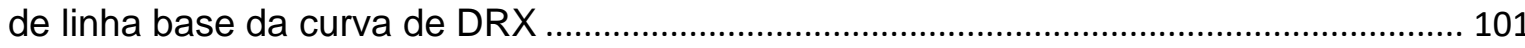

Figura 57 - Área total da região cristalina da blenda F3 - (NIR/25 kGy), após a correção

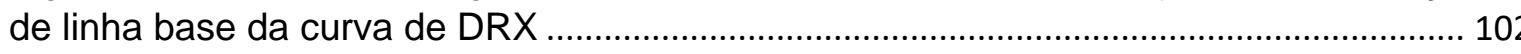




\section{LISTA DE ABREVIATURAS E SIGLAS}

\begin{tabular}{|c|c|}
\hline ASTM & American Society for Testing and Materials \\
\hline AFM & Atomic Force Microscopy - Microscopia de força atômica \\
\hline ATR-FTIR & $\begin{array}{l}\text { Attenuated Total Reflection Fourier Transform Infrared Spectroscopy } \\
\text { - Espectroscopia vibracional de absorção no infravermelho por } \\
\text { transformada de Fourier com Refletância Total Atenuada }\end{array}$ \\
\hline ССТM & Centro de Ciência e Tecnologia dos Materiais \\
\hline CNEN/SP & Comissão Nacional de Energia Nuclear de São Paulo \\
\hline CTR & Centro de Tecnologia das Radiações \\
\hline DMA & Dynamic Mechanical Analysis - Análise mecânico dinâmica \\
\hline DRX & Difração de raios $X$ \\
\hline DSC & $\begin{array}{l}\text { Differential Scanning Calorimetry - Calorimetria exploratória } \\
\text { diferencial }\end{array}$ \\
\hline et al. & et alii - e outros \\
\hline HDT & Heat Deflection Temperature - Temperatura de deflexão térmica \\
\hline IPEN & Instituto de Pesquisas Energéticas e Nucleares \\
\hline MA & Maleic Anhydride - Anidrido maleico \\
\hline MEH-PPV & Poli[2-metóxi-5-(2'-etilhexilóxi)-1,4-fenilenovinileno] \\
\hline MEV & Microscopia Eletrônica de Varredura \\
\hline MTPS & Maleated thermoplastic starch - Amido termoplástico maleatado \\
\hline NIR & Amostras não irradiadas \\
\hline $\mathrm{OM}$ & Óleo de mamona \\
\hline PCA & Poli(acetato de celulose) \\
\hline PCL & Poli(ع-caprolactona) \\
\hline PBAT & Poli(butileno adipato-co-tereftalato) \\
\hline PBSA & Poli(butileno succinato-co-adipato) \\
\hline PE & Polietileno \\
\hline PEG & Polietileno glicol \\
\hline PHB & Poli(hidroxibutirato) \\
\hline PHB-HV & Poli(hidroxibutirato-co-valerato) \\
\hline
\end{tabular}


PL Fotoluminescência

PLA Poli(ácido láctico)

PP Polipropileno

PP-g-MA Polypropylene-graft-Maleic Anhydride - Polipropileno grafitizado com anidrido maleico

PSGG Pea Starch-Guar Gum - Ervilha-goma guar

PU Poliuretano

PVC Policloreto de vinila

PVOH Poli(álcool vinílico)

REM Radiação eletromagnética

RNM Nuclear Magnetic Resonance - Ressonância magnética nuclear

TGA Thermogravimetric Analysis - Análise termogravimétrica

TPS Termoplastic Starch - Amido termoplástico

UTM Universal Testing Mechanical - Máquina de teste mecânico universal

UVA/UVC Tipos de radiação ultravioleta A/C 


\section{LISTA DE SÍMBOLOS}

\begin{tabular}{|c|c|}
\hline (R) & Marca registrada \\
\hline$\%$ & Porcentagem \\
\hline$\alpha$ & Radiação alfa \\
\hline$\beta$ & Radiação beta \\
\hline eV & Elétron volt \\
\hline$\gamma$ & Gama, letra grega que representa a radiação gama \\
\hline Gy & Gray, unidade de dose absorvida de radiação \\
\hline $\mathrm{J}$ & $\begin{array}{l}\text { Joule, unidade de medida de energia mecânica, equivalente no } \\
\text { Sistema Internacional de Unidades }(\mathrm{SI}) \text { a }\left(\mathrm{kg} \cdot \mathrm{m}^{2} / \mathrm{s}^{2}\right)\end{array}$ \\
\hline $\mathrm{kg}$ & Quilograma \\
\hline$\mu$ & Mi, letra grega que representa a unidade micro \\
\hline${ }^{60} \mathrm{Co}$ & Radionuclídeo Cobalto-60 \\
\hline $\mathrm{MeV}$ & Megaeletron volt (equivalente a $10^{6} \mathrm{eV}$ ) \\
\hline kGy & Quilogray (equivalente a $10^{3} \mathrm{~Gy}$ ) \\
\hline $\mathrm{H}_{2}$ & Gás hidrogênio \\
\hline $\mathrm{e}^{-}$ & Elétron \\
\hline $\mathrm{g} / \mathrm{cm}^{3}$ & Gramas por centímetro cúbico \\
\hline $\mathrm{g} / 10 \mathrm{~min}$ & Gramas por 10 minutos \\
\hline $\mathrm{g} / \mathrm{min}$ & Gramas por minuto \\
\hline${ }^{\circ} \mathrm{C}$ & Grau Celsius \\
\hline $\mathrm{NH}_{2}$ & Grupo amida \\
\hline$-\mathrm{OH}$ & Grupo hidroxila \\
\hline $\mathrm{g} / \mathrm{mL}$ & Gramas por mililitro \\
\hline$\lambda$ & $\begin{array}{l}\text { Lambda, letra grega que representa o comprimento de onda } \\
\text { incidente }\end{array}$ \\
\hline $\mathrm{T}_{\mathrm{m}}$ & Temperatura de fusão \\
\hline$\Delta \mathrm{H}$ & Entalpia \\
\hline $\mathrm{T}_{\mathrm{g}}$ & Temperatura de transição vítrea \\
\hline
\end{tabular}


$2 \theta$ Dois teta, Parâmetro angular indicativo de uma reflexão em curva de difração de raios $x$

$\quad$ Til, notação utilizada para representar o termo aproximadamente

kGy/h Quilogray por hora

$\mu \mathrm{A} \quad$ Miliampère

Gy/s Gray por segundo

$\mathrm{Mn}_{\mathrm{n}} \quad$ Massa molar numérica média

$\mathrm{M}_{\mathrm{w}} \quad$ Massa molar ponderada média

Cis $\quad$ Configuração espacial química para polímeros

$\pm \quad$ Mais ou menos

Gy/min Gray por minuto

$\mathrm{nm} \quad$ Nanometro $\left(10^{-9} \mathrm{~m}\right)$

g/mol Gramas por mol

$\geq \quad$ Igual ou maior

$\mathrm{mM} \quad$ Micelas por mol

${ }^{\circ} \mathrm{C} / \mathrm{min} \quad$ Graus Celsius por minuto

$\mathrm{T}_{\max } \quad$ Temperatura máxima de ativação

$\mathrm{pH} \quad$ Potencial hidrogeniônico

u $\quad$ Unidade de massa atômica

g Grama

rpm Rotações por minuto

m Massa

t Tempo

$\Delta \mathrm{t} \quad$ Variação de temperatura

$\mathrm{mL} / \mathrm{min} \quad$ Microlitros por minuto

cm Centímetro

kV Quilovolt $\left(10^{3} \mathrm{v}\right)$

S Segundo

$0^{\circ} \quad 0$ Graus Celcius

Ic Índice de cristalinidade de polímeros

$\mathrm{mm}^{3} \quad$ Milímetro cúbico 
Tonset Temperatura inicial de degradação em análise termogravimétrica

Tendset Temperatura final de degradação em análise termogravimétrica 200x Ampliação de 200x 
SUMÁRIO

1 INTRODUÇÃO

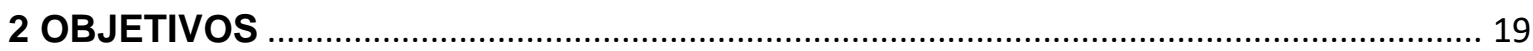

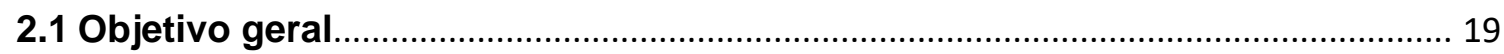

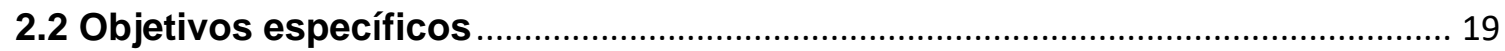

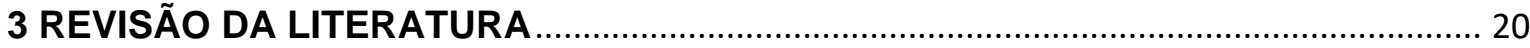

3.1 Biopolímeros, polímeros biodegradáveis e polímeros verdes............................ 20

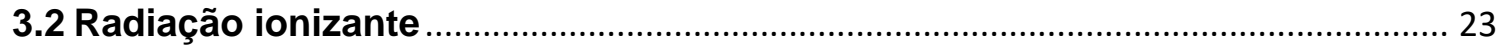

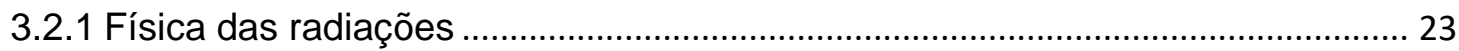

3.2.2 Efeitos das radiações nos polímeros e polímeros biodegradáveis ..................... 27

3.2.2.1 Irradiação de polímeros naturais e suas consequências .................................. 29

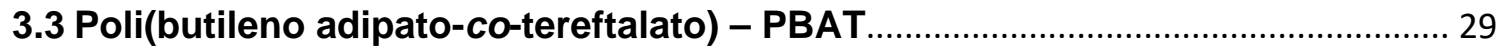

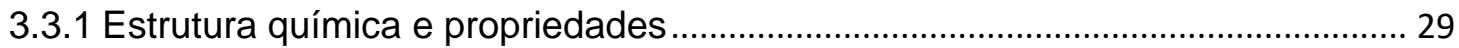

3.3.2 Interação com a radiação ionizante...................................................................... 31

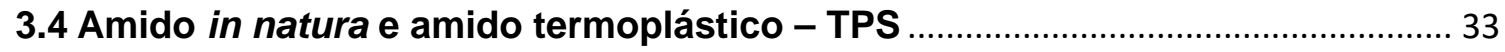

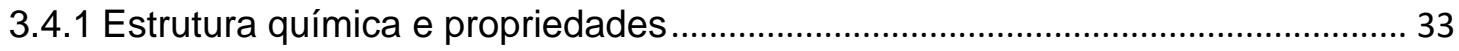

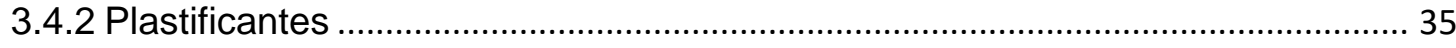

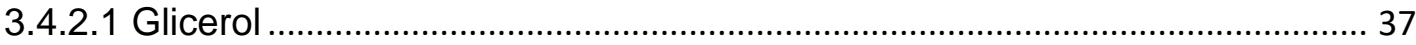

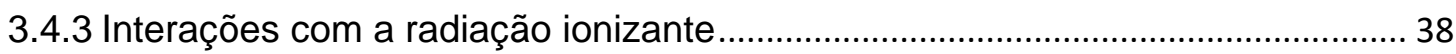

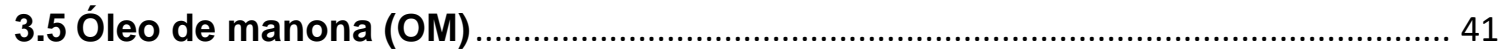

3.5.1 Estrutura, funcionalidades químicas e propriedades ........................................... 41

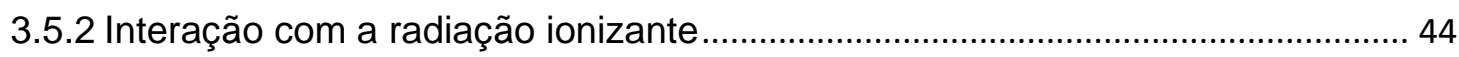

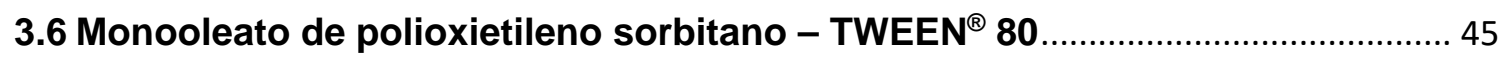

3.6.1 Estrutura química, propriedades e aplicações........................................................ 45

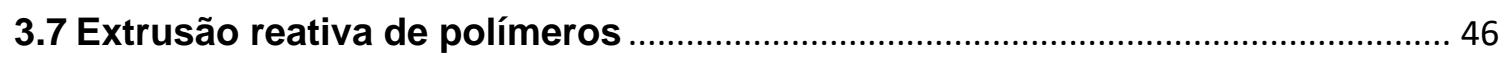

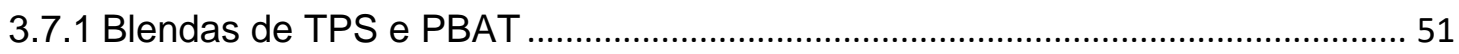

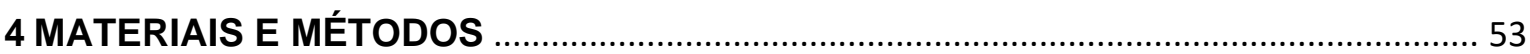

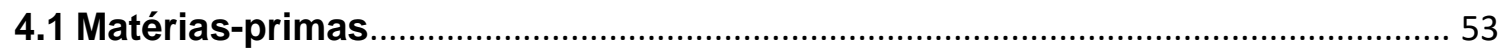

4.2 Preparação das amostras e procedimento experimental ....................................... 53

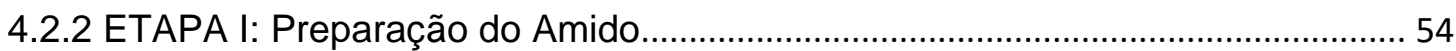

4.2.3 ETAPA II: Preparação das misturas e obtenção das blendas de TPS/PBAT ... 55

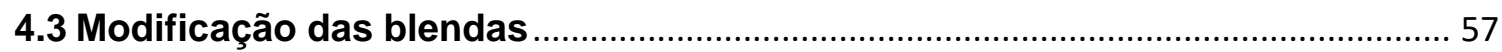

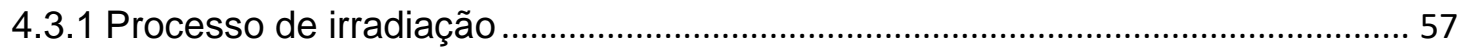

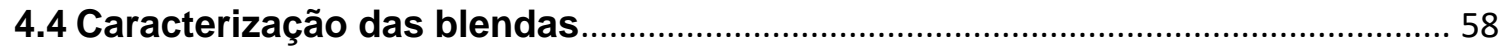


4.4.1 Análise termogravimetrica (TGA) e calorimetria exploratória diferencial por fluxo

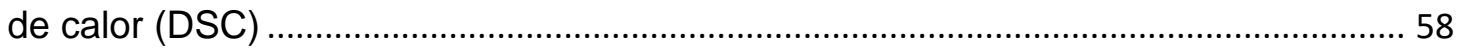

4.4.2 Espectroscopia vibracional de absorção no infravermelho por transformada de

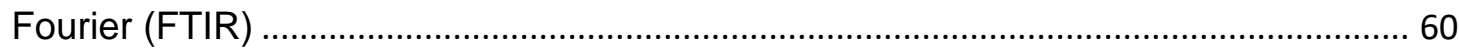

4.4.3 Microscopia eletrônica de varredura (MEV) ………………………....................... 62

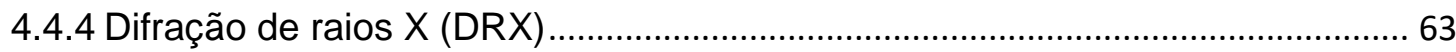

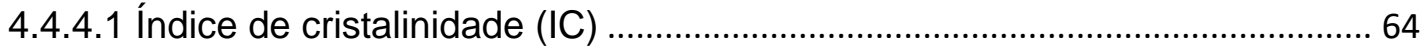

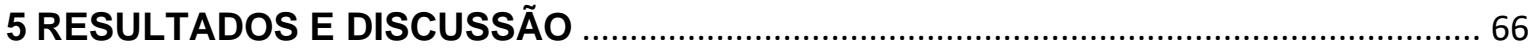

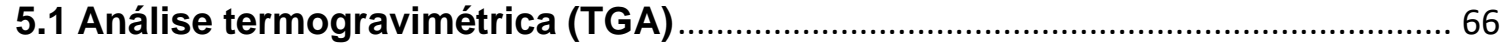

5.2 Calorimetria exploratória diferencial por fluxo de calor (DSC) ........................... 70

5.3 Espectroscopia vibracional de absorção no infravermelho por transformada

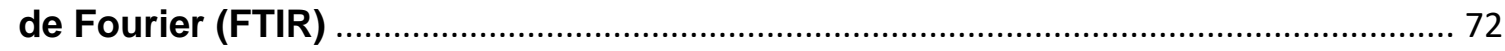

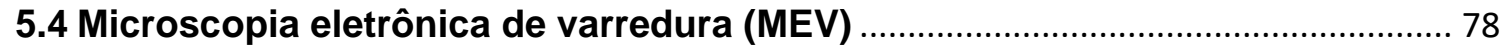

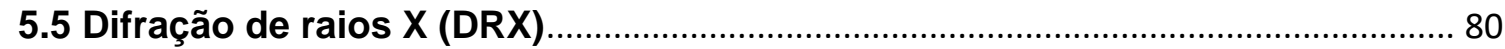

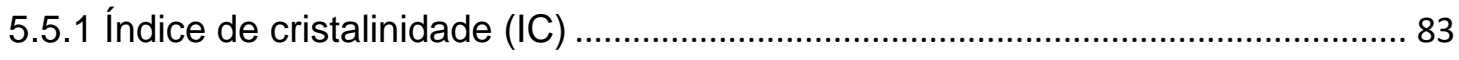

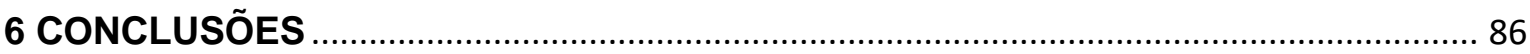

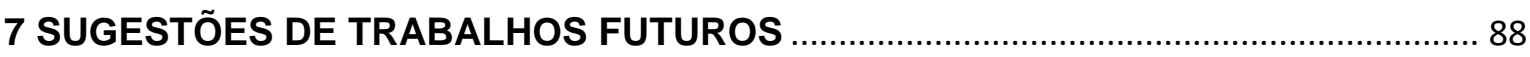

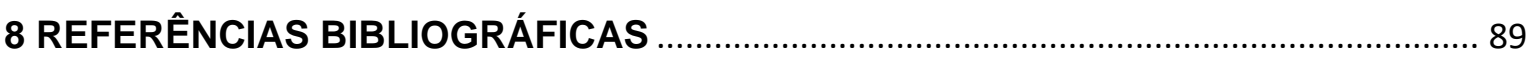

APÊNDICE A - Micrografias em diferentes perspectivas e magnificações das

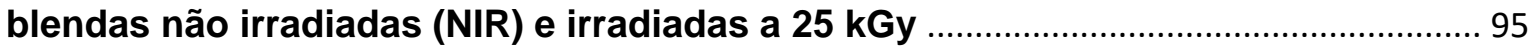

APÊNDICE B - Dados utilizados para cálculo do índice de cristalinidade das blendas por meio de curvas de DRX pelo método de subtração do halo amorfo ..... 99 ANEXO A - Laudo das propriedades físico-químicas do óleo de mamona 103 


\section{INTRODUÇÃO}

Diversas alternativas têm sido buscadas para minimizar o impacto ambiental causado pelos polímeros convencionais no meio ambiente. Uma alternativa é o uso de polímeros biodegradáveis; no entanto, em razão dos custos produtivos elevados quando comparados com polímeros convencionais, as misturas poliméricas biodegradáveis utilizando matérias-primas naturais degradáveis, tal como o amido modificado são uma das alternativas para resolver esse problema (MAGALHÃES; MIRANDA; JOSÉ, 2015).

A utilização de polímeros biodegradáveis tem mostrado ser uma alternativa viável ao uso de materiais derivados das poliolefinas, principalmente em embalagens, pelo fato de poderem ser compostados e biodegradados após o seu descarte. $\mathrm{O}$ desenvolvimento de blendas poliméricas fabricadas com matrizes de polímeros biodegradáveis sintéticos, e aditivos naturais, são considerados materiais menos agressivos ao meio ambiente; os quais podem ser degradados pela ação de micro-organismos ou enzimas (AMERICAN SOCIETY FOR TESTING AND MATERIALS, 2012; MAGALHÃES; MIRANDA; JOSÉ, 2015).

Entre estes materiais biodegradáveis, o amido termoplástico (TPS) apesar de ter baixa resistência mecânica quando comparado com outros e apresentar baixa resistência à água, se misturados com derivados sintéticos de co-poliésteres ou outros polímeros biodegradáveis, tais como poli-hidroxibutirato (PHB), poli(ácido láctico) (PLA), poli(e-caprolactona) ( $\mathrm{PCL})$, poli(butileno succinato-co-adipato) (PBSA), álcool polivinílico (PVOH), ou poli(butileno adipato-co-tereftalato) (PBAT), podem reduzir os custos produtivos e tornar a blenda biodegradável mais competitiva se comparada a outros materiais e embalagens convencionais disponíveis (HWANG et al., 2010; SANTOS et al., 2014).

As principais fontes comerciais de amido utilizadas atualmente são o milho, a batata, o arroz, o trigo e a mandioca. Porém, dentre outras fontes promissoras para a obtenção de amido estão os tubérculos e os grãos de aveia (MALI; GROSSMANN; YAMASHITA, 2010). 
Os plásticos e as resinas biodegradáveis, podem contribuir para o meio ambiente, já que, ao final de sua vida útil, são transformados por meio de processos bioquímicos e devolvidos ao meio ambiente pelos ciclos de carbono, nitrogênio e enxofre (MALI; GROSSMANN; YAMASHITA, 2010; AMERICAN SOCIETY FOR TESTING AND MATERIALS, 2012). Isto diminui de forma significativa o descarte em aterros sanitários e lixões, gerando um adubo que pode ser utilizado em pequenas propriedades e na cidade, por exemplo, pode ser citado o uso de filmes para agricultura, sacolas e embalagens em geral, que podem ser descartados após o uso sem interferência no plantio e consumo e auxiliando o gerenciamento de resíduos sólidos no final do seu ciclo de vida (BASF BRASIL, 2018).

O poli(butileno adipato-co-tereftalato) (PBAT), é um copoliéster alifático aromático biodegradável, que pode formar blendas poliméricas com o amido termoplástico (TPS), outros polióis e serem processados pela extrusão-sopro ou injeção, processo atualmente empregado para os plásticos tradicionais (AVEROUS; BOQUILLON, 2004).

Apesar da vantagem de serem biodegradados e compostáveis rapidamente no meio ambiente, é necessário que os plásticos biodegradáveis tenham uma durabilidade e resistência mecânica e química, adequada a sua aplicação final (ZEHETMEYER, 2016). Uma alternativa é o processo de irradiação que tem essa finalidade.

A modificação de polímeros naturais e artificiais biodegradáveis por radiação ionizante, como TPS misturados com outras blendas poliméricas, tem sido relatada por vários grupos de pesquisadores como um método limpo, rápido, de baixo custo e ambientalmente amigável (AKHAVAN; KHOYLOU; ATAEIVARJOVI, 2017).

O presente estudo, foi realizado seguindo uma metodologia modificada a partir de duas literaturas sobre desenvolvimento de blendas e compatibilização de polímeros.

BRANDELERO e colaboradores (2013), estudaram e desenvolveram blendas de PBAT e TPS com misturas à base de glicerol, óleo de soja e surfactante, visando a diminuição da hidrofilicidade da blenda, favorecendo as aplicações destes como embalagens, produzidas pelo método de transformação à sopro. 
O segundo estudo realizado por OLIVEIRA (2015), foi sobre o desenvolvimento e caracterização de blendas de TPS, e suas misturas com glicerol, água e ácidos carboxílicos, com o polipropileno, visando a melhoria de suas propriedades morfológicas, químicas e mecânicas.

Em base a estes estudos foram desenvolvidas blendas de TPS e PBAT com glicerol, óleo de mamona (OM) e monooleato de polioxietileno sorbitano (TWEEN ${ }^{\circledR} 80$ ), as quais, foram preparadas por extrusão e submetidas ao processo de irradiação e caracterizadas por análises térmicas, mecânicas e morfológicas. Posteriormente as blendas foram comparadas com uma blenda de TPS/PBAT sem OM e TWEEN ${ }^{\circledR}$ 80. Sendo que foi utilizado o OM em substituição ao óleo de soja, para análise da compatibilidade entre o TPS e o PBAT, e foi estudado os efeitos da radiação ionizante nas propriedades das blendas. 


\section{OBJETIVOS}

\subsection{Objetivo geral}

Preparar blendas de TPS/PBAT, utilizando glicerol e óleo de mamona como plastificantes, e o TWEEN ${ }^{\circledR} 80$ como compatibilizante.

\subsection{Objetivos específicos}

- Irradiar e caracterizar as blendas, comparando as irradiadas com as não irradiadas;

- Avaliar o comportamento do óleo de mamona em substituição ao glicerol;

- Analisar o comportamento do glicerol, óleo de mamona como plastificantes;

- Verificar a compatibilização das blendas ao usar o TWEEN ${ }^{\circledR} 80$;

- Verificar a morfologia e compatibilidade por meio de métodos de caracterização, para avaliar a interação entre os componentes das blendas poliméricas. 


\section{REVISÃO DA LITERATURA}

Neste capítulo realizou-se o apanhado histórico do contexto sobre os tipos de polímeros, suas propriedades e variantes no mercado. Com isto, mostraram-se as inúmeras possibilidades de composições entre polímeros e suas blendas na transformação de novos materiais e produtos a partir de processos de transformação existentes. Por fim enfatizou-se neste contexto, o uso da radiação ionizante na modificação das propriedades das matérias-primas envolvidas nesse estudo.

\subsection{Biopolímeros, polímeros biodegradáveis e polímeros verdes}

O crescente interesse na substituição das embalagens tradicionais (filmes, espumas e revestimentos) por materiais à base de polímeros naturais e biodegradáveis, busca a necessidade de procurar produtos novos e mais amigos do meio ambiente. O preparo de matérias-primas baseadas em misturas de vários polímeros naturais (polissacarídeos e proteínas) com polímeros artificiais naturais e biodegradáveis mostrada na Figura 1 é vista como uma alternativa sustentável e praticável (ABRAMOWSKA et al., 2015).

Figura 1 - Classificação dos polímeros biodegradáveis

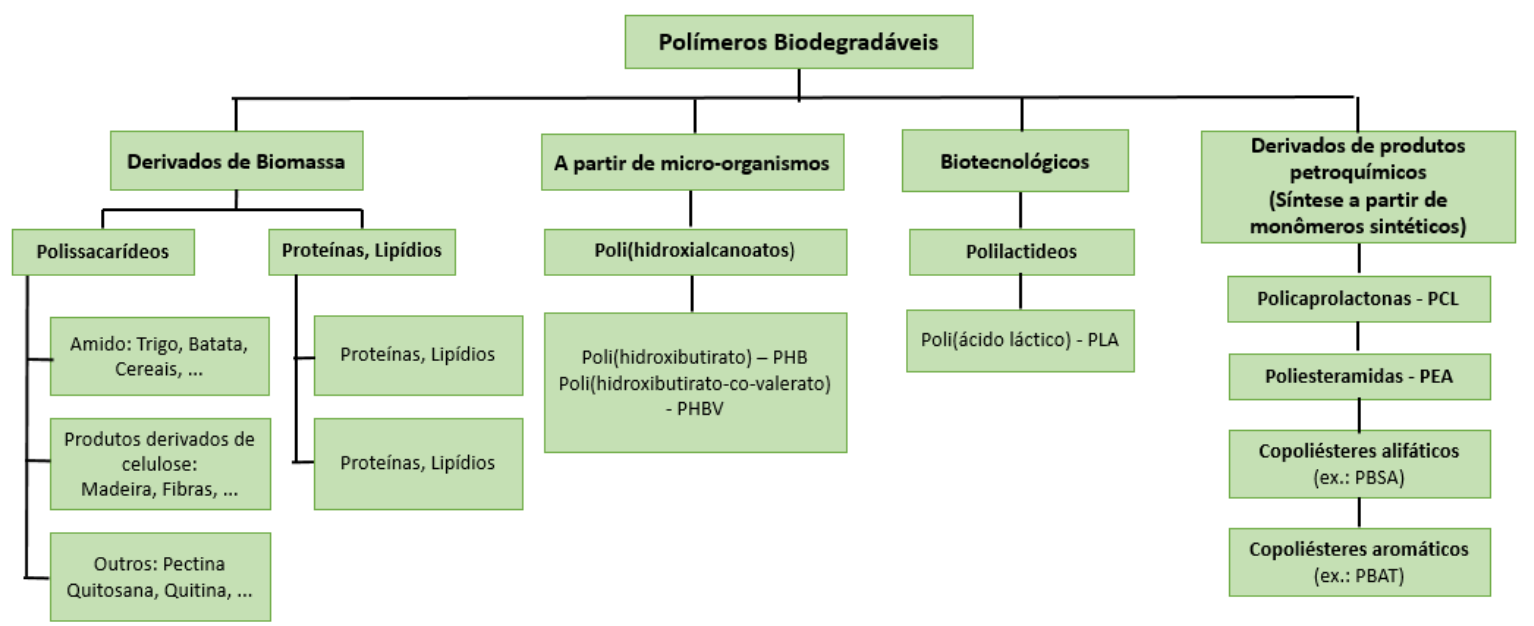

Fonte: AVEROUS e BOQUILLON, 2004.

Os biopolímeros são polímeros ou copolímeros produzidos a partir de matérias-primas de fontes renováveis, como: milho, cana-de-açúcar, celulose, 
quitina e outras. As fontes renováveis são conhecidas por possuir um ciclo de vida de produto, mais curto comparado com fontes não renováveis como os hidrocarbonetos (BRITO et al., 2011; ROGOVINA, 2016).

Já os polímeros biodegradáveis são polímeros nos quais a degradação resulta da ação de micro-organismos de ocorrência natural como bactérias, fungos e algas, nos quais quebram suas ligações químicas diminuindo sua massa molar, podendo ser consumidos em semanas ou meses sob condições favoráveis de biodegradação (BRITO et al., 2011; AMERICAN SOCIETY FOR TESTING AND MATERIALS, 2012; MAGALHÃES; MIRANDA; JOSÉ, 2015; GARRISON; MURAWSKI; QUIRINO, 2016). Eles podem ser provenientes de fontes naturais renováveis como milho, celulose, batata, cana-de-açúcar, ou serem sintetizados por bactérias a partir de moléculas como por exemplo o ácido butírico e o ácido valérico, que dão origem respectivamente ao poli(hidroxibutirato) - PHB e ao poli(hidroxibutirato-co-valerato) - PHB-HV os quais são mostrados na Figura 2 (BRITO et al., 2011; ROGOVINA, 2016).

Figura 2 - Ilustração das estruturas químicas: a) PHB; b) PHB-HV

a)

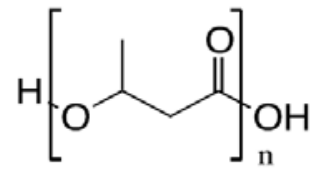

b)

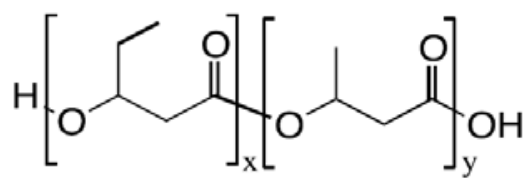

Fonte: GARRISON, MURAWSKI e QUIRINO, 2016.

BRITO e colaboradores (2011), referem-se a polímeros verdes os polímeros que durante sua síntese, processamento ou degradação produzem menor impacto ambiental que os polímeros convencionais. Eles são classificados como polímeros sustentáveis, cujo termo polímero verde indica que sua síntese é originaria de matéria-prima proveniente de fontes fósseis, mas que, devido aos avanços tecnológicos passaram também a ser sintetizados a partir de matéria-prima proveniente de fontes renováveis; por exemplo: polietileno verde e poli(cloreto de vinila) verde obtidos a partir da cana-de-açúcar. Essa família de polímeros mantêm as mesmas características físico-químicas dos obtidos por fontes não renováveis. 
Tanto o PE quanto o PVC verde não são biodegradáveis, entretanto, pelo fato de serem provenientes de fontes renováveis (Figura 3), são classificados como biopolímeros/polímeros verdes.

Figura 3 - Ilustração da rota de obtenção do polietileno verde

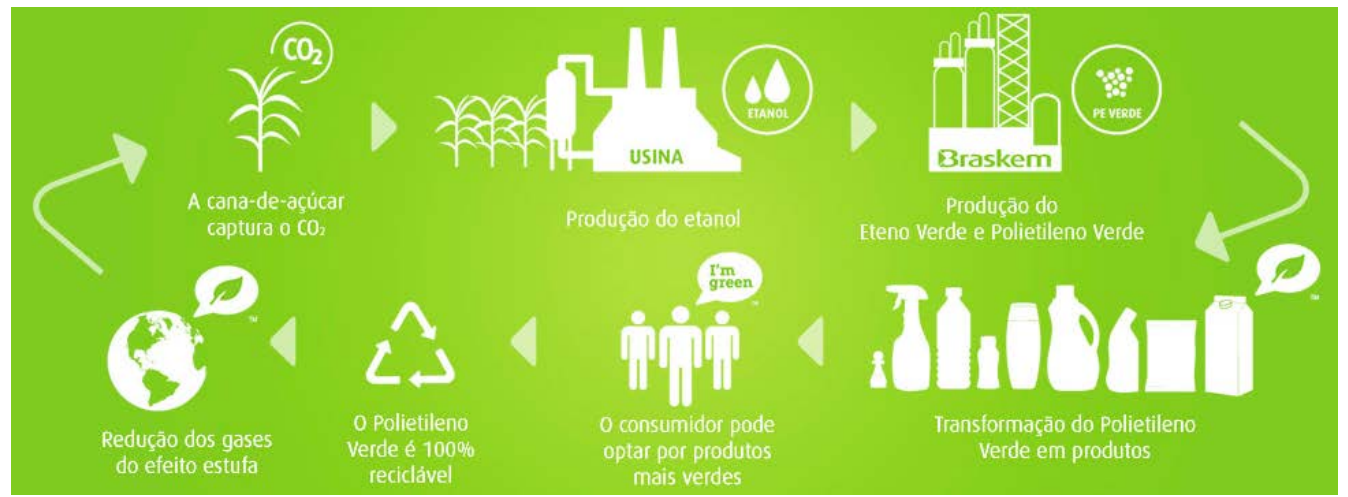

Fonte: BRASKEM, 2018

A biodegradabilidade dos polímeros foi estudada por vários pesquisadores utilizando matérias-primas, como açúcares, polissacarídeos, óleos vegetais, lignina e proteínas no desenvolvimento de diversas matrizes poliméricas biodegradáveis (ABRAMOWSKA et al., 2015; GARRISON; MURAWSKI; QUIRINO, 2016). A partir do ano 2000, a indústria química foi responsável por 15\% do consumo da produção global de óleos vegetais insaturados que são usados em diversas formulações de tintas e revestimentos por sofrerem reações de reticulação com o oxigênio atmosférico formando materiais com ligações cruzadas (crosslinking), além de ter fácil disponibilidade de obtenção, custo relativamente baixo e pouca toxidade (GARRISON; MURAWSKI; QUIRINO, 2016).

Assim o preparo de alguns poliésteres derivados de óleos vegetais que são utilizados na composição de polímeros biodegradáveis consiste em modificar sua estrutura química e polimerizá-lo devido a sua reatividade química. Eles podem ser preparados de diversas formas reagindo polióis com anidridos, diácidos ou isocianatos (GARRISON; MURAWSKI; QUIRINO, 2016).

O óleo de mamona e o ácido ricinoleico, estão começando a ser usados para o preparo de materiais à base de poliuretanos. Os óleos de soja, canola, milho e linhaça, também têm sido usados na síntese do poliuretano. Há também os óleos etoxilados (MSOLs) baseado em poliois, que são empregados na produção de poliuretanos aniônicos (GARRISON; MURAWSKI; QUIRINO, 2016). 


\subsection{Radiação ionizante}

\subsubsection{Física das radiações}

A energia que se propaga a partir de uma fonte emissora através de qualquer meio é chamada de radiação, podendo ser classificada como energia em trânsito. Ela se apresenta em forma de partículas atômicas ou subatômicas energéticas, tais como: partículas alfa $(\alpha)$, beta $(\beta)$, elétrons, pósitrons, prótons provocando a ionização dos átomos, exceto o nêutron o qual, interage somente com o núcleo atômico. A radiação eletromagnética, transfere sua energia para os elétrons que irão provocar reações subsequentes de ionização. São produzidas em aceleradores de partículas ou em reatores nucleares, sendo também emitidas espontaneamente pelo decaimento de núcleos dos átomos radioativos (OKUNO, 2013; SCHIMITBERGER, 2015).

As radiações ionizantes estudadas usualmente compreendem os seguintes grupos (YOSHIMURA, 2009):

- Radiação eletromegnética com energia de fóton acima de $12 \mathrm{eV}$ : Raios X resultantes da desexcitações atômicas (raios X característicos), e de partículas carregadas; raios gama $(\gamma)$ e fótons de aniquilação;

- Partículas eletricamente carregadas e que possuem energia cinética bem maior que a energia térmica: partículas carregadas rápidas (partículas alfa, beta e produtos de fissão), elétrons Auger e feixes produzidos por aceleradores de partículas (elétrons, pósitrons, prótons, dêuterons, íons em geral), radiação cósmica e produtos de sua interação com a atmosfera;

- Nêutrons livres com qualquer energia cinética e de origens diversas.

Já a radiação não ionizante é a energia que não ioniza os átomos e as moléculas com as quais interagem. Exemplos dessas energias são as ondas eletromagnéticas como a luz, calor e ondas de radiofrequência (FIOCRUZ, 2016).

Dependendo da frequência energética (Figura 4), as radiações podem ser descritas e classificadas como não ionizantes ou ionizantes. 
Figura 4 - Espectro eletromagnético das radiações

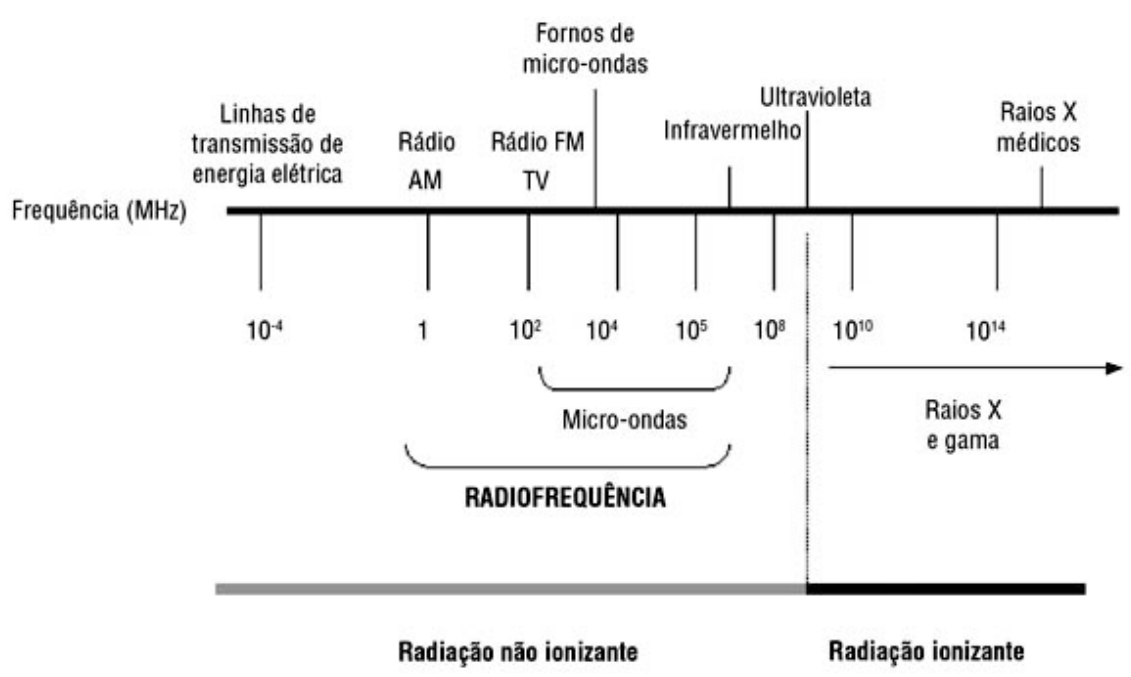

Fonte: BALBANI e KRAWCZYK, s.d.

A radiação eletromagnética (REM) pode interagir com a matéria de diferentes formas. A REM ionizante é tratada, em boa parte dos casos, como um conjunto de partículas - os fótons, sendo que os três principais processos atenuados dessa interação são o efeito fotoelétrico, efeito Compton e a produção de pares (YOSHIMURA, 2009; SCHIMITBERGER, 2015).

A unidade de medida após a interação da REM ionizante com a matéria (Equação 1), pode ser medida e expressa em Gray (Gy) (WOJNÁROVITS, 2003; SCHIMITBERGER, 2015).

Em que:

$$
1 \mathrm{~Gy}=1 \mathrm{~J} / \mathrm{kg}
$$

Na Tabela 1 são apresentados os tipos de interação da REM ionizante, quais são as consequências para o meio e para a REM, quais mudanças são produzidas ou liberadas e a consequência dessa interação para o átomo. 
Tabela 1 - Principais interações da radiação ionizante e suas consequências

Tipo de Interação

Efeito Compton

(espalhamento inelástico)

Efeito Fotoelétrico (ejeção de elétron ligado)

\section{Mudança no meio e consequência}

Espalhamento de um fóton por um elétron livre do material. Há transferência de parte da energia e do momento do fóton para o elétron, devido à diferença energética o átomo fica ionizado.
O fóton é absorvido pelo átomo e um elétron atômico é liberado para se mover no material. A energia cinética adquirida por esse elétron é a diferença entre a energia do fóton e a energia de ligação do elétron ao átomo; produzindo elétrons rápidos, raios $\mathrm{X}$ específicos, efeito Auger, e em decorrência esse processo recua o núcleo atômico deixando-o como íon excitado.

O fóton é absorvido e toda sua energia é convertida em massa de repouso e energia cinética de um par partícula/antipartícula - elétron/pósitron em razão da força coulombiana. 0 resultado dessa interação entre o fóton e o campo eletromagnético é a interação do fóton com o campo de qualquer partícula carregada, incluindo os elétrons atômicos. Neste caso, um elétron é ejetado, deixando o átomo em estado excitado.

Fonte: adaptado de YOSHIMURA, 2009.

A probabilidade de ocorrência desses efeitos está relacionada com a energia do feixe e com o número atômico do material incidente, e é chamado de coeficiente de atenuação linear $(\mu)$ (Equação 2), que é o comportamento dos fótons atravessando determinado material (SCHIMITBERGER, 2015).

$$
\frac{I}{I o}=e^{-\mu x}
$$

Em que:

I = Intensidade dos fótons ao atravessar o meio;

$\mathrm{I}_{0}=$ Intensidade inicial dos fótons incidentes em determinado meio;

$\mathrm{x}=$ Espessura do material irradiado. 
Na Figura 5 é mostrada a relação da incidência do feixe de fótons $(\gamma)$ na matéria em função da espessura do material.

Figura 5 - Variação da intensidade do feixe em função da espessura
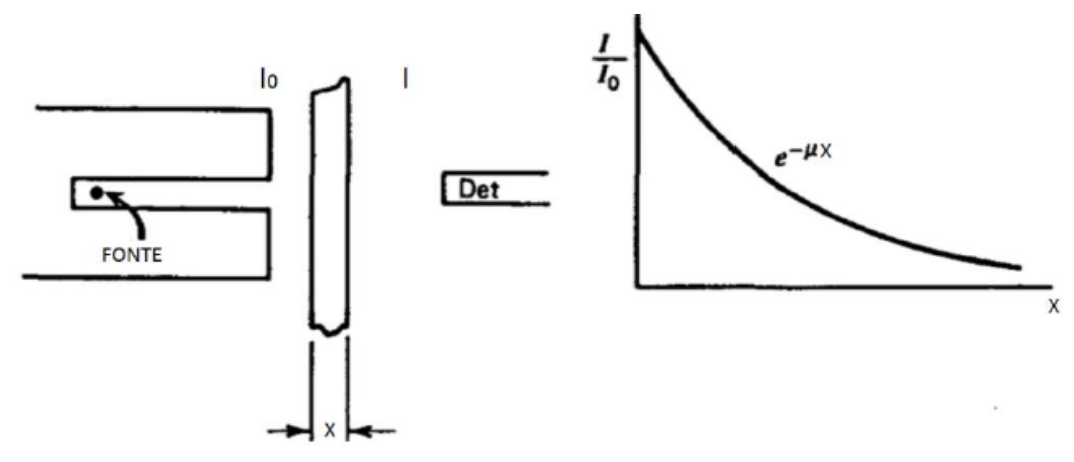

Fonte: SCHIMITBERGER, 2015.

As fontes de radiação mais utilizadas na irradiação de materiais são o ${ }^{60} \mathrm{Co}$ (radiação gama) e os aceleradores (feixe de elétrons) (WOJNÁROVITS, 2003), as quais dependem do tipo de material a ser irradiado e espessura.

As fontes de raios gama $(\gamma)$ mais comuns são dos isótopos radioativos: Cobalto-60 e Césio-137, sendo que o ${ }^{60} \mathrm{Co}$, é produzido em reatores nucleares a partir do isótopo estável do Cobalto-59, por meio da reação nuclear (Equação 3), por captura de nêutrons (WOJNÁROVITS, 2003).

$$
{ }^{59} \mathrm{Co}(\mathrm{n}, \gamma){ }^{60} \mathrm{Co}
$$

O decaimento e estado fundamental do ${ }^{60} \mathrm{Co}$, é representado pela Equação 4.

$$
{ }_{27}^{60} \mathrm{Co} \rightarrow \mathrm{B}^{-}+{ }_{28}^{60} \mathrm{Ni} \rightarrow \gamma+{ }_{28}^{60} \mathrm{Ni}
$$

$\mathrm{O}{ }^{60} \mathrm{Co}$ é o radioisótopo mais utilizado para experimentos e usos industriais, devido a sua meia vida ser de 5,27 anos. Durante seu decaimento, ocorre a liberação de raios $(\gamma)$ com a emissão de dois fótons de altas energias, 1,17 MeV e 1,33 MeV, totalizando 2,5 MeV de energia durante a desintegração (WOJNÁROVITS, 2003). 
3.2.2 Efeitos das radiações nos polímeros e polímeros biodegradáveis

O processamento por radiação é considerado como uma das técnicas mais promissoras para modificar polímeros biodegradáveis, pois oferece várias vantagens sobre outros métodos de modificação, sendo um processo ecologicamente correto, controlável, sem aditivos, temperatura e consumo de energia baixo. Assim, esta técnica tem sido bastante explorada para modificar vários polímeros biodegradáveis (HWANG et al., 2010; AKHAVAN; KHOYLOU; ATAEIVARJOVI, 2017).

Conforme abordado anteriormente, as três formas de interação dos fótons com os elétrons dos orbitais atômicos, geram transferência de energia que por sua vez criam espécies instáveis e reativas (radicais livres), que modificam a estrutura química dos polímeros, devido à quebra de ligações covalentes que se reagrupam novamente, gerando estabilidade química e modificando o polímero (LIMA FILHO et al., 2012; SCHIMITBERGER, 2015).

A cisão de cadeia e a formação de ligações cruzadas (crosslinking) nos polímeros são processos concorrentes e a porcentagem de formação desses dois processos vai depender da dose, temperatura de irradiação, da presença de oxigênio e principalmente, da estrutura dos polímeros irradiados (SCHIMITBERGER, 2015; NEMTANU; BRASOVEANU, 2017). Com isto, os polímeros que contém estruturas aromáticas são mais resistentes aos efeitos da radiação ionizante. Os polímeros alifáticos têm estruturas com diferentes graus de resistências à radiação, que dependem das quantidades de insaturações e substituições em sua cadeia (SCHIMITBERGER, 2015).

Essas interações da radiação que podem ser pelas fontes $(\gamma)$ ou feixe de elétrons geram as seguintes reações nos polímeros (WOJNÁROVITS, 2003):

- Cisão de cadeia: onde a radiação induz a degradação térmica nos polímeros a temperaturas baixas, devido a formação de regiões excitadas e ionizadas. A degradação pode ser controlada dependendo da dose de radiação e da massa molar do polímero;

- Reticulação (crosslinking): degradação ou modificação das propriedades dos polímeros pela radiação, entre elas estão o aumento da viscosidade, 
propriedades mecânicas, térmicas, químicas e massa molar. Um exemplo é o polietileno (PE) irradiado a 20 kGy, com modificação de sua temperatura de fusão $\left(T_{\mathrm{m}}\right)$ de 70 a $90^{\circ} \mathrm{C}$, até $\sim 250^{\circ} \mathrm{C}$.

Nas Figuras 6 a 8 são mostradas as diferentes etapas da irradiação do polietileno.

Figura 6 - Reticulação

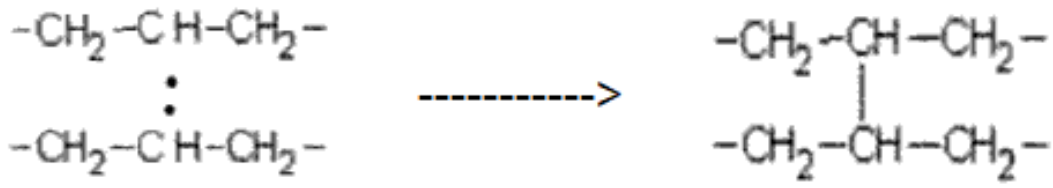

Fonte: WOJNÁROVITS, 2003.

Uma das reações secundárias que pode ocorrer no PE é quando há a liberação de hidrogênio $\left(\mathrm{H}_{2}\right)$ da cadeia do polímero, que provoca excitação e recombinação das ligações químicas modificando sua estrutura e formando ligações duplas.

Figura 7 - Inserção de ligações duplas

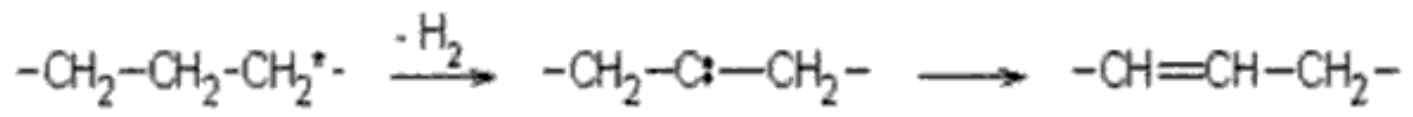

Fonte: WOJNÁROVITS, 2003.

Outra reação menos comum é a formação de pares de radicais livres, após a interação de elétrons ( $\mathrm{e}^{-}$) com a vizinhança das moléculas, liberando átomos de hidrogênio na reação de excitação e formando moléculas-íons no polímero.

Figura 8 - Formação de radicais livres e moléculas-íons

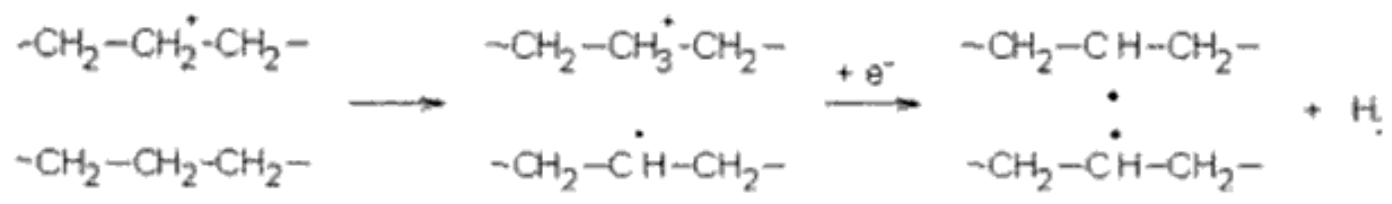

Fonte: WOJNÁROVITS, 2003. 
3.2.2.1 Irradiação de polímeros naturais e suas consequências

A irradiação com fonte de ${ }^{60} \mathrm{Co}$ é muito utilizada para a desinfecção e esterilização de produtos alimentares, contribuindo para a proteção microbiológica dos alimentos e aumento do ciclo de vida do produto, porém pode ocorrer modificações de suas propriedades químicas e nutricionais, dependendo do tipo de alimento e da dose aplicada no processo de irradiação (ZHU, 2016).

Entretanto dependendo da dose aplicada, os carboidratos podem sofrer hidrólise e oxidação gerando compostos mais simples, mas sem alterar seu valor nutricional; assim industrialmente aplica-se uma dose de radioesterilização utilizando uma fonte de ${ }^{60} \mathrm{Co}$ com uma margem de segurança variável entre 20 e 25 kGy, interferindo nos aspectos microbiológicos dos produtos sem alterar as propriedades finais (LIMA FILHO et al., 2012).

A irradiação de amidos pode gerar diversos radicais livres, que ao interagir com a água presente do próprio amido produz produtos de dextrina, por meio da radiólise induzida pela radiação $(\gamma)$ das moléculas de $\mathrm{H}_{2} \mathrm{O}(\mathrm{ZHU}, 2016)$.

Diversos pesquisadores e grupos de pesquisa realizaram estudos sobre 0 uso das radiações em polímeros e especialmente no TPS e PBAT, das quais segue um apanhado da literatura sobre a influência em suas propriedades. Os próximos itens específicos sobre a radiação fazem uma revisão da interação da radiação ionizante com os componentes da blenda deste estudo e as principais consequências desta interação, de forma a possibilitar uma aplicação futura do TPS/PBAT na área de materiais e afins com durabilidade e ciclo de vida estendido.

\subsection{Poli(butileno adipato-co-tereftalato) - PBAT}

\subsubsection{Estrutura química e propriedades}

O PBAT é um copoliéster randômico formado pela polimerização dos seguintes oligômeros de diésteres de ácido ádipico/butanodiol e ácido tereftálico. Os meros constituintes da cadeia do polímero são 1,4 butanodiol, ácido adípico e ácido tereftálico (VIEIRA, 2010). A unidade repetitiva do mero mostrada na Figura 9, por "y" (adipato de butileno) representa 57\% da sua composição e a unidade " $x$ " (tereftalato de butileno) ocupa o restante da estrutura química. Entretanto, as 
composições dos meros podem ter percentuais diferentes dependendo do fabricante e aplicação final do produto (PAN et al., 2016; ZEHETMEYER, 2016).

Figura 9 - llustração da estrutura química do PBAT

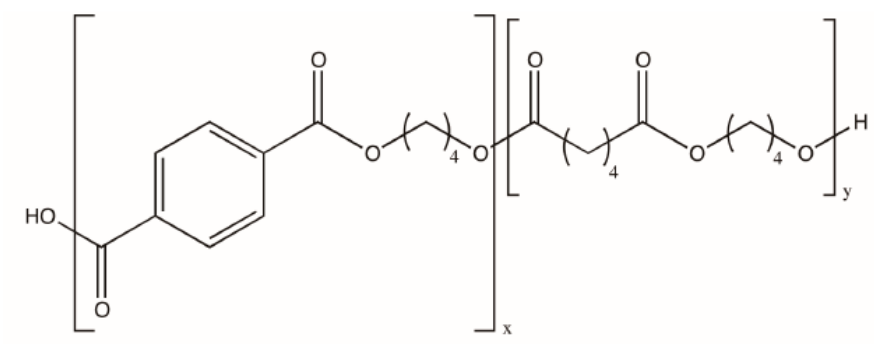

Fonte: GARRISON, MURAWSKI e QUIRINO, 2016.

O Ecoflex ${ }^{\circledR}$ é o nome comercial do PBAT, que possui estrutura molecular desenvolvida com o objetivo de balancear a biodegradação enzimática em condições de compostagem após alguns meses, além de ter propriedades mecânicas boas e fácil processabilidade, comparado com outros polímeros. Atende atualmente os requisitos, conforme as normas internacionais vigentes (HAN et al., 2009; POVEDA, 2015; MORAES et al., 2017).

O PBAT por ser um polímero termoplástico, semicristalino e biodegradável em condições de compostagem e ter propriedades físico-mecânicas próximas a da família dos polietilenos, pode ser utilizado em processos de transformação convencionais tais como: extrusão, sopro, misturadores, moldagem por injeção, entre outros (HAN et al., 2009; VIEIRA, 2010; MARINHO et al., 2017). Também é compatível com materiais de fontes renováveis como o amido, fibras vegetais, farelos de milho e soja entre outros (ZEHETMEYER, 2016). Na Tabela 2 são apresentadas algumas propriedades físico-químicas do PBAT.

Tabela 2 - Propriedades químicas gerais do PBAT $\left(\mathrm{Ecoflex}^{\circledR}\right)$

\begin{tabular}{|c|c|c|c|}
\hline \multicolumn{1}{c}{ Propriedades } & Unidade & Método/Norma & Valores \\
\hline Densidade & $\mathrm{g} / \mathrm{cm}^{3}$ & ISO 1183 & $1,25-1,27$ \\
\hline $\begin{array}{c}\text { Índice de fluidez } \\
\mathbf{1 9 0}{ }^{\circ} \mathbf{C}-\mathbf{2 , 1 6} \mathbf{~ k g}\end{array}$ & $\mathrm{g} / 10 \mathrm{~min}$ & ISO 1133 & $2,7-4,9$ \\
\hline Temperatura de fusão & ${ }^{\circ} \mathrm{C}$ & $\mathrm{DSC}$ & $110-120$ \\
\hline Dureza Shore D & - & ISO 868 & 32 \\
\hline Vicat VST A/50 & ${ }^{\circ} \mathrm{C}$ & ISO 306 & 90 \\
\hline Transparência & $\%$ & ASTM D 1003 & 82 \\
\hline
\end{tabular}

Fonte: PRODUCT INFORMATION ECOFLEX ${ }^{\circledR}$ F BLEND C 1200, 2018. 
Devido a versatilidade química e de transformação do PBAT, MA e colaboradores (2016), estudaram os efeitos da adição do PBAT em filmes a base de PLA/PHB para aplicação em embalagens de frutas. Sendo que o PLA/PHB é sintetizado por micro-organismos no qual; o PLA é derivado da família dos polissacarídeos, e o PHB um poliéster alifático. As concentrações de PBAT nos filmes de PLA/PBAT variaram de 5 a 20\%, nos quais após mistura e extrusão, foram estudadas suas propriedades morfológicas (MEV), mecânicas, químicas (FTIR), permeação a vapores e de biodegradação. Os resultados mostraram que a adição de PBAT na blenda de PLA/PHB, melhorou as propriedades mecânicas, sendo que houve aumento no alongamento e diminuição nos módulos de Young e tração. Os resultados de microscopia eletrônica de varredura (MEV) mostraram uma compatibilização da blenda com a adição do PBAT, já no teste de biodegradação em solo houve um aumento da massa em virtude da concentração de PBAT.

CHIU e colaboradores (2013) investigaram o comportamento mecânico e morfológico de blendas de PLA/PBAT em várias formulações, caracterizando-as por calorimetria exploratória diferencial (DSC), difração de raios $X(D R X)$, ensaios de tração e impacto, e temperatura de deflexão térmica (HDT). Os resultados obtidos mostraram que na análise de DSC as blendas apresentaram duas fases distintas que mostrou sua imiscibilidade. Na parte morfológica as blendas tiveram fases co-contínuas e irregulares o que impactou nas propriedades mecânicas; onde a amostra de PLA/PBAT (50/50) teve um melhor resultado dentre as amostras analisadas. Na análise de HDT, as blendas com maior cristalinidade apresentaram os melhores resultados em relação às demais.

\subsubsection{Interação com a radiação ionizante}

O pesquisador SCHIMITBERGER (2015), em sua tese de doutorado, investigou o comportamento de filmes de PBAT e poli[2-metóxi-5-(2'-etilhexilóxi)1,4-fenilenovinileno] (MEH-PPV) com radiação ultravioleta, beta e gama no intervalo de dose de radiação de 0 kGy a 4000 kGy, para aplicação em dispositivos fotoluminescentes radioinduzidos de custo baixo, Ele concluiu que após a caracterização dos filmes por espectroscopia vibracional de absorção no infravermelho (FTIR), Raman, espectroscopia de absorção (UV-Vis) e fotoluminescência (PL), mostrou o sucesso na obtenção do filme e da 
luminescência, utilizando o PBAT isoladamente (SCHIMITBERGER, 2015) e também como matriz polimérica, ressaltando que doses de radiação altas favoreceram a luminescência após a reticulação e degradação do MEH-PPV, devido a foto-emissão do PBAT e/ou radiação gama durante o processo de irradiação, que gerou defeitos na cadeia polimérica com grupos $\mathrm{NH}_{2}$ e ${ }^{-} \mathrm{OH}$ (SCHIMITBERGER, 2015). Na Figura 10 é mostrada a excitação após a absorção do laser emitido nos filmes de PBAT com concentração de 0,3 g/mL de MEH-PPV, sendo que o primeiro filme não foi excitado e irradiado, e os demais com suas respectivas doses apresentaram absorção e luminescência após a indução por radiação.

Figura 10: Filmes de PBAT excitados ao laser $(\lambda=405 \mathrm{~nm})$, após irradiação com fonte de ${ }^{60} \mathrm{Co}$
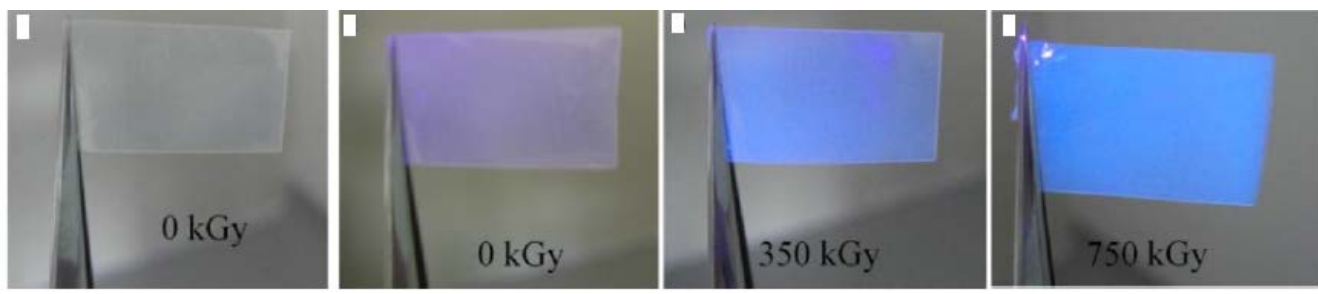

Fonte: adaptado de SCHIMITBERGER, (2015)

Geralmente, os polímeros que contêm estruturas com anéis aromáticos são mais resistentes aos efeitos da radiação. Os polímeros alifáticos exibem diferentes graus de resistências, que dependem das quantidades de insaturações e substituições em sua cadeia (SCHIMITBERGER, 2015).

HWANG e colaboradores (2010) estudaram o efeito da radiação por feixe de elétrons e seu impacto nas propriedades térmicas e mecânicas do PBAT. Foram feitos filmes utilizando a técnica por solução (casting) os quais foram irradiados com doses de 20 kGy a 200 kGy e submetidos a análises de termogravimetria (TGA), análise mecânico dinâmica (DMA) e máquina de teste mecânico universal (UTM). Os pesquisadores concluíram que o PBAT foi reticulado pelo processo de irradiação por feixe de elétrons. Sendo que o percentual de reticulação foi dependente da dose aplicada, e variou de $5 \%$ a $52 \%$ do PBAT, para doses entre 25 kGy e 200 kGy e consequente modificação estrutural ocasionada pela reticulação das cadeias do polímero (crosslinking), e modificação das propriedades térmicas, químicas e mecânicas. 
Uma das aplicações nucleares em polímeros foi estudada por CARDOSO e colaboradores (2017), que investigaram misturas de 5\% de PLA em massa préirradiadas com PBAT compatível compatibilizado com PLA (Ecovio ${ }^{\circledR}$ ), para solucionar problemas com formação de misturas de fases imiscíveis, devido à diferença entre os valores dos parâmetros de solubilidade do PLA e PBAT, melhorando assim a compatibilidade das misturas e visando melhorias mecânicas, morfológicas e de biodegradabilidade, devido à sua alta tenacidade e biodegradabilidade.

HAN e colaboradores (2009), estudaram os efeitos da radiação gama utilizando uma fonte de ${ }^{60} \mathrm{Co}$, nas propriedades térmicas e mecânicas em filmes de PBAT visando o ponto de fusão baixo, que restringe seu uso em algumas aplicações industriais. O PBAT foi irradiado com doses de 50 kGy a 300 kGy. Foram feitas análises de TGA, DMA, ensaios mecânicos e grau de reticulação. Os resultados mostraram que o PBAT foi reticulado pela radiação apresentando mudanças na temperatura de fusão $\left(T_{m}\right)$ e entalpia $(\Delta H)$, de acordo com as análises de DSC. Na análise de DMA o aumento da temperatura vítrea ( $\left.T_{\mathrm{g}}\right)$, mostrou que houve reticulação da cadeia do polímero. Por consequência da alteração dos valores de DSC, DMA a degradação térmica das amostras foi diretamente impactada pela radiação em que as curvas termogravimétricas (TGA), tiveram um aumento com a dose de radiação aplicada. Entretanto, as propriedades mecânicas de tração e deformação, tiveram um decréscimo com a dose aplicada.

\subsection{Amido in natura e amido termoplástico - TPS}

\subsubsection{Estrutura química e propriedades}

O amido é um homopolissacarídeo da família dos carboidratos composto por cadeias de amilose e amilopectina. A amilose é formada por unidades de glicose unidas por ligações glicosídicas $\alpha(1 \rightarrow 4)$, originando uma cadeia linear, embora em menor percentual, é responsável por influenciar parte das propriedades funcionais dos amidos (NEMTANU; BRASOVEANU, 2017). Já a estrutura da amilopectina é formada por unidades de glicose unidas em $\alpha(1 \rightarrow 4)$ e $\alpha(1 \rightarrow 6)$, formando uma estrutura ramificada. Embora a amilose seja definida como linear, atualmente se admite que algumas de suas moléculas possuem ramificações, semelhantes à 
amilopectina (MALI; GROSSMANN; YAMASHITA, 2010; FOOD INGREDIENTS BRASIL, 2015).

As proporções em que estas estruturas aparecem no amido diferem entre as diversas fontes, entre variedades de uma mesma espécie e, ainda, em uma mesma variedade, de acordo com o grau de maturação da planta (FOOD INGREDIENTS BRASIL, 2015). Na Figura 11 são mostradas as estruturas químicas do amido.

Figura 11 - llustração das estruturas químicas do amido: a) amilose; b) amilopectina

a)

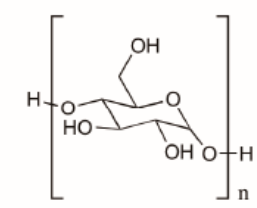

b)

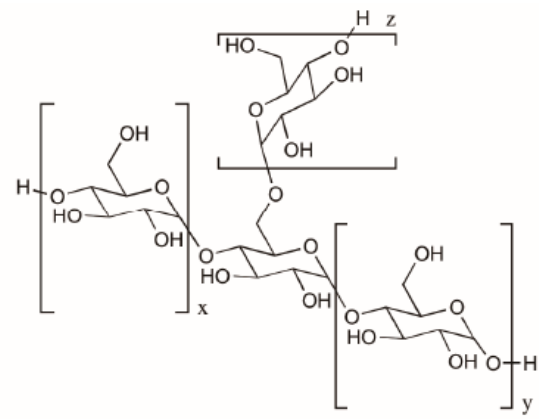

Fonte: GARRISON, MURAWSKI e QUIRINO, 2016.

A cristalinidade do grânulo de amido se deve basicamente à molécula de amilopectina. A amilose, embora linear, não é responsável pela cristalinidade do amido, provavelmente em razão do fato de se conformar na forma de hélice, o que dificulta sua associação regular com outras cadeias (CORRADINI et al., 2007).

Os padrões de cristalinidade encontrados no amido podem ser detetados pela técnica de DRX e são de três tipos: A, B e C. Em que: o tipo A é característico de amidos de cereais com ângulos de difração $2 \theta$ de $11,5^{\circ}, 15,1^{\circ} ; 17,1^{\circ} ; 18,1^{\circ} ; 20^{\circ}$ e $23^{\circ}$. O tipo B é característico de amidos de tubérculos e com $2 \theta$ de $5,6^{\circ}, 14,4^{\circ}$; $17,2^{\circ} ; 22,2^{\circ}$ e $24^{\circ}$. O tipo C é uma mescla dos tipos A e B e são encontrados em

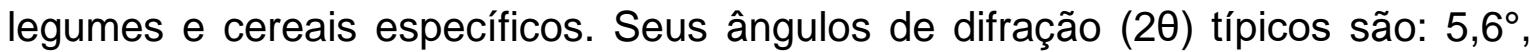
$15,3^{\circ} ; 17,3^{\circ}$ e $23,5^{\circ}$. Os tipos encontrados podem variar entre si, dependendo da sua estrutura cristalina, comprimento das cadeias, densidade, forma dos grânulos e presença de água (OLIVEIRA, 2015).

Como a cristalinidade deve-se a presença de amilose, o amido deverá ter em sua composição um percentual maior de amilose para a obtenção de filmes poliméricos resistentes a água (Tabela 3), favorecendo a formação de pastas 
opacas e filmes resistentes (MALI; GROSSMANN; YAMASHITA, 2010). Mas a natureza hidrofílica e semicristalina do amido dificulta o seu processamento via extrusão, ou seja, é um material muito mais suscetível às alterações de umidade e temperatura, e com maior rigidez estrutural que um polímero sintético convencional. Apesar dos problemas com processamento e conformação, o amido continua sendo um dos polissacarídeos mais promissores e estudados no desenvolvimento de embalagens e o grande desafio é adaptar o processo de transformação às suas limitações químicas (MALI; GROSSMANN; YAMASHITA, 2010).

Tabela 3 - Algumas fontes de amido e suas composições químicas

\begin{tabular}{|c|c|c|}
\hline Fonte & $\begin{array}{c}\text { Teor de } \\
\text { amilose (\%) }\end{array}$ & $\begin{array}{c}\text { Teor de } \\
\text { amilopectina (\%) }\end{array}$ \\
\hline Milho Dent & 25 & 75 \\
\hline Milho Waxy (Ceroso) & $<1$ & $>99$ \\
\hline Mandioca & 17 & 83 \\
\hline Batata & 20 & 80 \\
\hline Trigo & 25 & 75 \\
\hline Arroz & 19 & 81 \\
\hline
\end{tabular}

Fonte: adaptado de FOOD INGREDIENTS BRASIL, 2015.

A molécula do amido tem em sua estrutura dois importantes grupos funcionais: o grupo -OH que é suscetível à reações de substituição e a ligação glicosídica $\mathrm{C}-\mathrm{O}-\mathrm{C}$, suscetível à quebra de cadeia. Assim para obter o TPS é necessário romper a estrutura semicristalina dos grânulos. Para isso, o amido deve ser aquecido em temperaturas elevadas entre $\left(90^{\circ} \mathrm{C}-180^{\circ} \mathrm{C}\right)$ na presença de plastificantes e sob agitação, de forma que adquira características similares à maioria dos termoplásticos convencionais (CORRADINI et al., 2007; SCHLEMMER; SALES; RESCK, 2010).

Assim a resina de TPS (plastificado com o reagente escolhido) pode ser processada em conjunto com outras resinas sintéticas (VIEIRA, 2010; ABRAMOWSKA et al., 2015).

\subsubsection{Plastificantes}

Os plastificantes são aditivos muito empregados em materiais poliméricos para melhorar a processabilidade e aumentar a flexibilidade. São substâncias com 
massa molar menor em relação ao polímero e forma com ele um material aparentemente homogêneo, mais macio, mais flexível e mais fácil de processar aumentando a mobilidade das macromoléculas. Podem ser sólidos ou, como na maioria dos casos, líquidos de ponto de ebulição elevado (MILES, 1975; RABELLO, 2000; CORRADINI et al., 2007).

O amido in natura possui um ponto de fusão maior que sua temperatura de degradação, assim para seu processamento é necessário o uso de plastificantes para diminuir sua temperatura de fusão $\left(T_{m}\right)$ e aumentar sua flexibilidade (VIEIRA, 2010; OLIVEIRA, 2015).

Os plastificantes mais empregados em amidos são a água e os polióis, como o glicerol e o sorbitol, que proporcionam uma melhoria nas suas propriedades mecânicas e químicas (CORRADINI et al., 2007; MALI; GROSSMANN; YAMASHITA, 2010; OLIVEIRA, 2015).

Como exemplo pode-se citar alguns tipos de plastificantes utilizados junto com o amido para obtenção do TPS (OLIVEIRA, 2015):

- ácidos graxos;

- gliceróis;

- óleos vegetais.

Atualmente já existem vários trabalhos citando o uso de óleos vegetais como aditivos de materiais poliméricos. Diversos pesquisadores usaram plastificantes diferentes com o intuito de se obter propriedades especificas para cada aplicação (SCHLEMMER; SALES; RESCK, 2010).

Dentre as diversas aplicações é possível obter materiais fotoprotetores, fotoluminescentes, biocidas e com proteção a base de vitaminas e nutrientes e com estabilidade térmica excelente (SCHLEMMER; SALES; RESCK, 2010).

Vários pesquisadores estudaram biofilmes aditivados com óleos, ácidos graxos e surfactantes. Alguns estudos apontaram melhorias na propriedade de barreira ao vapor de água com o aumento da cadeia carbônica da substância hidrofóbica, isto ocorreu quando uma razão específica entre as porções hidrofílicas e hidrofóbicas do filme foi estabelecida, devido à plasticidade atribuída ao óleo utilizado no biofilme (SCHLEMMER; SALES; RESCK, 2010). 
A pesquisadora OLIVEIRA (2015), em sua tese de doutorado, estudou o comportamento de blendas de polipropileno (PP) com TPS plastificado a partir dos polióis: ácidos carboxílicos, ácido cítrico, glicerol e as olefinas (PP-g-MA e PP reciclado), em diferentes porcentagens nas amostras. Foram feitas análises de FTIR, TGA, MEV e microscopia óptica, tentando obter propriedades mecânicas superiores. Dentre as análises dos estudos feitos foram enfatizadas a TGA e a MEV em que, se concluiu que a adição de $2 \%$ de ácido cítrico em massa melhorou bastante o módulo de elasticidade e a resistência à tração. Já a adição dos ácidos carboxílicos em quantidade menor melhorou a resistência à degradação devido à esterificação entre o ácido e o amido. Já em concentrações elevadas, ocasionaram perda de ácido ao longo do tempo bem como a resistência à termodegradação do amido (OLIVEIRA, 2015). Nos ensaios de MEV evidenciou-se que a adição de água (umidade) melhorou a morfologia do amido, bem como a homogeneização, ocasionada pela esterificação (redução de forças intermoleculares) dos ácidos, as amostras ficaram mais gelatinizadas (OLIVEIRA, 2015). Assim a temperatura do processo de transformação foi crucial por permitir a difusão da umidade nos componentes da blenda.

Mais recentemente SABERI e colaboradores (2017) estudaram o comportamento de diversos plastificantes (glicóis, açucares e polióis) nas características de absorção de umidade e propriedades mecânicas, fisicas, ópticas e microestruturais de filmes de ervilha-goma guar (PSGG). Os resultados obtidos mostraram que os plastificantes descritos, obtiveram filmes com propriedades melhores, porém o constituído por polietileno glicol (PEG) não apresentou propriedades adequadas. Os resultados finais mostraram que o efeito de plastificação mais perceptível nas amostras analisadas foi exercido pela seguinte ordem: glicerol > etileno glicol $(E G)>$ propileno glicol $(P G)>$ xilitol $>$ frutose $>$ sorbitol $>$ manitol $>$ galactose $>$ glicose $>$ sacarose $>$ maltitol .

\subsubsection{Glicerol}

O glicerol ou propano-1,2,3-triol é um poliol, como mostrado na Figura 12a. Em estudos realizados, com até $25 \%$ de glicerol em massa a $T_{g}$ do amido não ficou abaixo de $20^{\circ} \mathrm{C}$ devido à baixa quantidade o que favoreceu a resistência ao impacto do material, isso sendo adotado o glicerol como único plastificante. Ao analisar 
algumas propriedades mecânicas, com o aumento do teor de glicerol o módulo e a resistência à tração diminuíram, enquanto o alongamento aumentou (OLIVEIRA, 2015).

SCHLEMMER e colaboradores (2010) estudaram o efeito da adição de glicerol e óleo de buriti como plastificantes em blendas de poliestireno (PS) com TPS. Após realizar análises de DSC, TMA e RMN, concluíram que blendas de PS/TPS se degradaram mais rapidamente e em mais etapas do que com o óleo de buriti, cuja composição química ( $76 \%$ de ácido oleico) se mostrou termicamente mais estável quando usado como plastificante para o amido, além do processo de plastificação com o amido ter sido mais eficiente em relação ao glicerol, apresentando uma maior suscetibilidade à degradação no solo. Na Figura 12 são mostradas as estruturas e funcionalidades do glicerol e ácido oleico.

Figura 12 - Ilustração das estruturas químicas: a) glicerol; b) ácido oleico

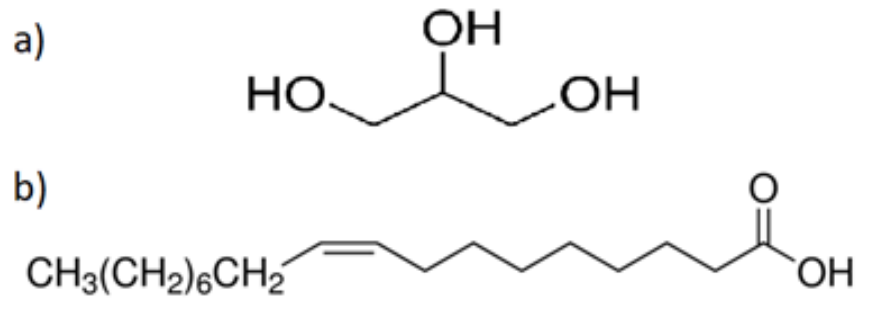

Fonte: adaptado de SIGMA ALDRICH, 2018.

\subsubsection{Interações com a radiação ionizante}

ABRAMOWSKA e colaboradores (2015), em seus estudos sobre filmes de amido/poli(vinil acetato) (PVA), preparados por casting com 30\% de glicerol em massa, verificaram que o tratamento por radiação gama $\left({ }^{60} \mathrm{Co}\right)$ com dose de $25 \mathrm{kGy}$ a uma taxa de dose de $5 \mathrm{kG} / \mathrm{h}$, melhorou a estabilidade térmica e as propriedades mecânicas dos filmes de amido/PVA, por meio de reações químicas ou grupos funcionais de enxerto do amido nas cadeias de PVA, sem adicionar um iniciador ou substâncias químicas à blenda.

NEMTANU e BRASOVEANU (2017), estudaram a degradação física de polissacarídeos, em especial a amilose que foi exposta a radiação por feixe de elétrons com doses entre 10 kGy e 50 kGy, intensidade de $2 \mu \mathrm{A}$ e taxa de dose de 2,5 Gy/s na presença de oxigênio. Os efeitos da radiação na massa molar da 
amilose (Figura 13) foram investigados usando as técnicas de cromatografia de permeação em gel (GPC), FTIR e MEV. Os resultados obtidos mostraram que a dose de radiação na amilose impactou diretamente nas suas propriedades, sendo que houve diminuição de até $40 \%$ de sua massa molar numérica média $\left(\mathrm{Mn}_{\mathrm{n}}\right)$ e 20\% para a massa molar ponderada média $\left(\mathrm{Mw}_{\mathrm{w}}\right)$ em doses a partir de 40 kGy.

Figura 13 - Ilustração da modificação química da amilose, induzida por feixe de elétrons

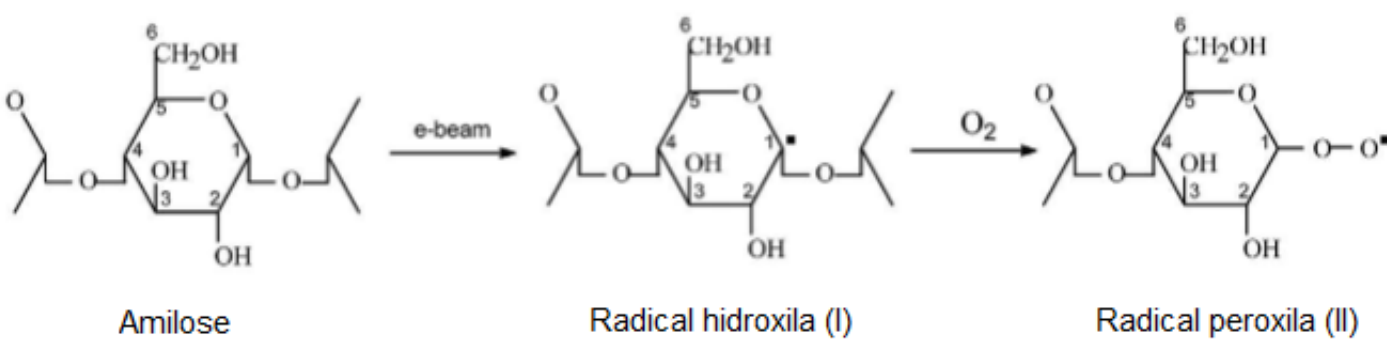

Fonte: NEMTANU e BRASOVEANU, 2017.

ATROUS e colaboradores (2015) conduziram um estudo em que foi verificado o efeito da radiação gama nas propriedades físico-químicas, térmicas, morfológicas e reológicas de amido de trigo obtido a partir de cereais, submetidos a doses de (3, 5, 10, 20, 35 e 50 kGy) aplicados na indústria alimentícia. O amido foi caracterizado pelas técnicas de espectroscopia de ressonância paramagnética eletrônica (RPE), FTIR, DRX, MEV, DSC, entre outras. Os resultados obtidos pelas técnicas de DRX e FTIR mostraram que a cristalinidade do amido não foi alterada com doses abaixo de 50 kGy, assim a radiação gama não interagiu com as regiões cristalinas do amido (amilose), limitando-se a interação apenas na região amorfa composta pela amilopectina quebrando suas ligações glicosídicas e dividindo-as em moléculas menores por meio da formação de radicais livres, devido a conformação em hélice de sua estrutura. Na parte morfológica (MEV) e térmica (DSC) observou-se que a mudança estrutural induzida pela radiação, depende da dose aplicada e da origem botânica do amido utilizado ou modificado, impactando diretamente na textura, tamanho de grão, gelatinização e aumento da solubilidade com redução da viscosidade, sendo que após a retirada de umidade do amido, as amostras irradiadas sofreram mudanças com o aumento da dose de radiação gama.

Outra mudança estudada e ocorrida na morfologia, e no tamanho dos grãos de amido, obtido a partir do arroz pelo processo de irradiação, usando uma fonte 
de ${ }^{60} \mathrm{Co}$, foi a quebra das cadeias, que ao interagir com a radiação gama agiu diretamente na molécula ou provocando a radiólise da água presente no amido e, consequentemente, a geração de radicais livres que atacaram sua estrutura química (POLESI et al., 2016).

Estudos sobre a interação da radiação gama no amido derivado de arroz, foram investigados por KUMAR e colaboradores (2017), em que as amostras foram irradiadas com doses de 5 kGy a 20 kGy, e submetidas às técnicas de MEV, DRX, FTIR, DSC, entre outras. Os resultados obtidos mostraram que o processo de irradiação provocou a diminuição do teor de amilose e inchamento dos grãos de amido. Também houve a diminuição da cristalinidade com o aumento da dose aplicada, mas as curvas de DRX mantiveram-se inalteradas, bem como, a superfície estrutural. A radiação gama melhorou algumas propriedades funcionais do amido como a diminuição da retrogradação da amilose, entalpia, gelatinização e portanto, podendo ser usada como um processo para sua modificação.

Os efeitos da radiação gama em amidos, incorporados em alimentos e produtos industrializados foi estudada por ZHU (2016), que observou a modificação e mudança de propriedades do amido, conforme a dose aplicada, estrutura do amido e alimento utilizado, a fim de obter ciclo de vida estendido para os produtos e combate as pragas naturais existentes.

A origem de produtos de dextrina termoplásticas (Figura 14) derivados da indução pela radiação $(\gamma)$, em processos de esterificação heterogênea das cadeias do amido utilizando-se trifluoanidrido acético e ácidos carboxílicos (entre eles o ácido láurico), foi estudada bem como suas propriedades químicas, térmicas e mecânicas pelas técnicas de ressonância magnética nuclear (RNM), GPC, FTIR, TGA, DSC, entre outras (LEE; DANJO; IWATA, 2018). 
Figura 14 - Ilustração da estrutura química da dextrina

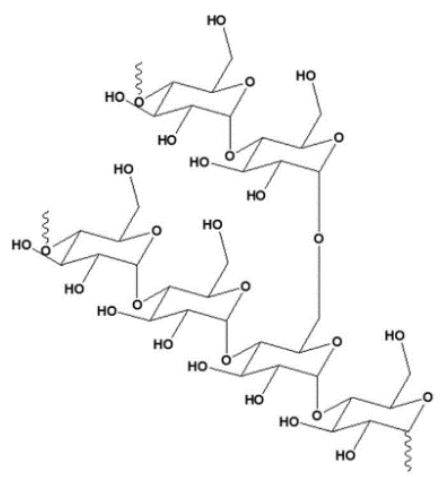

Fonte: LEE, DANJO e IWATA, 2018.

Os resultados obtidos por LEE, DANJO e IWATA (2018) mostraram que se obtiveram vários tipos de dextrina com comprimentos de cadeia diferentes. As análises de GPC, RNM e FTIR, mostraram dextrinas totalmente aciladas (DexAc) com massa molar elevada. A análise de TGA revelou a modificação dos grupos hidroxila por acila, melhorando as propriedades térmicas consideravelmente. Nas análises de DSC e DRX as temperaturas de fusão não foram detectadas para todas as amostras de ésteres dextrina, devido a serem polímeros amorfos e a $\mathrm{Tg}$ diminuiu conforme o aumento da cadeia acila. Assim a termoplasticidade da dextrina e sua hidrofobicidade foi melhorada pela esterificação, bem como os filmes produzidos.

GANI e colaboradores (2012) investigaram os efeitos da radiação gama em doses de 5, 10 e $20 \mathrm{kGy}$, com taxa de dose de 2 kGy/h em temperatura ambiente nas propriedades físico-químicas e morfológicas de amidos derivados da família das leguminosas (feijões). Foram realizadas caracterizações utilizando MEV, DRX entre outras. Os resultados obtidos pelas técnicas de MEV e DRX mostraram que as amostras tiveram uma redução no percentual de cristalinidade e fissuras superficiais nos grânulos de acordo com a dose de radiação, devido à quebra das cadeias de amilose e amilopectina. Entretanto o processo de irradiação aumentou o tempo de ciclo de vida do produto.

\section{5Óleo de manona (OM)}

\subsubsection{Estrutura, funcionalidades químicas e propriedades}

O óleo de mamona $(\mathrm{OM})$ é o triacilglicerol do ácido ricinoleico, originário da família Ricinus communis, composto por um ácido graxo com estrutura química 
$\mathrm{C}_{18} \mathrm{H}_{34} \mathrm{O}_{3}$, tendo uma insaturação cis no carbono 9 e uma hidroxila no carbono 12 , mostrada na Figura 15. Diferentemente da maioria dos óleos vegetais, no ácido ricinoleico, existem três sítios passíveis de sofrerem modificações químicas: a hidroxila, a insaturação e a carboxila (NUNES; MARTINELLI; PEDROSO, 2008).

Figura 15 - Ilustração da estrutura química do triacilglicerol do ácido ricinoleico

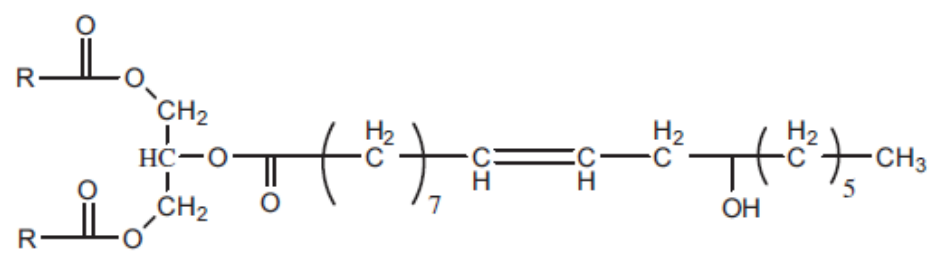

Fonte: SATHISKUMAR e MADRAS, 2011.

Entre esses sítios passíveis de modificações no OM, a radiação ionizante pode atuar como moderadora natural na reticulação do OM com o amido, em razão de sítios compatíveis, como a hidroxila, carbonilas e grupos ésteres, presentes em sua estrutura química (NUNES; MARTINELLI; PEDROSO, 2008; SATHISKUMAR; MADRAS, 2011), e a partir da quebra de ligações glicosídicas do amido (ATROUS et al., 2015), e também apresentada por outros pesquisadores nas seções 3.4.1 e 3.4.3.

Na Tabela 4 são apresentadas algumas das propriedades físico-químicas do OM utilizado neste estudo. O laudo de sua análise encontra-se no ANEXO A.

Tabela 4 - Propriedades físico-químicas do óleo de mamona industrializado

\begin{tabular}{|c|c|c|c|}
\hline Tipo & Método & Especificação & $\begin{array}{l}\text { Valor do lote } \\
(01 / 06-2017)\end{array}$ \\
\hline Aspecto a $25^{\circ} \mathrm{C}$ & Visual & $\begin{array}{l}\text { Líquido amarelo } \\
\text { ligeiramente turvo }\end{array}$ & De acordo \\
\hline Cor lovibond $51 / 4$ & $\begin{array}{c}\text { MA-22 / AOCS Cc } 13 b-45 \\
(2.009)\end{array}$ & Máx. 40 A / 4,0 V & $23 \mathrm{~A} / 2,3 \mathrm{~V}$ \\
\hline $\begin{array}{c}\text { Acidez \% (como ácido } \\
\text { oleico) }\end{array}$ & $\begin{array}{c}\text { MA-09 / AOCS Ca 5a - } 40 \\
(2.009)\end{array}$ & MÁX. 1,0\% & 0,85 \\
\hline Umidade (PPM/\%) - KF & MA-20 & Máx. 3750 ppm / 0,375 \% & 635 \\
\hline \multicolumn{4}{|c|}{ Propriedades informativas } \\
\hline Índice de iodo & $\begin{array}{l}\text { MA-01 / AOCS Tg 1a - } 64 \\
\text { (2.009) }\end{array}$ & $81-88$ & 84 \\
\hline $\begin{array}{l}\text { Índice de saponificação } \\
\text { (mgKOH/g) }\end{array}$ & $\begin{array}{c}\text { MA-03 / AOCS TI 1a- } 64 \\
(2.009)\end{array}$ & $176-182$ & 180 \\
\hline $\begin{array}{l}\text { Índice de hidroxila } \\
\text { (mgKOH/g) }\end{array}$ & $\begin{array}{c}\text { MA-17 / AOCS Cd } 13-60 \\
(2.009)\end{array}$ & $155-165$ & 161 \\
\hline
\end{tabular}


O OM tem aproximadamente 90\% em composição de ácido ricinoleico, e pequenas quantidades de outros ácidos, como: oleico, linoleico, esteárico e dihidroxiesteárico. O óleo é obtido por prensagem mecânica das sementes de Ricinus communis, e não contém a toxina ricina, pois a proteína da semente permanece no subproduto da extração (FONSECA; SOTO-BLANCO, 2014).

Assim, o OM tem sido bastante utilizado para fins industriais, devido às suas características físico-químicas, uma vez que suporta variações bruscas de temperatura (NUNES; MARTINELLI; PEDROSO, 2008).

Além disso, há diversas pesquisas sobre sua utilização na fabricação de cosméticos, bem como na indústria de medicamentos e fabricação de vários tipos de óleos epóxidados e modificados, que servem de base para produção de biodiesel, poliuretanas e diversos materiais biodegradáveis (NUNES; MARTINELLI; PEDROSO, 2008; SATHISKUMAR; MADRAS, 2011; FONSECA; SOTO-BLANCO, 2014).

Uma destas modificações químicas do OM foi estudada pelos pesquisadores SATHISKUMAR e MADRAS (2011), que investigaram a biodegradabilidade e compatibilidade humana para o OM transesterificado em solução com dois diácidos (sebácico e cítrico) e D-mannitol, um poliol derivado da família dos açucares. O processo de transesterificação é mostrado na Figura 16. Foram utilizadas quatro formulações distintas e variáveis, entre as nove misturas produzidas estequeometricamente a partir do $\mathrm{OM}$, que após aquecimento a $160^{\circ} \mathrm{C}$ até se homogeinizar completamente, foi reaquecido a $170 \pm 5^{\circ} \mathrm{C}$ durante $1 \mathrm{~h}$ sob atmosfera inerte de nitrogênio, para reagir quimicamente e estudar as diferentes possibilidades de polimerização e propriedades do polímero sem o uso de catalisadores/iniciadores para deixar o polímero atóxico. O OM modificado foi caracterizado pelas técnicas de DSC, FTIR, ensaios mecânicos, ressonância magnética nuclear (RMN), intumescimento, entre outras. Os resultados mostraram que os polímeros obtidos são flexíveis para aplicações diversas, e as formulações diversificadas com seus respectivos tempos de cura pós-polimerização, permitindo diversas aplicações em seres humanos devido a rápida biodegradação e compatibilidade. 
Figura 16 - Ilustração da reação de transesterificação de diácidos/poliois com o ácido ricinoleico

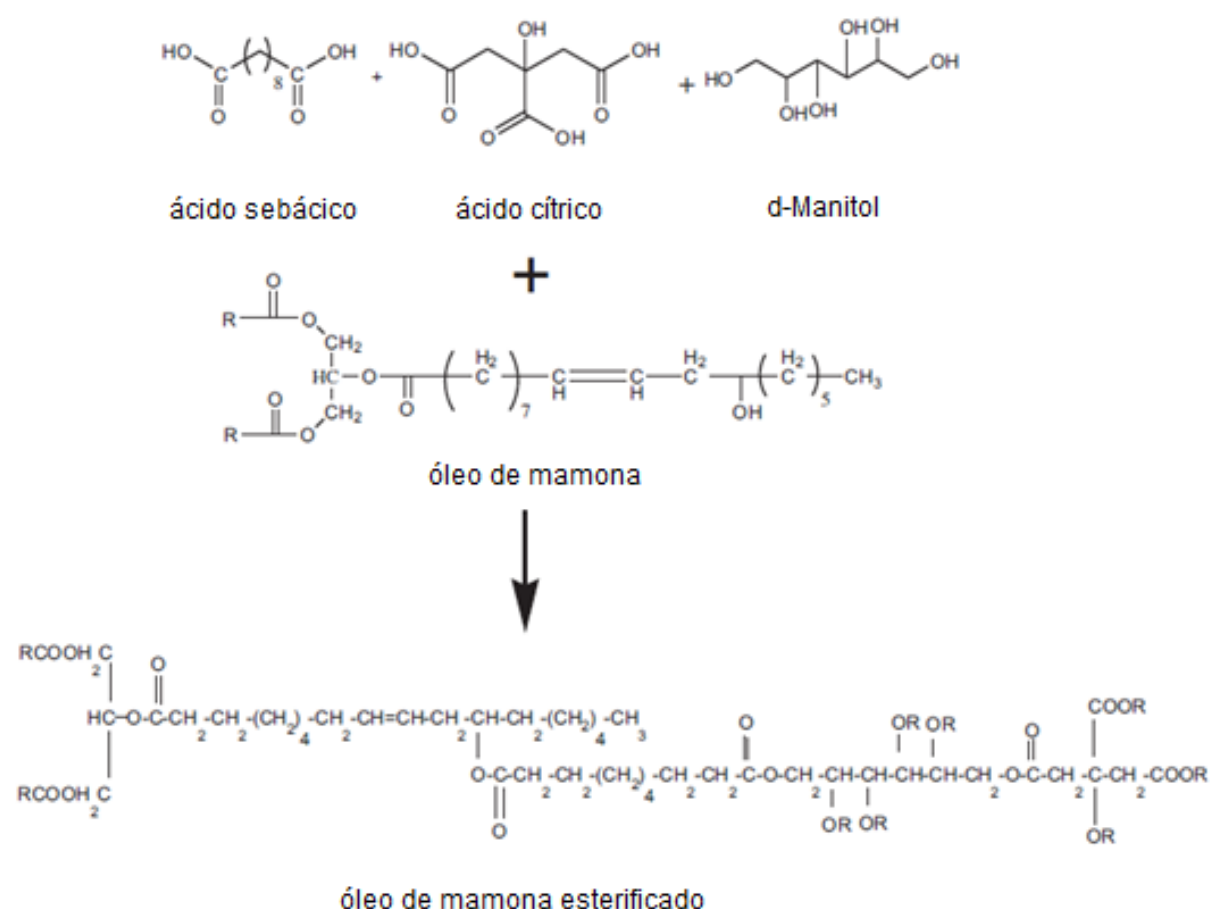

Fonte: SATHISKUMAR e MADRAS, 2011.

3.5.2 Interação com a radiação ionizante

AZEVEDO e colaboradores (2011) estudaram os efeitos da radiação gama de fonte de ${ }^{60} \mathrm{Co}$ nas propriedades de adesivos de poliuretanos derivados do óleo de mamona. Foram aplicadas doses de 0,2 kGy a 25 kGy com taxa de dose de 5 Gy/min, que foram submetidas as técnicas de caracterização por DRX, microscopia de força atômica (AFM) e propriedades mecânicas. Os resultados obtidos mostraram que as amostras sofreram modificações apesar da reticulação natural induzida quimicamente. As curvas de DRX apresentaram leve aumento com a dose aplicada. Nas propriedades de AFM, a morfologia e rugosidade das amostras tiveram alterações, mas não apresentaram mudanças significativas no ângulo de contato com a água. Nas propriedades mecânicas, as amostras tiveram uma melhoria de propriedades mesmo em doses baixas, a dureza aumentou em até $40 \%$ próxima da superfície para doses de 25 kGy e o módulo de elasticidade também variou, mostrando a reticulação do poliuretano em doses de até 25 kGy.

Em um estudo posterior desenvolvido com poliuretanos (PU) derivados do óleo de mamona, AZEVEDO e colaboradores (2013) estudaram as propriedades após a irradiação com radiação gama $\left({ }^{60} \mathrm{Co}\right)$ com doses de 25 kGy e 100 kGy, e 
radiações ultravioleta (UVA e UVC) respectivamente com 350 nm e 253 nm, visando aplicações biomédicas. As amostras foram caracterizadas por técnicas de DRX, AFM e propriedades mecânicas. Os resultados obtidos mostraram que o PU resistiu à radiação gama, esterilizou as amostras e melhorou a resistência superficial. Com a radiação ultravioleta as amostras apresentaram uma melhoria de propriedades de dureza e módulo de elasticidade em virtude da reticulação e oxidação pela radiação UVA, entretanto houve um decréscimo de propriedades com a irradiação por UVC, devido à cisão das cadeias do polímero, mas com melhoria de propriedades antibacterianas.

\subsection{Monooleato de polioxietileno sorbitano - TWEEN ${ }^{\circledR} 80$}

\subsubsection{Estrutura química, propriedades e aplicações}

Os estabilizantes são muito importantes para as emulsões, especialmente de óleos em água ou em moléculas polares. Essa estabilidade é alcançada quando não há mudança no tamanho das gotas ou mudança do arranjo delas no meio. Um desses estabilizantes surfactantes não-iônicos comerciais é o TWEEN ${ }^{\circledR} 80$, desenvolvido pela Sigma-Aldrich (Figura 17), o qual possui uma massa molar média de $1.310 \mathrm{~g} / \mathrm{mol}$ (AGUILERA-MIGUEL et al., 2018).

Figura 17 - Ilustração da estrutura química do TWEEN ${ }^{\circledR} 80$

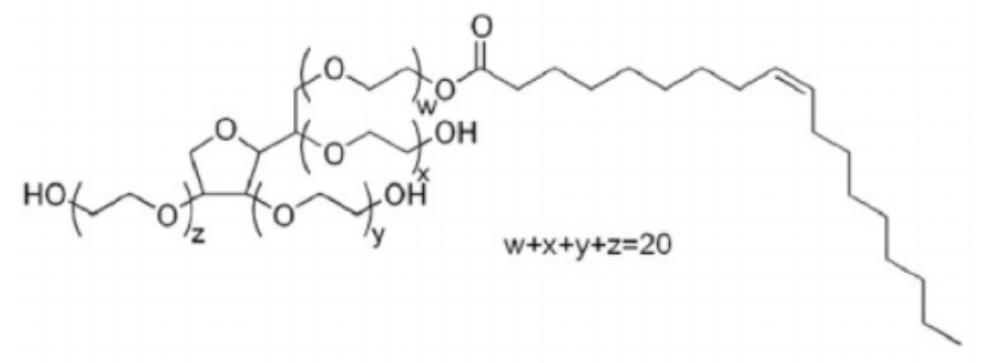

Fonte: AGUILERA-MIGUEL et al., 2018.

Em estudo análogo realizado com óleo de buriti, o TWEEN ${ }^{\circledR} 80$ por ter em sua composição cerca de $60 \%$ de ácido oleico, pode ser considerado um bom estabilizante e plastificante para o amido (SCHLEMMER; SALES; RESCK, 2010). $\mathrm{Na}$ Tabela 5 são apresentadas algumas de suas propriedades gerais e físicoquímicas. 
Tabela 5 - Propriedades físico-químicas do TWEEN ${ }^{\circledR} 80$ (P1754)

\begin{tabular}{|c|c|}
\hline Tipo & Não-iônico \\
\hline Estado físico & Liquido viscoso \\
\hline Massa molar & $\begin{array}{c}\text { Massa molar média por micela }=79.000 \mathrm{~g} / \mathrm{mo} \\
\text { Massa molar média }=1.310 \mathrm{~g} / \mathrm{mol}\end{array}$ \\
\hline Composição & $\begin{array}{c}\text { Ácido oleico, } \geq 58,0 \text { (balanceados com: ácidos, } \\
\text { linoleico, palmítico e esteárico.) }\end{array}$ \\
\hline Concentração crítica micelar (CMC) & $0,012 \mathrm{mM}\left(20-25^{\circ} \mathrm{C}\right)$ \\
\hline Temperatura de transição & $65^{\circ} \mathrm{C}$ (ponto de turvagem) \\
\hline Densidade & $1,064 \mathrm{~g} / \mathrm{cm}^{3}$ \\
\hline Balanço hidrofílico-lipofílico (HLB) & 15 \\
\hline
\end{tabular}

Fonte: adaptado de SIGMA-ALDRICH, 2018.

A importância dos estabilizantes de emulsões e coloides foram estudadas por AGUILERA-MIGUEL e colaboradores (2018). Eles pesquisaram as propriedades de estabilizantes comerciais (TWEEN ${ }^{\circledR}$ 80), e estabilizantes copolíméricos (ABA-Block/Pluronic ${ }^{\circledR}$ ) versus estabilizantes anfifílicos poliméricos

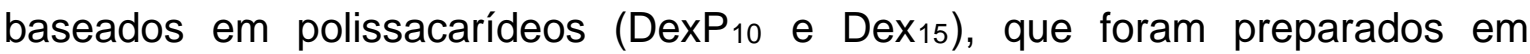
emulsão de óleo em água e caracterizados por diversas técnicas. Os resultados mostraram que os baseados em polissacarídeos podem ser promissores em relação aos comerciais mesmo não tendo rendimento em relação a algumas propriedades dos comerciais.

Em um estudo realizado na área de embalagens por BRANDELERO, GROSSMANN e YAMASHITA (2013) investigou-se os efeitos da adição de TWEEN $^{\circledR} 80$ na plasticidade do amido com o óleo de soja (OS) em blendas com o PBAT, visando melhores propriedades de barreira a gases e vapores de água para produção de filmes plásticos. Os resultados mostraram que a adição de OS melhorou as propriedades de barreira dos filmes, entretanto ao adicionar o TWEEN $^{\circledR} 80$ os filmes ficaram mais hidrofílicos, em virtude da adsorção de agua pelas interações químicas do surfactante.

\subsection{Extrusão reativa de polímeros}

O processo de extrusão é um método importante para a transformação de materiais termoplásticos, sendo prático e rápido, requer pouco espaço para 
produzir grandes quantidades se comparado com outros métodos de produção e transformação. É conhecido que o processo de extrusão dependendo das condições impostas e da quantidade dos polímeros envolvidos, podem afetar as propriedades e compatibilidade das blendas, obtendo-se blendas com propriedades finais elevadas (MORAES et al., 2017).

A extrusão reativa é um dos tipos de tecnologia utilizados para produção de amido modificado e TPS. Embora a extrusão reativa não seja muito utilizada, ela pode fazer com que o amido nativo tenha diversificação e funcionalização por meio de um processo de transformação contínuo (ZUO et al., 2016).

GILES JUNIOR, WAGNER JUNIOR e MOUNT III (2004) descreveram que para o processo de extrusão ter êxito, os parâmetros devem estar devidamente especificados, com controle de temperatura e resfriamento, bem como as matériasprimas a serem processadas devem estar bem formuladas. Assim, evita-se problemas de processo, agregando valor ao produto sem perda de propriedades.

Na Figura 18 é mostrada, o perfil longitudinal interno de uma extrusora e seus componentes de homogeneização.

Figura 18 - Perfil longitudinal interno de uma extrusora

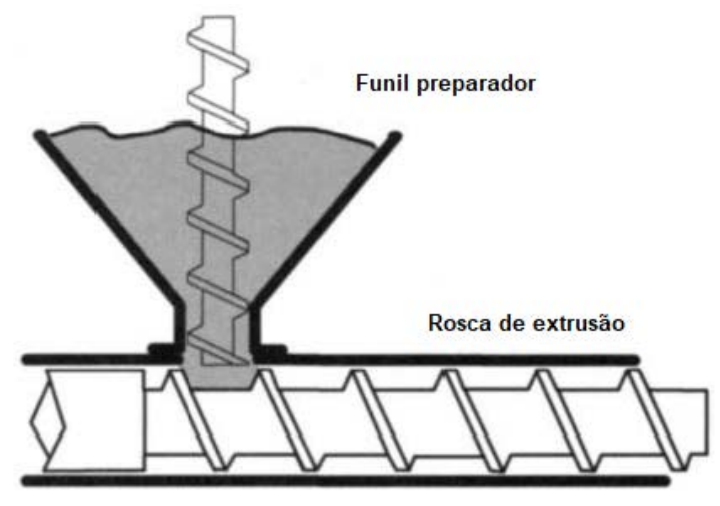

Fonte: GILES JUNIOR, WAGNER JUNIOR e MOUNT III, 2004.

Atualmente há vários tipos de composições e segmentos de roscas/parafusos de extrusão, a aplicação final do produto determinará o tipo a ser utilizado. Dentre os tipos existentes de parafusos de extrusão (Figura 19) os mais utilizados são: os co-rotantes, em que os perfis giram em um mesmo sentido e os contra-rotantes, em que os perfis giram em sentidos opostos (GILES JUNIOR; WAGNER JUNIOR; MOUNT III, 2004). 
Figura 19 - Tipos de entrelaçamento e sentido das roscas de dupla extrusão

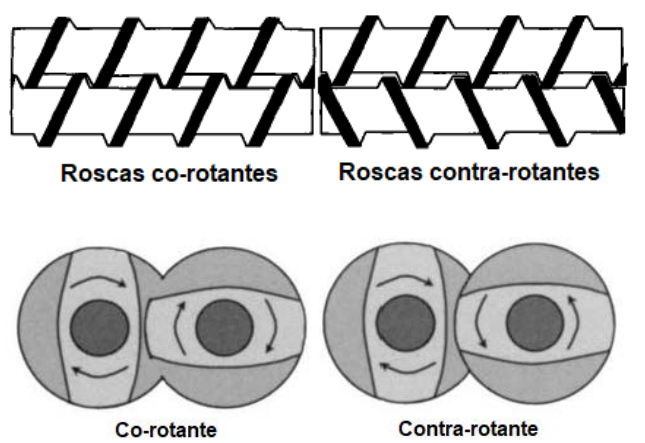

Fonte: GILES JUNIOR, WAGNER JUNIOR e MOUNT III, 2004.

As distâncias da linha central do eixo (ID) e o diâmetro dos parafusos (OD) podem variar o volume livre dentro do canhão da extrusora; as taxas de cisalhamento; homogeneização e transporte de material. Assim sendo, usa-se matematicamente a relação largura-diâmetro (L/D) para escolha do perfil a ser utilizado (Figura 20).

Figura 20 - Perfil transversal de rosca com detalhamento (L/D)

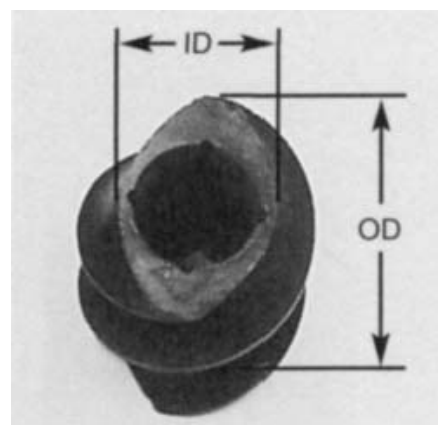

Fonte: GILES JUNIOR, WAGNER JUNIOR e MOUNT III, 2004.

Na extrusão continua, uma combinação e homogeneização única dos componentes no estado fundido são importantes para mostrar e obter a morfologia co-contínua das blendas, sendo que a adição de agentes compatibilizantes ajuda e aumenta a adesão entre as fases da blenda. Assim, a estrutura de blendas cocontínuas permite, melhores propriedades mecânicas tais como resistência à tração e impacto, e em geral normalmente excede as propriedades analisadas de qualquer componente individualizado da mistura (OLIVEIRA, 2015).

ZUO e colaboradores (2016) estudaram os efeitos e plasfificação de amido termoplástico maleatado (MTPS) com glicerol e anidrido maleico (MA) via extrusão reativa. Foram feitas caracterizações de grau de substituição (DS), FTIR, DRX, 
DSC, TGA, propriedades mecânicas, entre outras. Na Figura 21 é mostrada a interação química dos componentes durante o processo de transformação.

Figura 21 - Reação química entre o amido e o anidrido maleico por extrusão reativa

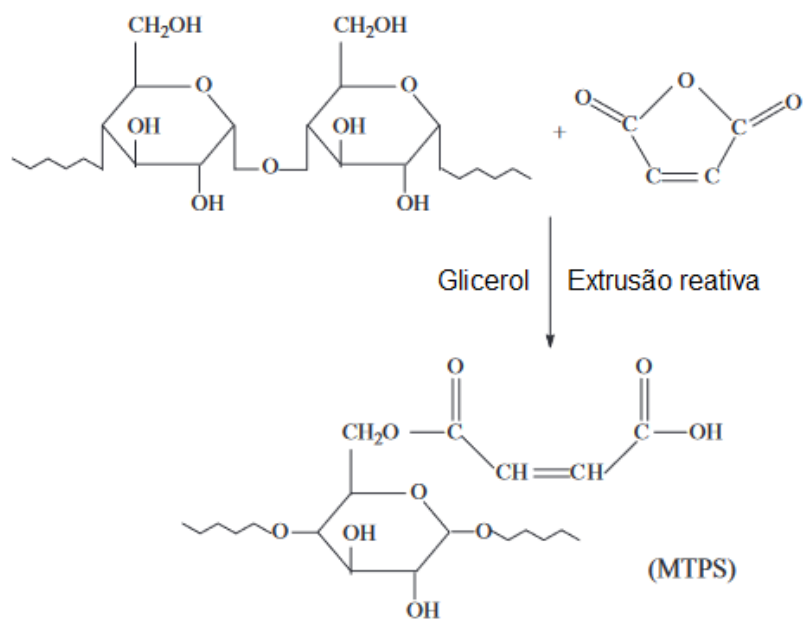

Fonte: ZUO et al., 2016.

Os resultados obtidos mostraram, que o processo de transformação por extrusão reativa foi alcançado e o amido plastificado com o anidrido sofreu reação de esterificação melhorando suas propriedades. O DS do MTPS aumentou com a quantidade de anidrido. A reação de esterificação entre os componentes fez com que a estrutura cristalina do TPS sofresse modificação, assim, enquanto o grau de cristalinidade diminuía as propriedades termoplásticas melhoravam. A adição de anidrido foi favorável à fusão do amido, facilitando sua plastificação. Os resultados de DRX e DSC mostraram que a esterificação melhorou as propriedades conforme o aumento de DS, contribuindo para uma menor absorção de água pelo material. Nas propriedades mecânicas com o aumento de anidrido, houve um decréscimo na ruptura enquanto se observou um aumento no alongamento. Nas propriedades térmicas o MTPS decompôs-se mais rapidamente que o TPS, em razão da interação química que diminuiu sua cristalinidade e apresentou menor ponto de fusão do anidrido, o que ocasionou maior perda em massa.

WELLEN e colaboradores (2013) estudaram o efeito da técnica de calorimetria exploratória diferencial (DSC), nas propriedades do polímero semicristalino poli(3-hidroxibutirato) processados pela técnica de injeção de acordo com a norma ASTM D-638, na qual variou-se as condições de aquecimento para a determinação dos seus pontos de fusão e cristalinidade. As varreduras de DSC 
realizadas a $1^{\circ} \mathrm{C} / \mathrm{min}$ e $20^{\circ} \mathrm{C} / \mathrm{min}$ em amostras de aproximadamente $5 \mathrm{mg}$, mostraram picos de fluxo de calor endotérmicos nas amostras de PHB, onde o fluxo de calor máximo de fusão dependeu da razão de aquecimento aplicada; afetando a intensidade, simetria e posição dos picos nas curvas obtidas.

ESMAEILI e colaboradores (2018), investigaram o impacto da morfologia nas propriedades térmicas (DSC/TGA) e de biodegradação em blendas de poli(ácido lático) (PLA) e amido termoplástico (TPS) à base de glicerol/sorbitol em várias formulações, compatibilizadas fisicamente por meio de extrusora co-rotante. Os resultados obtidos mostraram que a morfologia das amostras com proporções aproximadas de 40PLA; 60PLA, tiveram fases co-contínuas e as amostras 20PLA e 80PLA tiveram fases dispersas. Os resultados de DSC indicaram uma migração dos plastificantes do TPS para a fase constituinte do PLA. Já as curvas termogravimétricas (TGA) mostraram uma maior compatibilização das amostras e uma menor $T_{\max }$, energia de ativação e $T_{g}$ para amostras de 20PLA devido a ter uma maior quantidade de TPS e plastificantes em sua composição. Nas propriedades de biodegradação as amostras constituídas por maior proporção de TPS obtiveram melhores resultados para a proliferação de micro-organismos e degradação em 4 semanas, sendo que a amostra 20PLA foi a que teve uma biodegradação mais rápidas entre as amostras estudadas.

Os pesquisadores MOUSTAFA, GUIZANI e DUFRESNE (2017) estudaram as propriedades de blendas de compósitos biodegradáveis à base de PBAT, poli(etileno glicol) - PEG e pó de café (CG), processados por extrusão co-rotante em perfis de rosca alternados (L/D), e caracterizadas pelas técnicas de MEV, DRX, TGA, propriedades mecânicas, entre outras. Os resultados mostraram que os compósitos de PBAT/CG-plastificados apresentaram melhores propriedades mecânicas, homogeneização e dispersividade. Os compósitos adicionados com PEG obtiveram menores módulos de elasticidade. As propriedades térmicas foram investigadas onde a inserção de PEG, provocou melhores resultados à degradação em virtude da compatibilização com a matriz de PBAT. Pela técnica de DRX observou-se que não houve mudanças nos parâmetros de difração das amostras de PBAT/PEG sem adição de CG, entretanto com a adição de CG, houve interação química de esterificação que alterou a curva de difração das amostras. 


\subsubsection{Blendas de TPS e PBAT}

A mistura de polímeros visa melhorar as propriedades dos materiais poliméricos já existentes. As blendas são materiais originários de dois ou mais polímeros com características constitucionais ou configuracionais diferentes, e que possuem baixo grau de ligação química entre si podendo ser miscíveis ou imiscíveis. A produção de blendas de amido e polissacarídeos que são de origem biodegradável com polímeros petroquímicos biodegradáveis como o PBAT, tem a intenção de encontrar uma solução e minimizar os impactos destes, devido ao seu tempo de degradação natural ser de centenas de anos (ULTRACKI, 2002; SCHLEMMER; SALES; RESCK, 2010; BRANDELERO; GROSSMANN; YAMASHITA, 2011).

As blendas de polímeros biodegradáveis são frequentemente preparadas misturando uma resina termoplástica com uma resina biodegradável. A mistura deve produzir uma dispersão de uma matriz em outra que, após a desintegração da parte biodegradável do polímero, a parte termoplástica se desintegrará em conjunto (ULTRACKI, 2002; MA et al., 2016).

BRANDELERO, GROSSMANN e YAMASHITA (2011) estudaram a processabilidade e propriedades térmicas, químicas e mecânicas de TPS derivado da mandioca e PBAT em extrusão reativa com glicerol como plastificante. Foram feitas análises de espessura, densidade, permeabilidade ao vapor, FTIR e MEV. Eles concluíram que a produção de blendas de TPS/PBAT, teve efeito positivo nas propriedades mecânicas, estruturais e de permeabilidade a gases, dos filmes biodegradáveis produzidos por extrusão reativa na forma de balão, variando as propriedades conforme os diferentes tipos de amostras produzidas.

Em um trabalho desenvolvido por MORAES e colaboradores (2017) foi estudada a obtenção de chapas por extrusão e calandragem de resinas biodegradáveis à base de amido plastificado com glicerol (TPS), acetato de celulose (PCA) e PBAT para fins comerciais. Também foram investigadas as composições e condições de processamento bem como, as propriedades morfológicas, térmicas e mecânicas pelas técnicas de MEV, FTIR, DSC, TGA, entre outras. Os resultados obtidos mostraram que as blendas obtidas de TPS/PCA apresentaram compatibilidades em temperaturas altas de processamento, 
seguidas das TPS/PCA/PBAT que não tiveram a mesma compatibilidade, porém apresentaram ótima homogeneização entre as partes constituintes. Já as chapas biodegradáveis de TPS/PCA tiveram características de processabilidade melhores e manuseáveis que lhes confere como uma resina, que poderá suceder as commodities utilizadas atualmente.

MARINHO e colaboradores (2017) estudaram a degradação e recuperação de blendas de TPS/PBAT com até 30\% de TPS, em que foram avaliadas as propriedades de torque (viscosidade do material) com e sem aditivo extensor de cadeia $\left(\right.$ Joncryl $\left.^{\circledR}\right)$, após a mistura mecânica em laboratório. Os resultados mostraram que o percentual de TPS promoveu a degradação térmica nas misturas PBAT/TPS em níveis superiores aos observados em componentes puros, em um processo bastante dependente da composição e temperatura, no qual o Joncryl ${ }^{\circledR}$ promoveu uma recuperação parcial das blendas em temperaturas elevadas de processamento, mostrando-se efetivo na recuperação de poliésteres (PBAT) aumentando sua massa molar, porém nem tanto para os polissacarídeos (TPS).

PAN e colaboradores (2016) estudaram as propriedades de blendas de TPS/PBAT com o compatibilizante anidrido maleico. Inicialmente, o TPS reagiu com o anidrido para obter amido termoplástico maleado (MTPS) por esterificação. Em seguida, as blendas de PBAT/MTPS foram transformadas em filmes soprados. Foram realizadas caracterizações por DMA, DRX, morfológicas, térmicas, entre outras. Os resultados mostraram que as blendas apresentaram cristalinidade baixa; degradação térmica maior; e propriedades mecânicas boas proporcionais à quantidade de MTPS, devido ao processo de esterificação ocasionado pelo anidrido. A viscosidade das amostras aumentou com a quantidade de MTPS, o que favoreceu a produção de filmes soprados para aplicações diversas. 


\section{MATERIAIS E MÉTODOS}

\subsection{Matérias-primas}

Nesta pesquisa foram utilizados o amido de milho regular contendo $28 \%$ de amilose, 5,5\% de pH máximo e 14\% de umidade máxima, o Amidex ${ }^{\circledR} 3001$ da Ingredion, e o PBAT copoliéster biodegradável, Ecoflex ${ }^{\circledR}$ F Blend C 1200 da BASF SE. Utilizou-se também as seguintes matérias-primas e surfactante:

- Glicerol G9012 com 99,5\% de pureza e 92,09 u, da Sigma-Aldrich ${ }^{\circledR}$;

- Óleo de Mamona da A. Azevedo Ind. e Com. de Óleos, e

- TWEEN $^{\circledR} 80$ P1754 da Sigma-Aldrich ${ }^{\circledR}$.

\subsection{Preparação das amostras e procedimento experimental}

As formulações utilizadas neste trabalho estão apresentadas na Tabela 6 , as quais se basearam nos estudos realizados por BRANDELERO, GROSSMANN e YAMASHITA (2013), com alteração das formulações e substituição do óleo de soja pelo o óleo de mamona no processo de plastificação do amido. Após a preparação das composições do TPS com o PBAT, elas foram misturadas e modificadas reativamente (extrusão) formando a blenda. Neste estudo, as formulações representaram um massa individual de $384 \mathrm{~g}$ respectivamente. $\mathrm{O}$ processo de obtenção e transformação estão descritos, detalhadamente, nas seções 4.2 .2 e 4.2.3.

Tabela 6 - Formulações e composições das blendas de TPS/PBAT adicionadas de glicerol, óleo de mamona e/ou TWEEN ${ }^{\circledR} 80$ em percentual

\begin{tabular}{c|c|c|c|c|c|}
\cline { 3 - 6 } & \multicolumn{4}{|c}{ Composições do TPS } \\
\hline Formulação & $\begin{array}{c}\text { PBAT } \\
\text { (\% em massa) }\end{array}$ & $\begin{array}{c}\text { Amido } \\
\text { (\% em massa) }\end{array}$ & $\begin{array}{c}\text { Glicerol } \\
\text { (\% em massa) }\end{array}$ & $\begin{array}{c}\text { Óleo de Mamona } \\
\text { (\% em massa) }\end{array}$ & $\begin{array}{c}\text { TWEEN }{ }^{\circledR} 80 \\
\text { (\% em massa) }\end{array}$ \\
\hline F0 & 51,0 & 27,0 & 22,0 & ------- & ------ \\
\hline F1 & 51,0 & 27,0 & 20,5 & ------ & 1,5 \\
\hline F2 & 51,0 & 27,0 & ------ & 22,0 & ------ \\
\hline F3 & 51,0 & 27,0 & ------- & 20,5 & 1,5 \\
\hline
\end{tabular}

Fonte: autor da dissertação. 
Foram processados filmes de amido/PBAT com concentrações de $27 \%$ de amido/51\% de PBAT adicionados de glicerol, óleo de mamona (OM) e TWEEN ${ }^{\circledR} 80$, nas quantidades apresentadas na Tabela 6 . Os filmes com $22 \%$ de glicerol sem TWEEN $^{\circledR} 80$ e OM (F0) foram desenvolvidos para efeito de comparação entre as formulações. Já nos filmes F1 e F3 a quantidade de glicerol/OM com TWEEN ${ }^{\circledR} 80$, teve que ser diminuída para melhorar o fluxo do material termoplástico na direção da matriz de saída, conforme relatado em estudos realizados por BRANDELERO, GROSSMANN e YAMASHITA (2013).

\subsubsection{ETAPA I: Preparação do Amido}

Na Figura 22 são mostradas as curvas termogravimétricas do amido in natura, confirmando a perda de massa, referente à perda de água residual (12\%) até cerca de $150^{\circ} \mathrm{C}$ sem degradação química. A análise foi obtida na termobalança da TA Instruments na faixa de temperatura entre $20^{\circ} \mathrm{C}$ e $400^{\circ} \mathrm{C}$, sob atmosfera dinâmica de ar comprimido com vazão de $100 \mathrm{~mL} / \mathrm{min}$, razão de aquecimento de $20^{\circ} \mathrm{C} / \mathrm{min}$, em cadinho de alumina com massa de amostra de aproximadamente 10 mg. A partir da análise da curva de TGA, o amido foi seco em estufa a vácuo por 48 horas, a $90 \pm 0,2^{\circ} \mathrm{C}$. Essa etapa e as seguintes da preparação do TPS, foram desenvolvidas no Laboratório de Preparação de Polímeros no Centro de Tecnologia das Radiações (CTR) do Instituto de Pesquisas Energéticas e Nucleares (IPEN-CNEN/SP), conforme metodologia desenvolvida e adaptada de OLIVEIRA (2015).

Figura 22 - Curvas termogravimétricas do amido in natura

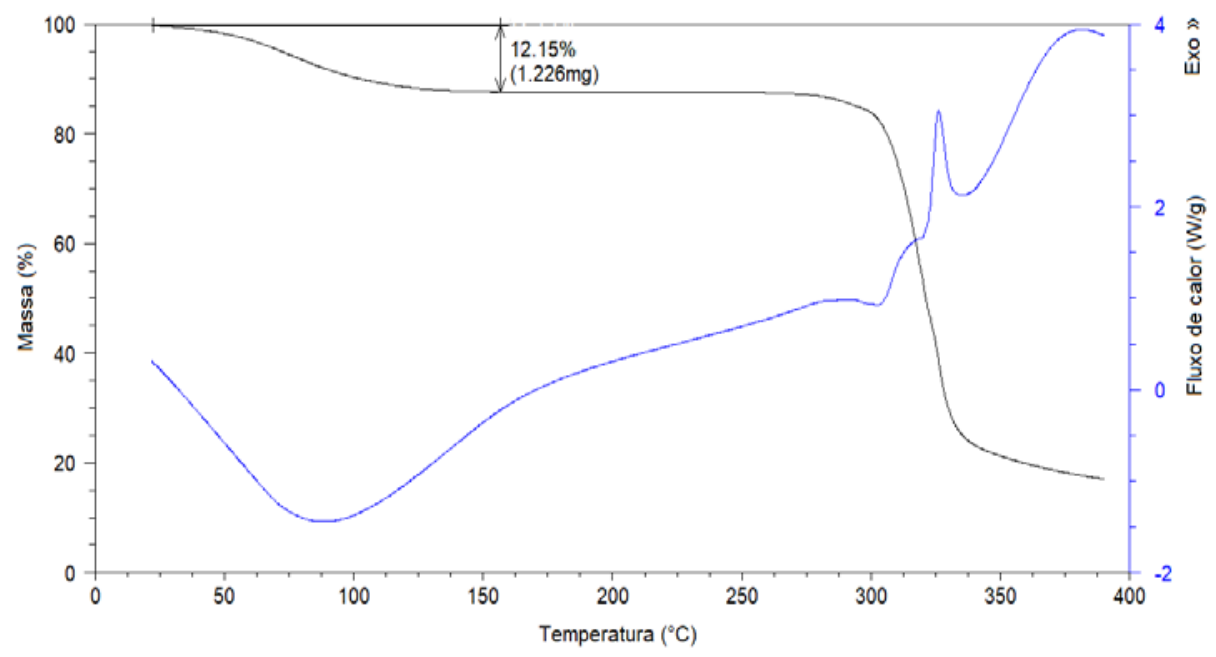

Fonte: autor da dissertação. 
4.2.3 ETAPA II: Preparação das misturas e obtenção das blendas de TPS/PBAT

Após a conclusão da etapa I, seguiu-se para a preparação e estabilização das misturas produzidas e posteriormente para o processo de extrusão e conformação dos pellets das blendas, conforme mostrado na Figura 23.

Figura 23 - Representação esquemática para obtenção das blendas de TPS/PBAT

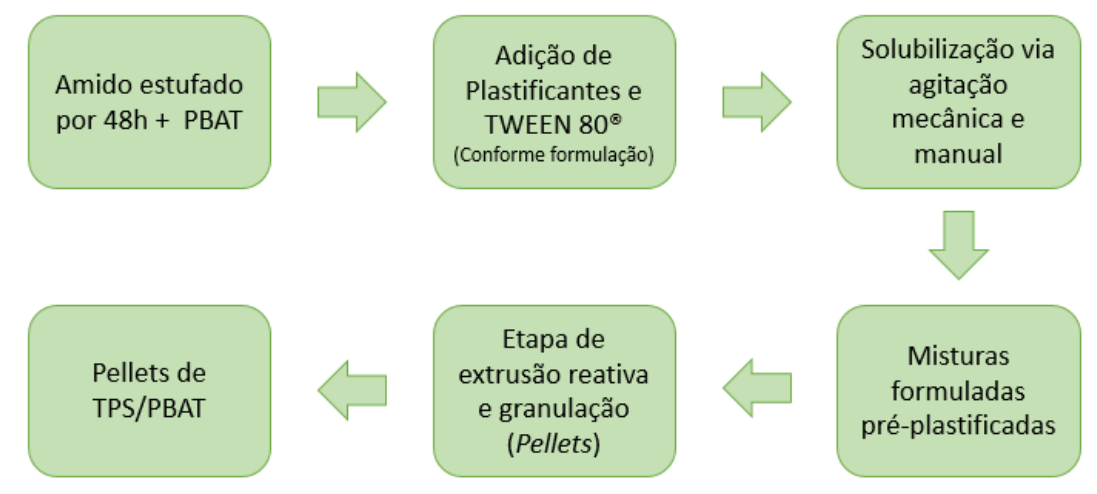

Fonte: autor da dissertação.

Na preparação do TPS, utilizou-se além do amido de milho, os plastificantes: glicerol, OM e TWEEN ${ }^{\circledR}$ 80, conforme as formulações apresentadas na Tabela 6. As amostras foram pesadas junto com os pellets de PBAT e solubilizadas, parcialmente com auxílio do agitador mecânico modelo "713" da Fisatom (Figura 24), a 400 rpm, por 2 min até obter consistência e homogeneidade, e concluídas com mistura manual, devido ao processo de plasticidade e intumescimento das formulações no decorrer da inserção dos plastificantes no amido e no PBAT.

Figura 24 - Mistura mecânica das formulações de blendas de TPS/PBAT

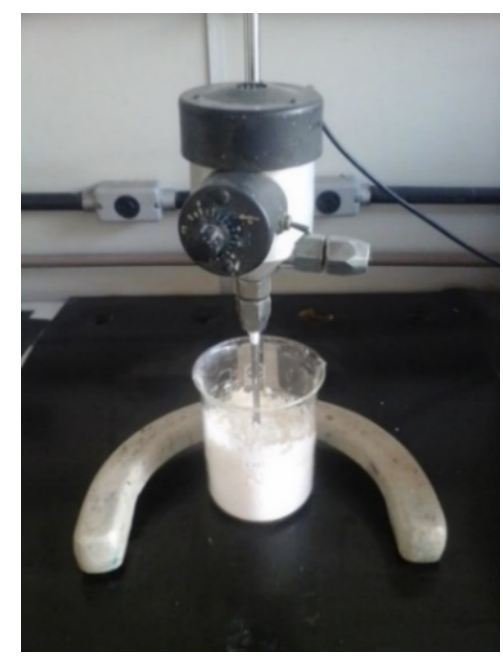

Fonte: autor da dissertação. 
As amostras foram extrusadas na extrusora dupla rosca co-rotante (Figura 25), modelo "AX16LD40" da AX Plásticos Máquinas Técnicas Ltda, localizada no CTR do IPEN/CNEN-SP, com os seguintes parâmetros de temperaturas para extrusão do funil para a saída da matriz: $120^{\circ} \mathrm{C}-122^{\circ} \mathrm{C}-124^{\circ} \mathrm{C}-126^{\circ} \mathrm{C}-126^{\circ} \mathrm{C}$ $128^{\circ} \mathrm{C}-130^{\circ} \mathrm{C}-132^{\circ} \mathrm{C}-134^{\circ} \mathrm{C}$, utilizando-se de uma rotação de $75 \mathrm{rpm}$ (cerca de 13\% da rotação máxima do equipamento).

Figura 25 - Extrusora utilizada para obtenção de blendas de TPS/PBAT

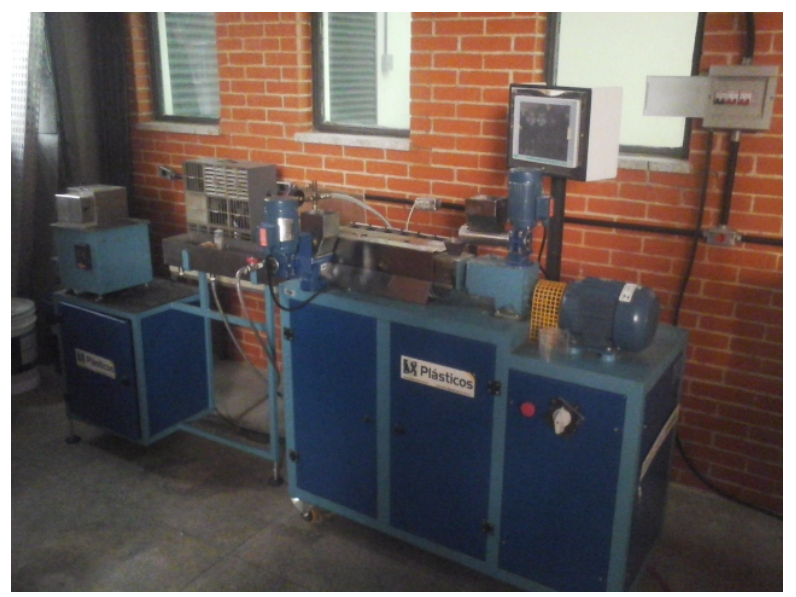

Fonte: autor da dissertação.

O resfriamento do material ao sair da matriz, foi feito por ventilação forçada e por calha d'agua, que foi cortado em grânulos (pellets) como mostrado na Figura 26. Após a extrusão, os pellets das blendas foram separados e guardados em embalagens identificadas conforme sua formulação.

Figura 26 - Pellets de TPS/PBAT com glicerol (F0)

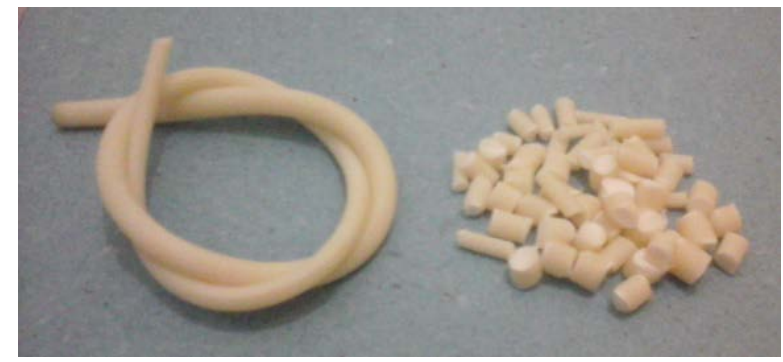

Fonte: autor da dissertação.

Durante o processo de extrusão as blendas F2 e F3, apresentaram maior fluidez na saída da matriz da extrusora em relação as amostras extrudadas F0 e $\mathrm{F} 1$, em virtude dos reagentes utilizados, temperatura de processamento $\mathrm{e}$ quantidade utilizada no processo de plastificação do amido e formação da blenda. 
Eventos similares ocorreram em estudos desenvolvidos por BRANDELERO, GROSSMANN e YAMASHITA (2013); OLIVEIRA, (2015).

\subsection{Modificação das blendas}

A partir da literatura, e com base no estudo abordado nas seções 3.3.2 e 3.4.3, sobre a interação com a radiação ionizante nas matérias-primas desse experimento definiu-se a dose de radiação.

SCHIMITBERGER (2015), relatou que são necessárias doses a partir de 10 kGy de radiação gama, para modificação da estrutura isolada do PBAT, em razão da foto-emissão induzida pelo polímero. Já as pesquisadoras NEMTANU e BRASOVEANU (2017), em sua pesquisa sobre a modificação de amilose por radiação por feixe de elétrons, relataram que doses entre 10 e 50 kGy, são suficientes para modificar as propriedades do amido em razão de sua estrutura química.

Com base nestes estudos sobre a interação da radiação com o amido e o PBAT (51\% em composição), neste trabalho utilizou-se a dose de radiação de 25 kGy.

\subsubsection{Processo de irradiação}

As blendas foram irradiadas com dose de $25 \mathrm{kGy}$ no irradiador de ${ }^{60} \mathrm{Co}$, modelo Gammacell 200 (Figura 27), com taxa de dose de 0,662 kGy/h, à temperatura ambiente, na presença de ar, localizado no CTR do IPEN-CNEN/SP.

Figura 27 - Irradiador de ${ }^{60} \mathrm{Co}$

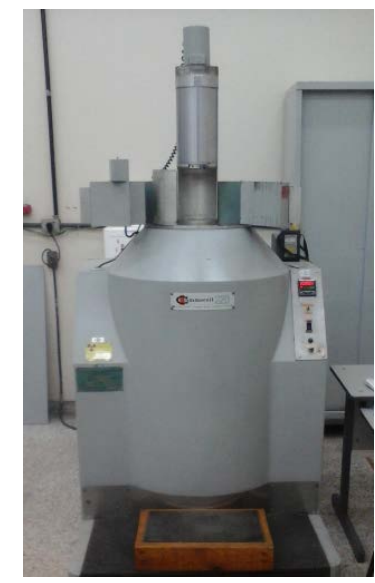

Fonte: autor da dissertação. 
Após o processo de irradiação as amostras foram identificadas, separadas e guardadas em embalagens, livres da exposição ambiente para evitar os efeitos da pós-irradiação e da luz ambiente até a aplicação dos ensaios e caracterização.

\subsection{Caracterização das blendas}

4.4.1 Análise termogravimetrica (TGA) e calorimetria exploratória diferencial por fluxo de calor (DSC)

A análise de TGA (thermogravimetric analysis), tem como finalidade observar as temperaturas de transição vítrea, cristalinidade e degradação das amostras, além de acompanhar a variação de massa (m) em função do tempo ( $\mathrm{t}$ ) ou temperatura (T) de acordo com a Equação 5. Essa técnica permite conhecer e interpretar as alterações provocadas na massa das substâncias estudadas, obtendo dados como reações de desidratação, oxidação, combustão e decomposição, entre outras (MATOS; MACHADO, 2004).

$$
\mathrm{m}=\mathrm{f}(\mathrm{T} \text { ou } \mathrm{t})
$$

Podem ser analisadas por esta técnica diversos materiais poliméricos, entre eles (MATOS; MACHADO, 2004):

- Termoplásticos e termorrígidos;

- Elastômeros;

- Blendas;

- Aditivos;

- Compósitos, entre outros.

Na termogravimetria derivada (DTG), as curvas são registradas a partir de curvas de TGA e correspondem a primeira derivada da variação da massa em relação ao tempo/temperatura conforme mostrado na Equação 6:

$$
\mathrm{dm} / \mathrm{dt}=\mathrm{f}(\mathrm{T} \text { ou } \mathrm{t})
$$

A técnica de DSC (diferencial exploratory scanning) por fluxo de calor, é uma técnica derivada da análise térmica diferencial (DTA). A propriedade física medida pela DSC é a diferença de temperatura (T) entre a amostra (A) e sua referência (R), submetidas à controle rigoroso de temperatura, obtendo-se a variação de entalpia 
e as propriedades caloríficas e térmicas da amostra (MACHADO; MATOS, 2004; WELLEN et al., 2013). Na Equação 7 é mostrada a aplicação matemática dessa variação.

$$
\Delta \mathrm{T}=\mathrm{T}_{\mathrm{A}}-\mathrm{T}_{\mathrm{R}}
$$

Em que: $\Delta \mathrm{T}=$ variação de temperatura; $\mathrm{T}_{\mathrm{A}}=$ temperatura da amostra; $\mathrm{T}_{\mathrm{R}}=$ temperatura da referência.

Uma vez que as propriedades térmicas/mecânicas dos polímeros são sensíveis a temperatura, a técnica de DSC torna-se importante na etapa de caracterização dos materiais poliméricos, em que após o aquecimento e alcançada a temperatura de transição vítrea $\left(\mathrm{T}_{\mathrm{g}}\right)$, o polímero sólido se transforma em estado borrachado com movimentação intramolecular rotacional até seu estado fundido ( $\left.T_{m}\right)$ e viscoso (CALLISTER JUNIOR; RETHWISCH, 2009).

Neste trabalho as duas técnicas analíticas foram utilizadas, por serem obtidas simultaneamente pelo equipamento.

As análises foram feitas de acordo com a norma AMERICAN SOCIETY FOR TESTING OF MATERIALS (2017), na termobalança, modelo TGA-DSC SDT Q600 da TA Instruments (Figura 28), localizada no laboratório de análise térmica no CTR do IPEN-CNEN/SP, na faixa de temperatura entre $20^{\circ} \mathrm{C}$ e $600^{\circ} \mathrm{C}$, sob atmosfera dinâmica de ar comprimido com vazão de 100 mL/min, razão de aquecimento de $20^{\circ} \mathrm{C} / \mathrm{min}$, colocadas em cadinho de alumina com massa de amostra de aproximadamente $10 \mathrm{mg}$. A obtenção das curvas de TGA/DSC e a interpretação dos resultados foram feitas por meio do software TA Universal Analysis ${ }^{\circledR}$.

Figura 28 - Equipamento de TGA/DSC simultâneo

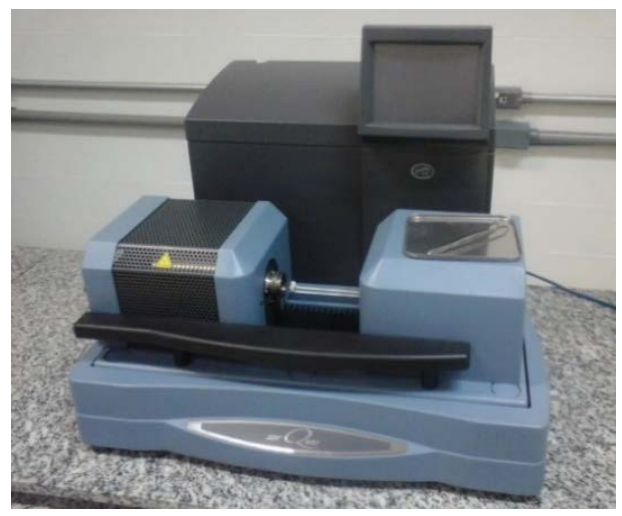

Fonte: autor da dissertação. 
4.4.2 Espectroscopia vibracional de absorção no infravermelho por transformada de Fourier (FTIR)

A espectroscopia é o estudo da radiação eletromagnética com a matéria. A natureza corpuscular manifesta-se pelos efeitos Compton e fotoelétrico, originando três processos distintos: absorção, emissão e espalhamento de radiação (KAWANO, 2004).

A espectroscopia vibracional no infravermelho estuda a transição vibracional das moléculas das quais são apresentadas na Tabela 7 (KAWANO, 2004).

Tabela 7 - Tipos de vibrações moleculares e suas consequências

\begin{tabular}{c|c}
$\begin{array}{c}\text { Tipos de vibrações } \\
\text { moleculares }\end{array}$ & \multicolumn{1}{c}{ Consequências } \\
\hline Estiramento de ligação & $\begin{array}{l}\text { Simétrico, anti-simétrico, } \\
\text { degenerado, em fase, pulsação } \\
\text { ou respiração de anel. }\end{array}$ \\
\hline $\begin{array}{c}\text { Vibração angular e } \\
\text { torção }\end{array}$ & $\begin{array}{l}\text { Simétrico: "balanço", "torção", } \\
\text { "rotação"; } \\
\text { Degenerado, no plano, fora do } \\
\text { plano, deformação de anel e } \\
\text { torção. }\end{array}$ \\
\hline $\begin{array}{c}\text { Movimento vibracional } \\
\text { definido }\end{array}$ & Vibração normal. \\
\hline
\end{tabular}

Fonte: adaptado de KAWANO, 2004.

As moléculas simples ou compostas são constituídas de átomos, que formam uma rede tridimensional com distância e ligações químicas definidas, assim apresentando uma simetria molecular. A estrutura molecular é responsável pelas propriedades e características químicas intrínsecas do composto (KAWANO, 2004; SILVERSTEIN; WEBSTER; KIEMLE, 2005).

O espectrômetro de FTIR é constituido por uma fonte de radiação, um interferometro, compartimento de amostra e um detector de radiação, sendo que a espectroscopia de FTIR pode ser dividida em três regiões distintas: 
$(\mathrm{FIR})$

400

a $4000 \mathrm{~cm}^{-1} \quad$ IR médio

(MIR)

4000

a $12820 \mathrm{~cm}^{-1}$

IR próximo

$(\mathrm{NIR})$

A maioria dos estudos em materiais poliméricos ocorrem na região média do infravermelho (MIR), onde ocorre as frequências vibracionais fundamentais para deteção dos modos de deformação, deformações angulares e geometria dos átomos, sendo o dispositivo de absorção ATR (Refletância Total Atenuada) acoplado ao equipamento (Figura 29), utilizado por se obter boa qualidade de espectros de materiais poliméricos em diversas formas (KAWANO, 2004; SILVERSTEIN; WEBSTER; KIEMLE, 2005; AMERICAN SOCIETY FOR TESTING OF MATERIALS, 2013).

Figura 29 - Funcionamento típico de um dispositivo de ATR-FTIR

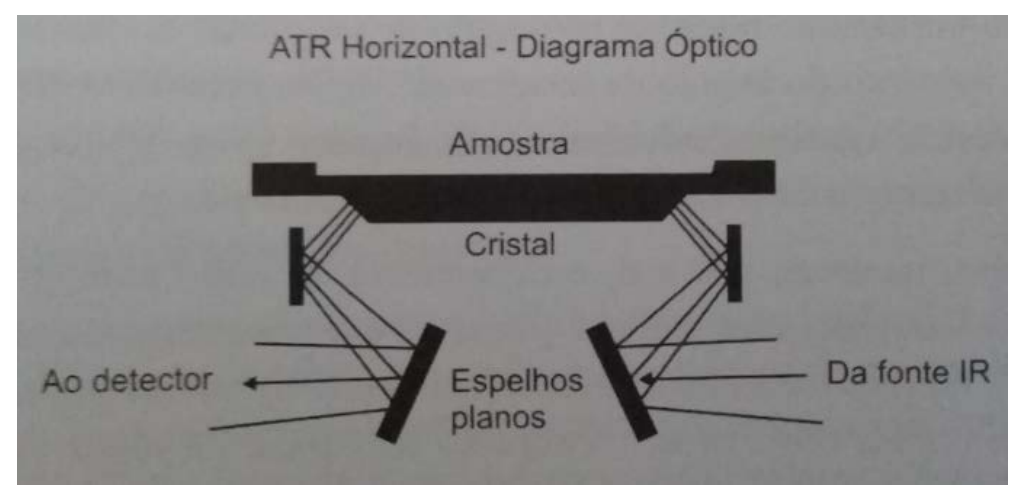

Fonte: KAWANO, 2004.

O feixe de IR, ao atingir a superfície da amostra presente no cristal, é absorvido ou transmitido pela mesma e a diferença energética é detectada pelo equipamento resultando em um espectro de absorbância/transmitância (KAWANO, 2004).

As análises foram feitas de acordo com a norma AMERICAN SOCIETY FOR TESTING OF MATERIALS (2013), em espectrofotômetro modelo Spectrum One da Perkin Elmer (Figura 30), acoplado com dispositivo universal ATR ("Sampling Acessory"), no modo de transmitância com frequência média (MIR) e resolução de $2 \mathrm{~cm}^{-1}$, localizado no laboratório de análises no CTR do IPEN-CNEN/SP. 
Figura 30 - Equipamento de ATR-FTIR

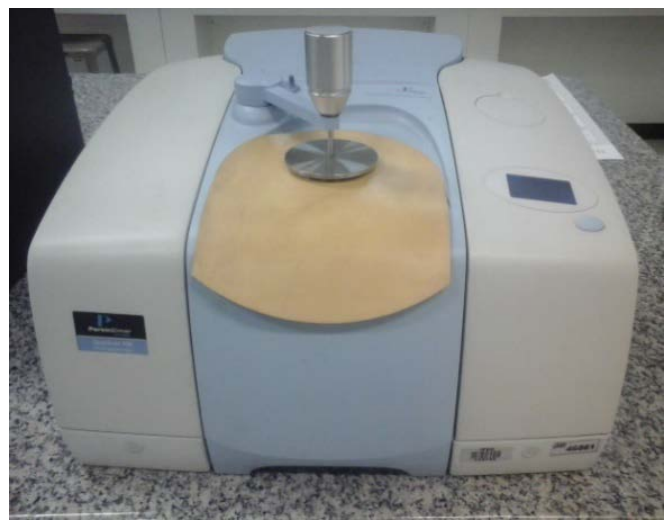

Fonte: autor da dissertação.

\subsubsection{Microscopia eletrônica de varredura (MEV)}

A microscopia eletrônica de varredura, tem como principal aplicação a análise da estrutura superficial e morfologia de amostras, também pode ser obtida informações como estrutura e composição química a partir de equipamentos acoplados (CALLISTER JUNIOR; RETHWISCH, 2009). As imagens em alta definição, são geradas a partir de um feixe de elétrons por um filamento de tungstênio em amostras envoltas por filmes metálicos condutores, que causam excitação a nível energético, ocasionando os espalhamentos elástico e inelástico que são captados pelo equipamento gerando as micrografias. Além de ser possível visualizá-las em cores pré-definidas pelo equipamento (GONÇALVES, 2004; CALLISTER JUNIOR; RETHWISCH, 2009; YOSHIMURA, 2009).

Entretanto GONÇALVES (2004), relatou que imagens obtidas de amostras preparadas constituídas de materiais poliméricos são difíceis de obter imagens com bom contraste, devido a sua composição química à base de elementos leves $(C, H$, O e outros). Assim é necessário o coloramento químico ou um bom preparo da amostra para facilitar sua interpretação.

Outra alternativa de preparo de amostras de blendas poliméricas para a $M E V$, é a técnica de fratura criogênica em temperaturas baixas, que evita a deformação plástica e destaca a morfologia interna da amostra, sendo possível visualizar as fases constituintes da blenda ou detalhes estruturais (GONÇALVES, 2004). 
As amostras foram analisadas no equipamento modelo JSM 6510 Series da JEOL (Figura 31), acoplado com um dispositivo EDS (Espectroscopia de raios $X$ por energia dispersiva) e equipado com filamento de tungstênio, pertencente a Escola de Engenharia da Universidade Presbiteriana Mackenzie. As amostras primeiramente passaram pela técnica de fratura vítrea com $\mathrm{N}_{2}$ e em seguida revestidas por nanopartículas de ouro. As micrografias foram coletadas utilizandose voltagem de 30 kV sob diferentes magnificações (25x, 27x, 30x, 200x e 500x).

Figura 31 - Equipamento de MEV-EDS

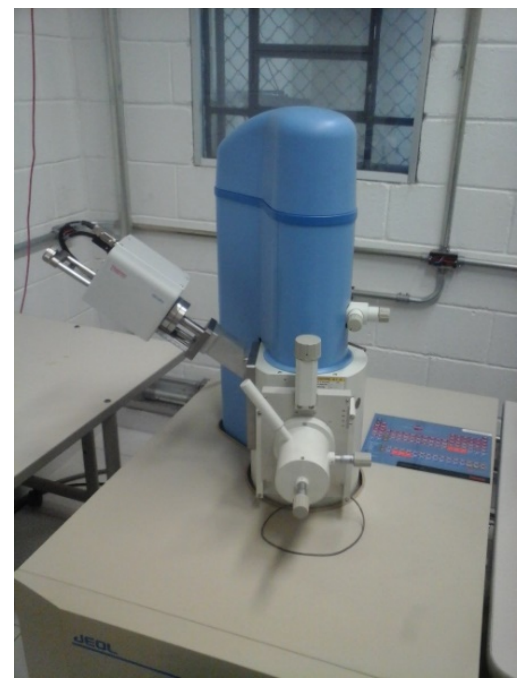

Fonte: autor da dissertação.

\subsubsection{Difração de raios X (DRX)}

Essa técnica consiste no espalhamento da radiação $X$ (seguindo a lei de Bragg - Equação 8), estudando as estruturas cristalinas organizadas (cristais), e a morfologia dos materiais, determinando assim sua estrutura cristalina ou fração cristalina no caso dos materiais poliméricos. Outras técnicas combinadas como o DSC e DRX, podem também avaliar a cristalinidade dos materiais poliméricos (BAUMHARDT NETO, 2004; CALLISTER JUNIOR; RETHWISCH, 2009).

$$
\mathrm{n} \lambda=2 \mathrm{~d}_{\mathrm{hkl}} \operatorname{sen} \theta
$$

Em que: $\mathrm{n}=$ ordem de difração (número inteiro); $\lambda=$ comprimento de onda da radiação utilizada; $d$ = distância entre os planos cristalinos; $\theta$ = ângulo de difração.

O plano cristalino e a distância interplanar (Equação 9) de uma estrutura, é determinada a partir da difração ordenada das ondas de raios $X$ nos 
cristalitos/esferulitos ou lamelas dos materiais poliméricos (BAUMHARDT NETO, 2004).

$$
d_{h k l}=\frac{\mathrm{a}}{\sqrt{\mathrm{h}^{2}+k^{2}+l^{2}}}
$$

Em que: $\mathrm{d}$ = espaçamento interplanar; $\mathrm{a}=$ parâmetro da célula unitária; hkl = índices de Miller.

Os testes foram realizados no equipamento, modelo X-Ray Diffractometer Multiflex da Rigaku Denki Co. Ltd. (Figura 32), localizado no laboratório de difração de raios $X$ no Centro de Ciência e Tecnologia dos Materiais (CCTM) do IPENCNEN/SP, utilizando-se de radiação CuKa $(\lambda=1,541 \AA)$ monocromática, sob voltagem de $40 \mathrm{kV}$; corrente de $20 \mathrm{~mA}$; ângulo de difração entre 5-60; ordem de difração = 1 e velocidade de varredura de 4 s. a cada $0,06^{\circ}$ de inclinação.

Figura 32 - Equipamento de difração de raios X com detalhe interno do difratometro

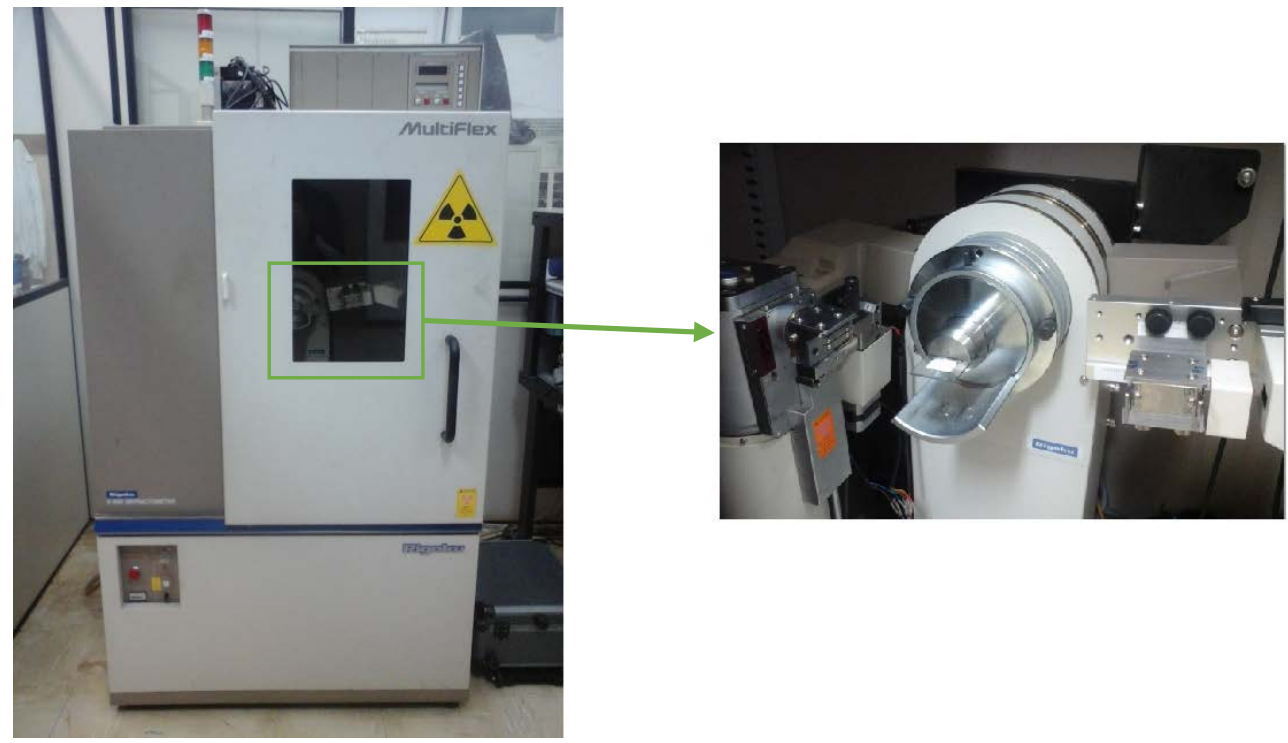

Fonte: autor da dissertação.

\subsubsection{1 Índice de cristalinidade (IC)}

O cálculo de índice de cristalinidade (IC) das blendas foi realizado de acordo com o método de Ruland e consistiu na subtração do halo amorfo das amostras (CHUNG; SCOTT, 1973; BAUMHARDT NETO, 2004; CORREIA, 2015; PAN et al., 2016). Por meio deste método, uma linha base foi aplicada nas curvas de DRX com auxílio do software Bruker DIFFRAC.EVA ${ }^{\circledR}$ V4.22. Assim, após a subtração do halo 
amorfo os picos cristalinos e seu IC, foram calculados por meio da razão entre a área da região cristalina e a área total conforme a Equação 10 (CORREIA, 2015):

$$
I_{C} \%=\left(\frac{A_{C}}{A_{T}}\right) \times 100
$$

Em que: $I_{c} \%=$ porcentagem do índice de cristalinidade; $A_{c}=$ área cristalina; $\mathrm{A}_{\mathrm{t}}=$ área total.

Para o cálculo da área cristalina $\left(\mathrm{A}_{\mathrm{c}}\right)$, a área do gráfico passou por correção da linha base, desconsiderando-se os picos remanescentes das curvas de DRX. 


\section{RESULTADOS E DISCUSSÃO}

\subsection{Análise termogravimétrica (TGA)}

As análises termogravimétricas das blendas mostraram a variação da perda de massa em função da temperatura das amostras não irradiadas (NIR) e irradiadas com $25 \mathrm{kGy}$, realizadas a $20^{\circ} \mathrm{C} / \mathrm{min}$ até $600^{\circ} \mathrm{C}$.

Nas Figuras 33 e 34 são mostradas as curvas termogravimétricas das amostras e seus componentes.

Figura 33 - Curvas termogravimétricas das amostras NIR e seus componentes

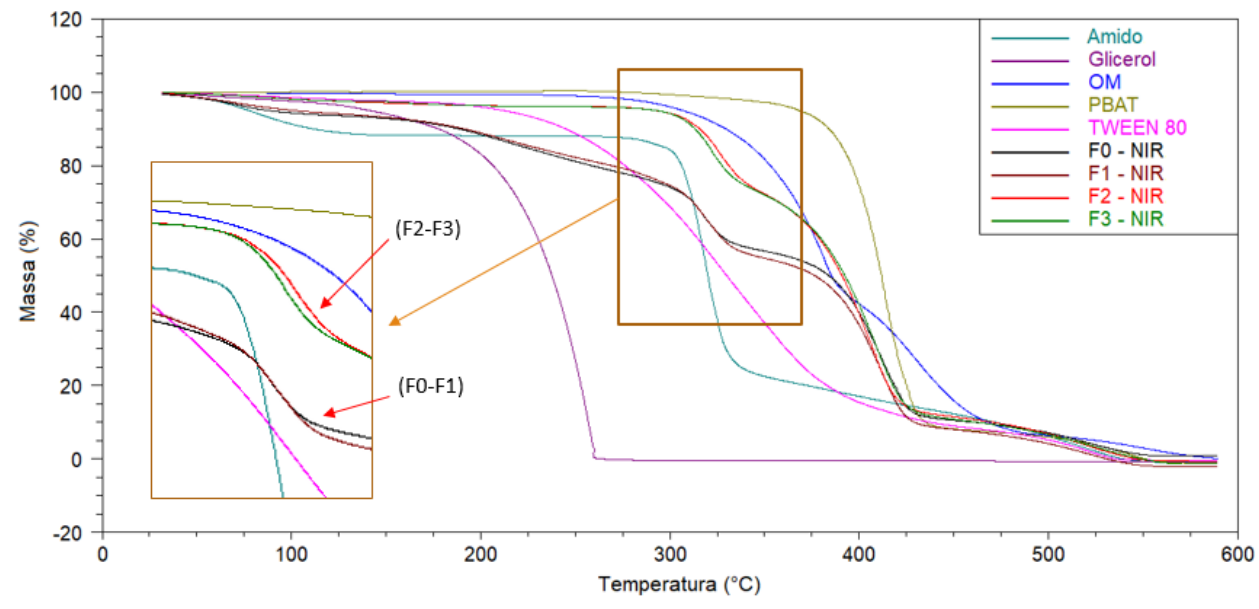

Fonte: autor da dissertação.

Figura 34 - Curvas termogravimétricas das amostras irradiadas a 25 kGy e seus componentes

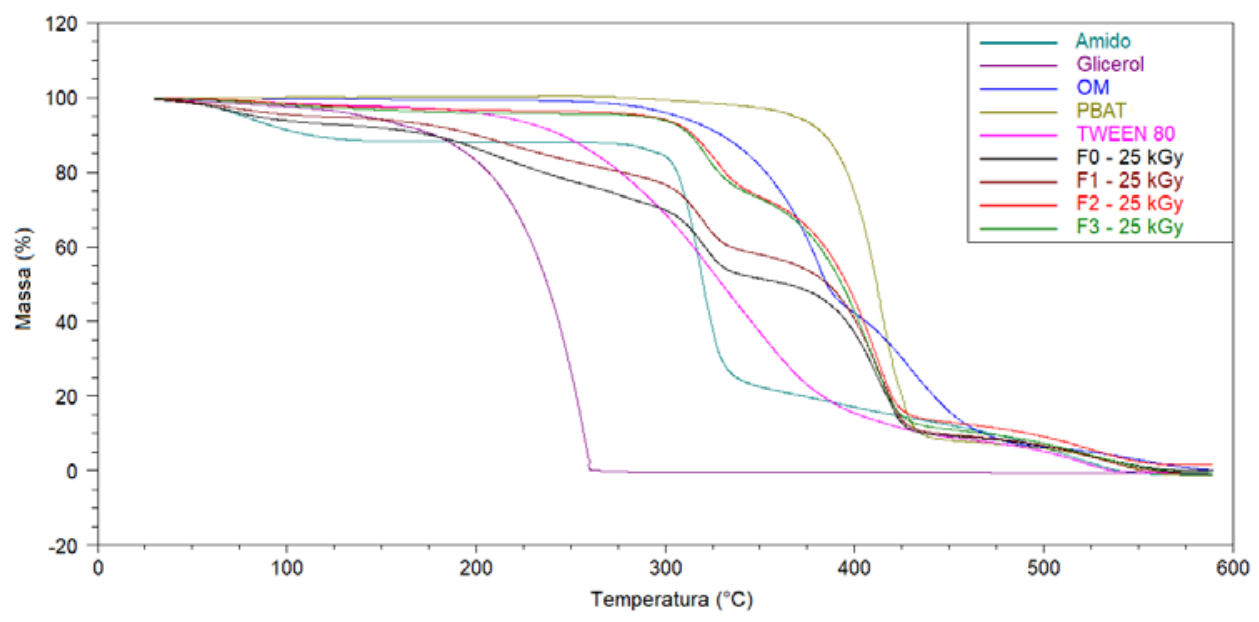

Fonte: autor da dissertação. 
A partir das análises das curvas termogravimétricas da perda de massa em função da temperatura nas Figuras 33 e 34, observou-se que o evento de degradação ocorreu em várias etapas e iniciou-se na temperatura ambiente em todas as formulações estudadas, no caso do amido iniciou-se em torno de $150^{\circ} \mathrm{C}$, porém as blendas F2 e F3 tiveram maior resistência à degradação em relação as F0 e F1 devido ao processo de esterificação do óleo de mamona, utilizado no processo de plastificação do amido em extrusão reativa, o que está de acordo com os estudos análogos realizados por SATHISKUMAR e MADRAS (2011), MOUSTAFA, GUIZANI e DUFRESNE (2017), e apresentado neste trabalho na seção 3.5.2.

Na Tabela 8 são apresentadas as temperaturas de início da degradação térmica dos componentes e das blendas NIR e irradiadas e também a influência da radiação $(\gamma)$ na temperatura e no processo de modificação da blenda. A temperatura inicial dos eventos foi obtida pela técnica de TGA, de acordo com a norma AMERICAN SOCIETY FOR TESTING OF MATERIALS (2017), e a variação de massa correspondente às condições especificadas foi detetada e registrada. $\bigcirc$ evento inicial da degradação, obteve-se a partir da correlação aproximada de linhas tangentes à curva obtida pelo equipamento, conforme mostrado na Figura 35 e é chamado de Tonset.

Figura 35 - Curvas termogravimétricas com destaque para a Tonset da formulação F2

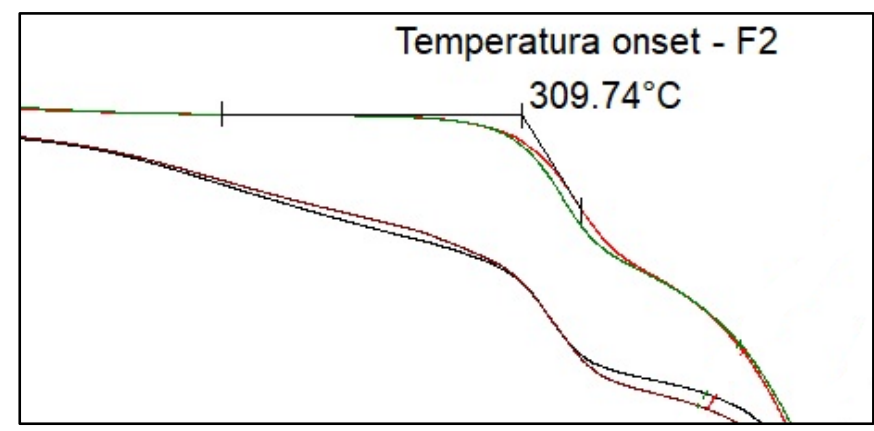

Fonte: autor da dissertação.

Os resultados referentes às temperaturas de início da degradação térmica das amostras NIR e irradiadas em relação a curva padrão do amido puro são apresentados na Tabela 8, bem como dos seus componentes. 
Tabela 8 - Temperaturas (Tonset) dos componentes e das blendas, calculadas pelas curvas mostradas nas Figuras 33 e 34 e interpretadas pelo software TA Universal Analysis ${ }^{\circledR}$

\begin{tabular}{|c|c|c|}
\hline Componentes & \multicolumn{2}{|c|}{ Temperatura (Tonset) } \\
\hline Amido & \multicolumn{2}{|c|}{$306,9^{\circ} \mathrm{C}$} \\
\hline PBAT & \multicolumn{2}{|c|}{$393,9^{\circ} \mathrm{C}$} \\
\hline Glicerol & \multicolumn{2}{|c|}{$214,9^{\circ} \mathrm{C}$} \\
\hline Óleo de Mamona & \multicolumn{2}{|c|}{$341,6^{\circ} \mathrm{C}$} \\
\hline TWEEN ${ }^{\circledR} 80$ & \multicolumn{2}{|c|}{$259,7^{\circ} \mathrm{C}$} \\
\hline Formulações & NIR & $\begin{array}{l}\text { Irradiadas } \\
\text { a } 25 \mathrm{kGy}\end{array}$ \\
\hline FO & $308,9^{\circ} \mathrm{C}$ & $307,2^{\circ} \mathrm{C}$ \\
\hline F1 & $304,0^{\circ} \mathrm{C}$ & $306,8^{\circ} \mathrm{C}$ \\
\hline F2 & $309,7^{\circ} \mathrm{C}$ & $306,6^{\circ} \mathrm{C}$ \\
\hline F3 & $307,6^{\circ} \mathrm{C}$ & $306,7^{\circ} \mathrm{C}$ \\
\hline
\end{tabular}

Fonte: autor da dissertação.

Nas Figuras 36 e 37 são mostradas as curvas termogravimétricas derivadas (DTG) e os eventos de degradação ocorridos nas amostras e seus componentes.

Figura 36 - Curvas de DTG das blendas NIR

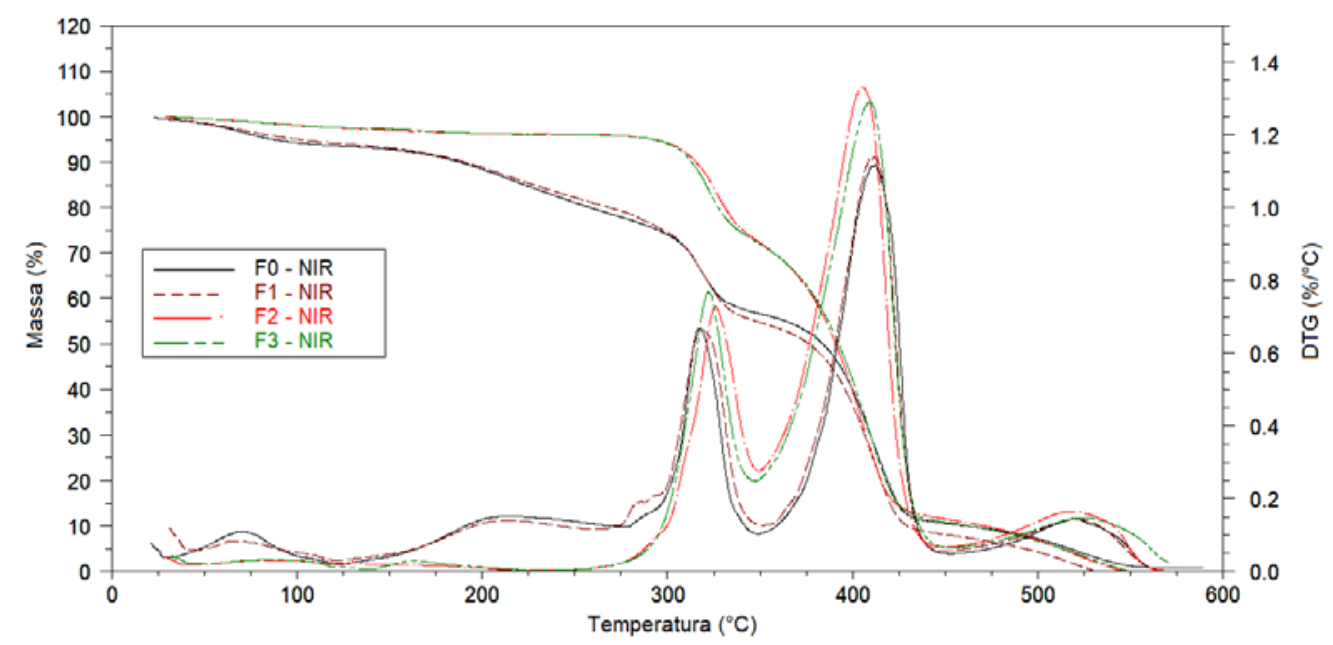

Fonte: autor da dissertação. 
Figura 37 - Curvas de DTG das blendas irradiadas a 25 kGy

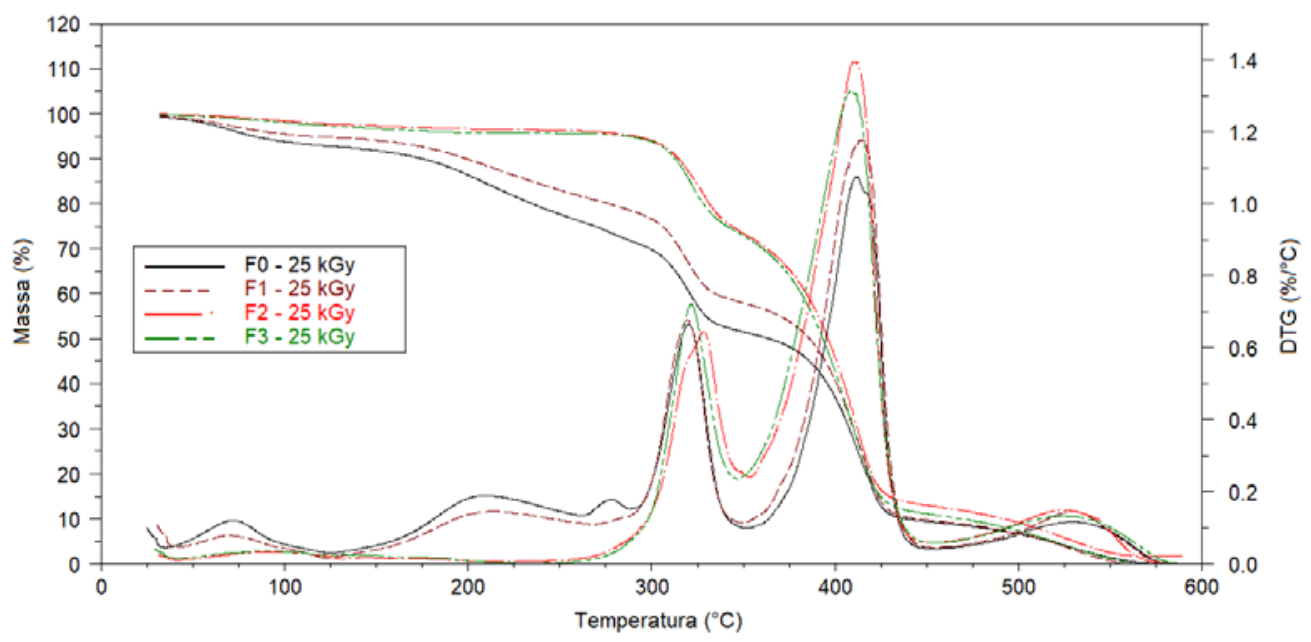

Fonte: autor da dissertação.

A partir da análise dos resultados apresentados na Tabela 8 e das curvas de DTG mostradas nas Figuras 36 e 37, observou-se cinco estágios correlatos de degradação das amostras e seus constituintes, os quais estão descritos a continuação.

1. O primeiro estágio de entalpia, com reação endotérmica das amostras F0 e F1, seguida de perda de umidade presente no amido constituinte nas amostras e degradação inicial em $150^{\circ} \mathrm{C}$, conforme mostrado na seção 4.2.2;

2. O segundo estágio, com o glicerol das amostras F0 e F1 a partir de $\sim 190^{\circ} \mathrm{C}$ até o início da degradação do amido em razão da inserção dos plastificantes que torna as ligações químicas mais fracas (OLIVEIRA, 2015). Seguido pela degradação sequencial das amostras FO e F1; e após os eventos secundários;

3. O terceiro estágio com degradação de todas as amostras iniciando-se pelo amido em $\sim 307^{\circ} \mathrm{C}$ Tonset, PBAT, TWEEN ${ }^{\circledR} 80$ e óleo de mamona (OM), respectivamente em $\sim 330^{\circ} \mathrm{C}$ Tonset, evidenciando as diferenças entre os ácidos oleico (TWEEN ${ }^{\circledR} 80$ ) e ricinoleico (OM) (OLIVEIRA, 2015), em relação as amostras constituídas por glicerol (F0 e F1);

4. O quarto estágio do evento de degradação iniciou-se a partir de $420^{\circ} \mathrm{C}$ com o evento exotérmico, e caracterizou-se pela degradação final do amido 
presente nas amostras e início da degradação térmica final do PBAT em $\sim 350^{\circ} \mathrm{C}$, em decorrência da desintegração do amido (ESMAEILI et al., 2018). 5. No último estágio de degradação térmica as amostras sofreram carbonização e foram convertidas a gases $\mathrm{CO}, \mathrm{CO}_{2}, \mathrm{H}_{2} \mathrm{O}$, entre outros (ESMAEILI et al., 2018), com transição final em torno de $\sim 530^{\circ} \mathrm{C}$ Tendset.

Observou-se também a partir das curvas de TGA/DTG, que as amostras irradiadas F0 com glicerol e F1 com glicerol e TWEEN ${ }^{\circledR} 80$, sofreram decréscimo nas curvas de TGA em relação as amostras F0 com glicerol e F1 com glicerol e TWEEN $^{\circledR} 80$ (NIR), devido a uma provável degradação da amilose presente no amido, induzida pela radiação $(\gamma)$, conforme observado em estudos realizados por NEMTANU e BRASOVEANU (2017), utilizando-se o processo de irradiação com feixe de elétrons e por ATROUS e colaboradores (2015) com fonte de ${ }^{60} \mathrm{Co}$, e também pela perda de glicerol utilizado como plastificante ao longo do tempo.

Já as amostras F2 com OM e F3 com OM e TWEEN ${ }^{\circledR} 80$, tiveram o mesmo comportamento degradativo, tanto nas amostras NIR e irradiadas, o que se pôde observar nas curvas de TGA/DTG, obtidas dos dois gráficos. Assim sendo, concluiu-se que o processo de esterificação e compatibilização do OM com os demais constituintes, pode ser obtido por extrusão reativa e indução por radiação $(\gamma)$, vantagem observada em relação ao glicerol tanto compatibilizado (F1) e não compatibilizado com TWEEN ${ }^{\circledR} 80$ (F0). Sendo que as amostras F2 e F3 não sofreram com a perda de plastificantes ao longo do tempo em relação as amostras F0 e F1, o que favoreceu suas propriedades térmicas finais.

\subsection{Calorimetria exploratória diferencial por fluxo de calor (DSC)}

A análise de DSC das amostras, mostrou a variação do fluxo de calor pela temperatura em relação a sua massa, ocorrida nas amostras não irradiadas (NIR) e irradiadas a $25 \mathrm{kGy}$, realizadas a $20^{\circ} \mathrm{C} / \mathrm{min}$ até $600^{\circ} \mathrm{C}$.

Nas Figuras 38 e 39 são mostradas as curvas de TGA/DSC, das amostras não irradiadas (NIR) e irradiadas a 25 kGy. 
Figura 38 - Curvas de TGA/DSC das blendas não irradiadas (NIR)

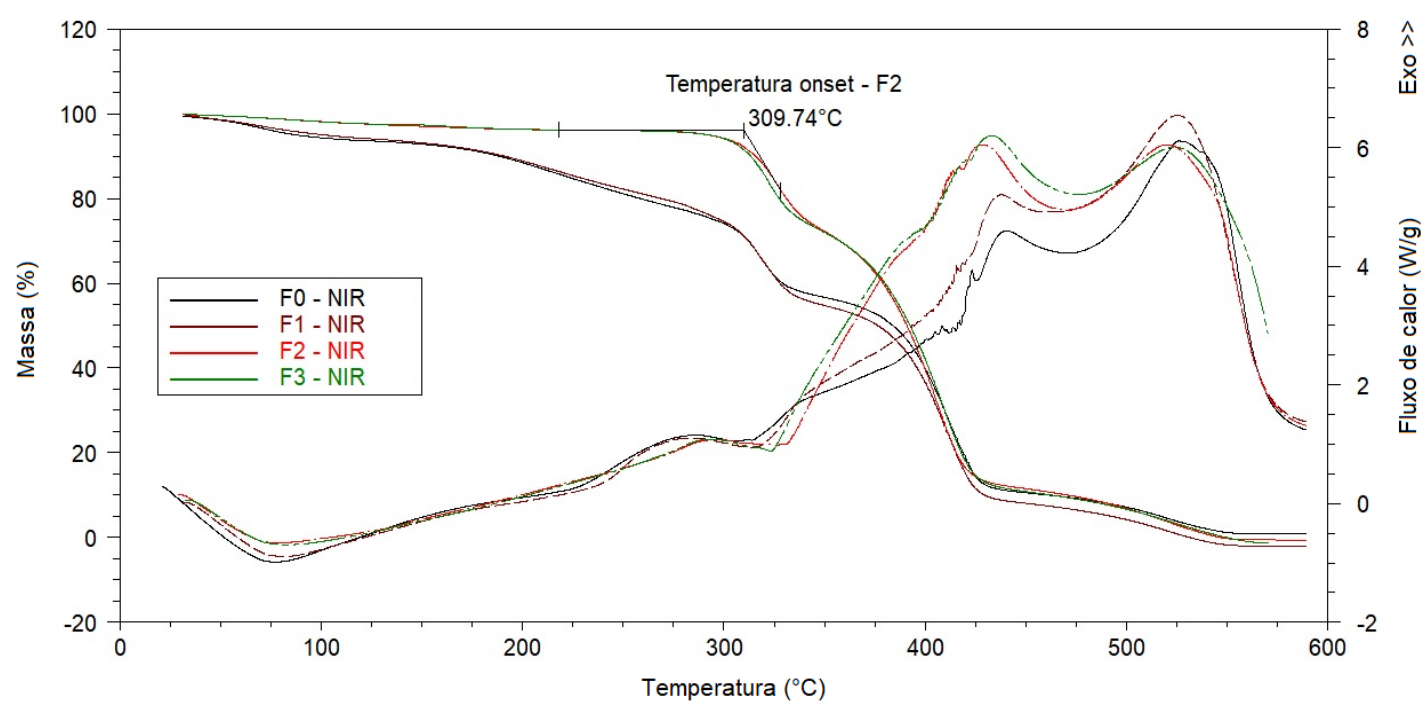

Fonte: autor da dissertação.

Figura 39 - Curvas de TGA/DSC das blendas irradiadas a 25 kGy

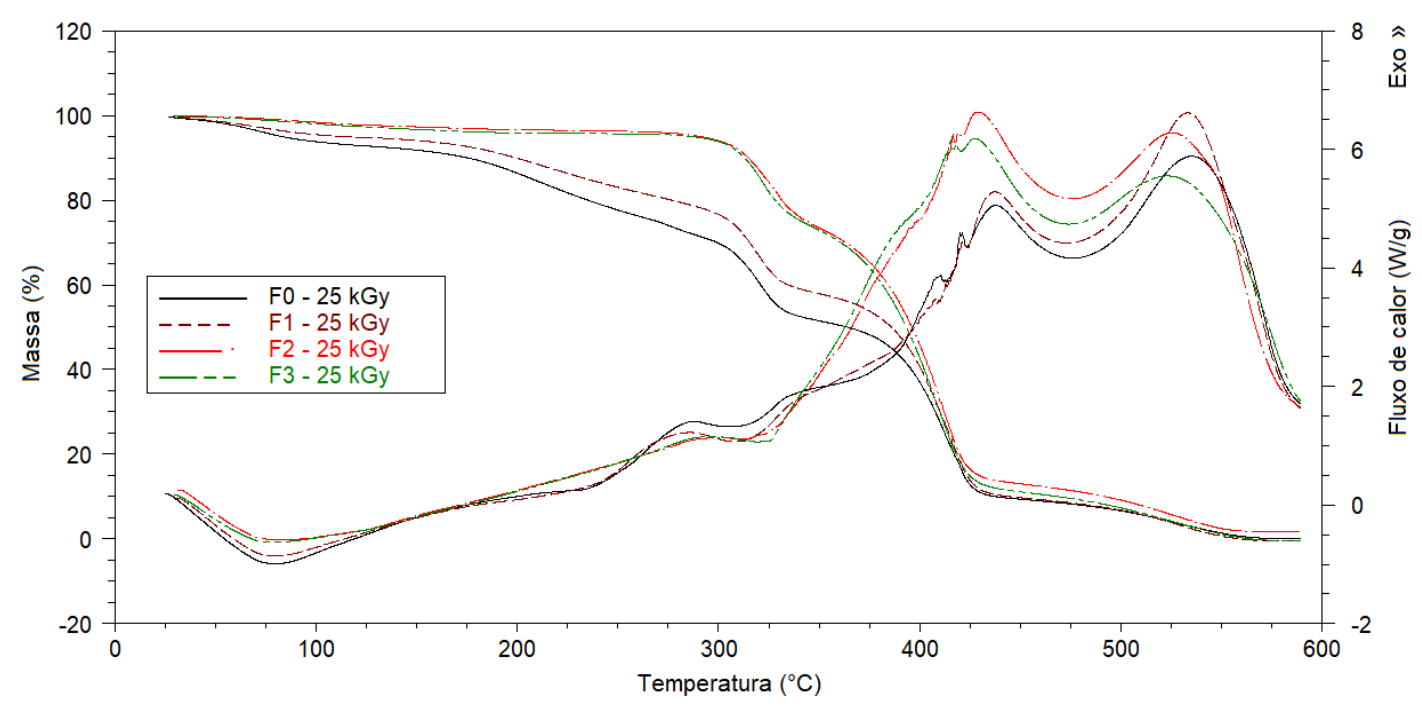

Fonte: autor da dissertação.

Observou-se também a partir das Figuras 38 e 39, que a dose de radiação gama não alterou significativamente as curvas de fluxo de calor entre as amostras F0 (glicerol) e F1 (glicerol e TWEEN ${ }^{\circledR} 80$ ); e F2 (óleo de mamona) e F3 (óleo de mamona e TWEEN ${ }^{\circledR} 80$ ) até $350^{\circ} \mathrm{C}$, bem como os eventos degradativos das amostras, e do amido, observado por uma transição endotérmica nas amostras entre $20^{\circ} \mathrm{C}$ e $100^{\circ} \mathrm{C}$ (ATROUS et al., 2015), seguida de leve transição endotérmica na faixa de temperatura entre $200^{\circ} \mathrm{C}$ e $300^{\circ} \mathrm{C}$ para as amostras irradiadas F0 e F1 em virtude da interação, migração e degradação do glicerol utilizado como 
plastificante, por ter a menor temperatura de degradação dentre os reagentes e também da quantidade utilizada no processo de plastificação do amido (OLIVEIRA, 2015).

Observou-se também nas Figuras 38 e 39, os picos exotérmicos e assimétricos primários das amostras NIR e irradiadas na faixa de $350^{\circ} \mathrm{C}$ a $450^{\circ} \mathrm{C}$ e $500^{\circ} \mathrm{C}$ a $560^{\circ} \mathrm{C}$, ocasionados pelas diferentes degradações das amostras (WELLEN et al., 2013). Na faixa de $350^{\circ} \mathrm{C}$ a $450^{\circ} \mathrm{C}$, ocorreram picos de degradação secundários em todas as amostras; sendo que o pico primário de degradação na faixa de $500^{\circ} \mathrm{C}$ a $560^{\circ} \mathrm{C}$, teve amplitude maior de degradação para as amostras $\mathrm{FO}$ e F1 não irradiadas (NIR), onde as amostras NIR e irradiadas compostas por glicerol e TWEEN ${ }^{\circledR} 80(F 1)$, tiveram o maior fluxo de calor no estágio final de degradação.

Assim a adição dos plastificantes e surfactante, não contribuiu para a variação de entalpia entre as formulações F0-F1 e F2-F3, porém ficou evidenciado as diferenças químicas e de resistência à temperatura entre as formulações que contém respectivamente glicerol (F0) e glicerol com TWEEN ${ }^{\circledR} 80$ (F1); OM (F2) e OM com TWEEN ${ }^{\circledR} 80(\mathrm{~F} 3)$, tanto nas amostras NIR, quanto nas irradiadas a $25 \mathrm{kGy}$, que de acordo com NUNES, MARTINELLI e PEDROSO (2008), é justificado pelo fato de o OM e consequentemente o TWEEN ${ }^{\circledR} 80$, suportarem variações bruscas de temperatura e pressão.

\subsection{Espectroscopia vibracional de absorção no infravermelho por transformada de Fourier (FTIR)}

As análises de FTIR foram realizadas com a finalidade de se ter um comparativo entre as amostras compostas por glicerol (F0) e glicerol com TWEEN $^{\circledR} 80$ (F1) e OM (F2) e OM com TWEEN ${ }^{\circledR} 80$ (F3), tanto para as não irradiadas (NIR), quanto para as irradiadas (25 kGy), observando-se a interação da radiação na estrutura química dos compostos da blenda e suas modificações. Os espectros de ATR-FTIR obtidos são mostrados nas Figuras 40 a 43.

$\mathrm{Na}$ Tabela 9 são apresentadas as bandas de absorção vibracional dos espectros FTIR características das blendas F0 e F1. 
Tabela 9 - Bandas de absorção FTIR características das blendas F0-F1

\begin{tabular}{|l|l|}
\hline \multirow{4}{*}{ F0 - F1 } & 600 e $800 \mathrm{~cm}^{-1}$ deformações $\mathrm{CH}_{2}$ \\
\cline { 2 - 2 } & 600 e $900 \mathrm{~cm}^{-1}$ ligações glicosídicas \\
\cline { 2 - 2 } & 915 e $1000 \mathrm{~cm}^{-1}$ ligações C-OH; vibrações C-O-H \\
\cline { 2 - 2 } & $1500 \mathrm{~cm}^{-1}$ absorção de agua residual do amido \\
\cline { 2 - 2 } & 3300 e $3500 \mathrm{~cm}^{-1}$ ligações $-\mathrm{OH}$ (hidroxilas) \\
\hline
\end{tabular}

Fonte: autor da dissertação.

Figura 40 - Espectros de ATR-FTIR das blendas F0 (NIR/25 kGy)
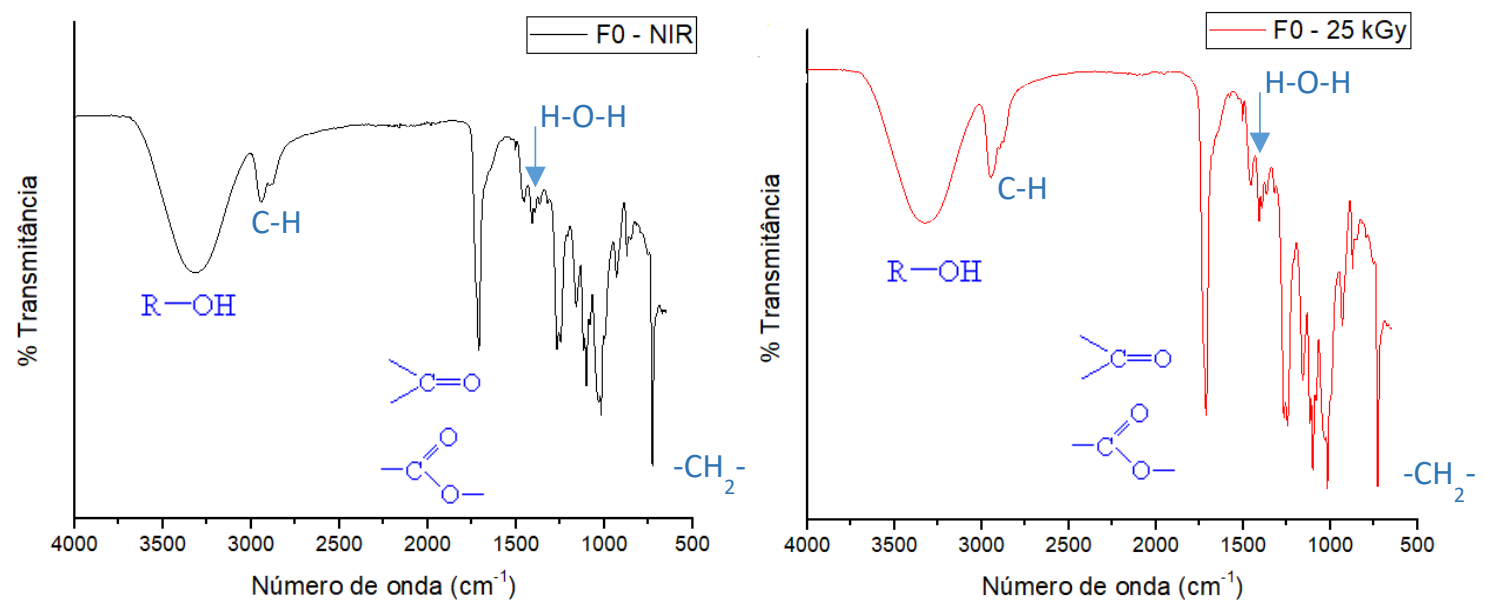

Fonte: autor da dissertação.

Figura 41 - Espectros de ATR-FTIR das blendas F1 (NIR/25 kGy)
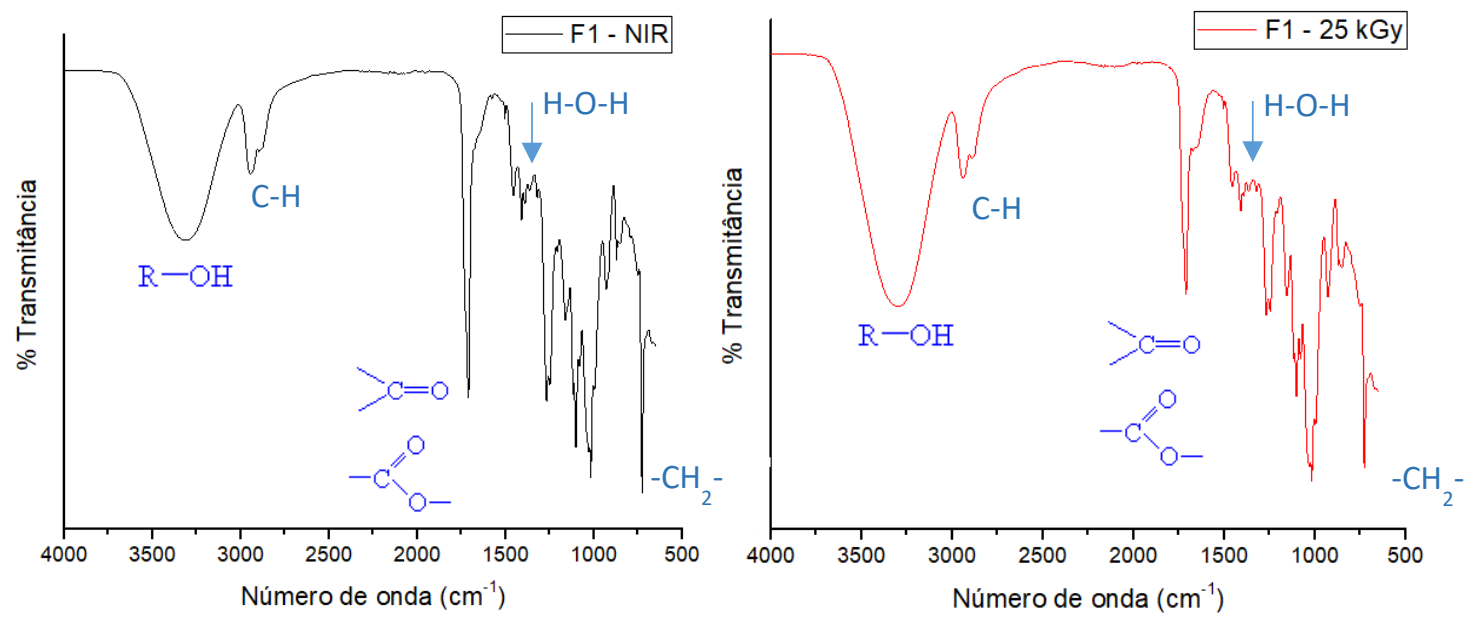

Fonte: autor da dissertação. 
$\mathrm{Na}$ Tabela 10 são apresentadas as bandas de absorção vibracional dos espectros FTIR características das blendas F2 e F3.

Tabela 10 - Bandas de absorção FTIR características das blendas F2-F3

\begin{tabular}{|l|l|}
\hline \multirow{4}{*}{ F2 - F3 } & 1000 e $1200 \mathrm{~cm}^{-1}$ ligações ésteres C-O-C \\
\cline { 2 - 3 } & $1750 \mathrm{~cm}^{-1}$ ligações ésteres C=O do OM/PBAT \\
\cline { 2 - 2 } & 1400 e $1550 \mathrm{~cm}^{-1}$ ligações de carbonos aromáticos \\
\cline { 2 - 2 } & 2800 e $2900 \mathrm{~cm}^{-1}$ ligações C-H metil \\
\cline { 2 - 2 } & 3500 e $3700 \mathrm{~cm}^{-1}$ ligações $-\mathrm{OH}$ (hidroxilas) \\
\hline
\end{tabular}

Fonte: autor da dissertação.

Figura 42 - Espectros de ATR-FTIR das blendas F2 (NIR/25 kGy)

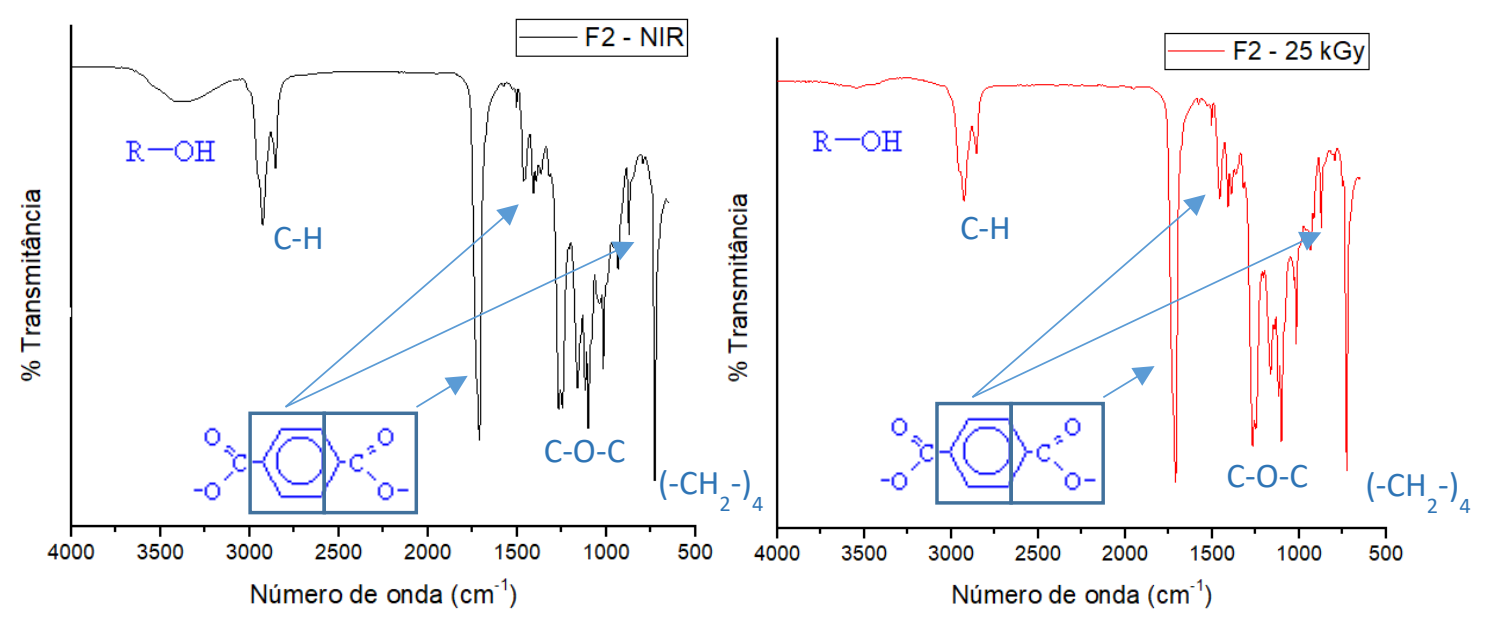

Fonte: autor da dissertação.

Figura 43 - Espectros de ATR-FTIR das blendas F3 (NIR/25 kGy)

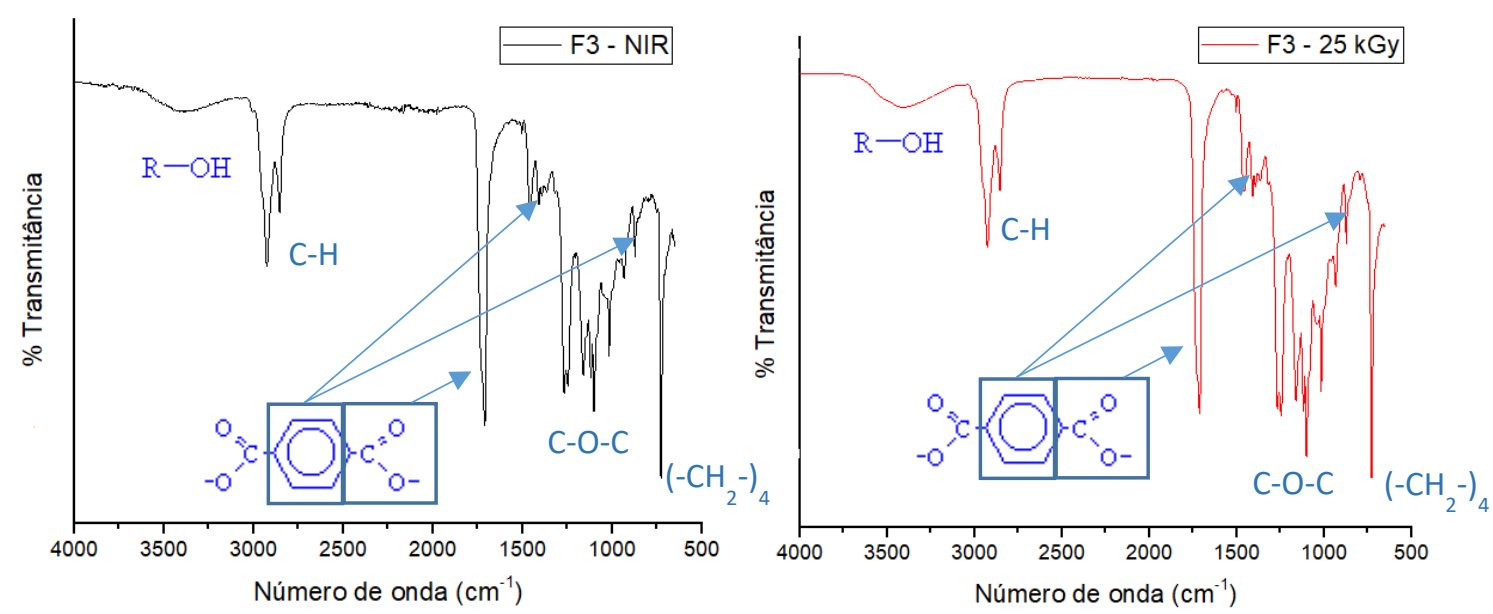

Fonte: autor da dissertação. 
Em estudos realizados por KUMAR e colaboradores (2017) o amido não irradiado (NIR) apresentou bandas características de suas ligações, entre $900 \mathrm{~cm}^{-1}$ e $600 \mathrm{~cm}^{-1}$, as quais foram atribuídas às ligações glicosídicas que unem as moléculas de amido; os picos na faixa entre $1000 \mathrm{~cm}^{-1}$ e $915 \mathrm{~cm}^{-1}$ foram responsáveis pelas ligações $\mathrm{C}-\mathrm{OH}$, vibrações moleculares $\mathrm{C}-\mathrm{O}-\mathrm{H}$ e deformações $\mathrm{CH}_{2}$ - Em estudos com amido realizados por ATROUS e colaboradores (2015) e NEMTANU e BRASOVEANU (2017), houve uma diminuição das bandas dos espectros na faixa de $1050 \mathrm{~cm}^{-1}(\mathrm{O}-\mathrm{H})$ e $1600 \mathrm{~cm}^{-1}$ (C-O; C-O-H) das amostras irradiadas comparadas com as não irradiadas (NIR), indicando uma quebra das estruturas químicas e despolimerização do amido, respectivamente, por ligações glicosídicas e por meio da radiólise da água devido a dose de radiação aplicada. Esse evento foi também observado por outros autores. A banda de absorção $\mathrm{H}-\mathrm{O}-\mathrm{H}$ na faixa de $1500 \mathrm{~cm}^{-1}$, foi atribuída a água presente no amido (BRANDELERO et al., 2011; KUMAR et al., 2017). Os picos vibracionais na faixa de 3300 a 3500 cm$^{-1}$, são representados pelas ligações $-\mathrm{OH}$, originárias da interação das hidroxilas presentes no amido/glicerol constituintes das blendas F0 e F1 (BRANDELERO et al., 2011). Os espectros FTIR de amido irradiado e NIR e seus picos de absorção, obtidos em estudos realizados por KUMAR e colaboradores (2017), são mostrados na Figura 44 para melhor compreensão dos resultados obtidos neste trabalho. Entretanto, a banda de absorção na faixa de $2350 \mathrm{~cm}^{-1}$ é atribuída e característica das ligações $\mathrm{C}-\mathrm{H}$ de metanos presentes no amido de arroz, estudado por KUMAR e colaboradores (2017).

Figura 44 - Espectros de FTIR (transmitância) do amido puro irradiado de 0 a 20 kGy

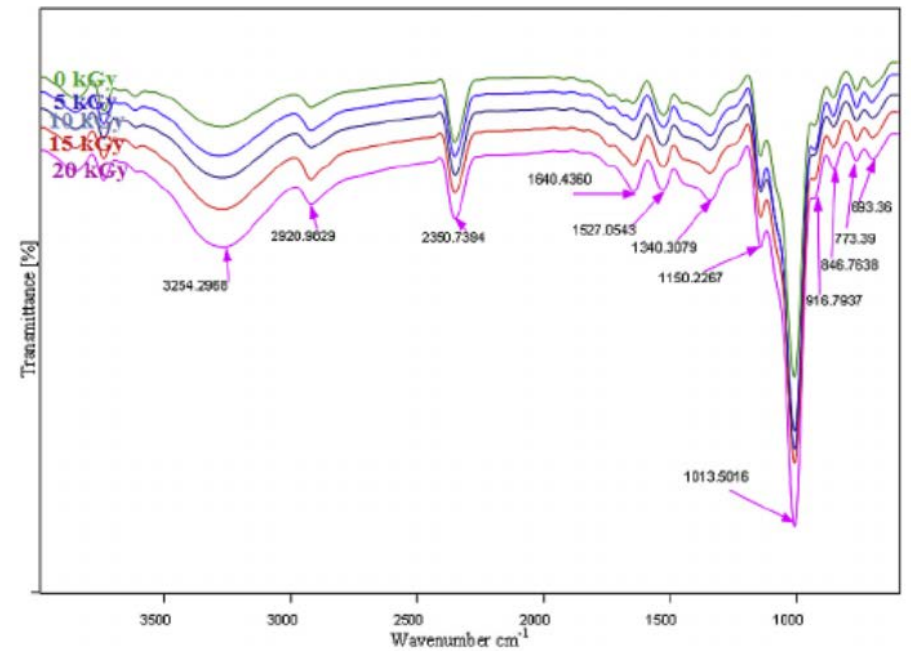

Fonte: KUMAR et al., 2017. 
Nas blendas F2 e F3, o pico de absorção da banda de $1750 \mathrm{~cm}^{-1}$ corresponde às ligações ésteres $\mathrm{C}=\mathrm{O}$ características do $\mathrm{OM}$ e do PBAT, estando de acordo com os estudos realizados por SCHIMITBERGER, (2015) e BRANDELERO e colaboradores (2011). As bandas de absorção no espectro FTIR entre $1400 \mathrm{~cm}^{-1}$ e $1550 \mathrm{~cm}^{-1}$, representam respectivamente os estiramentos das ligações duplas $\mathrm{C}=\mathrm{C}$ do carbono presentes no anel aromático do PBAT. A banda de estiramento representada pelos picos entre $2800 \mathrm{~cm}^{-1}$ e $2900 \mathrm{~cm}^{-1}$ são da ligação C-H do grupo metil do OM e do PBAT (SATHISKUMAR; MADRAS, 2011; SCHIMITBERGER, 2015). A banda representada pelos picos entre $1000 \mathrm{~cm}^{-1} \mathrm{e}$ $1200 \mathrm{~cm}^{-1}$, caracteriza as ligações ésteres C-O-C do OM (SATHISKUMAR; MADRAS, 2011; SCHIMITBERGER, 2015). O espectro FTIR da resina de PBAT utilizada nos estudos realizados por SCHIMITBERGER, (2015) é mostrado na Figura 45 para melhor compreensão dos resultados obtidos neste trabalho.

Figura 45 - Espectro de FTIR (absorbância) do PBAT

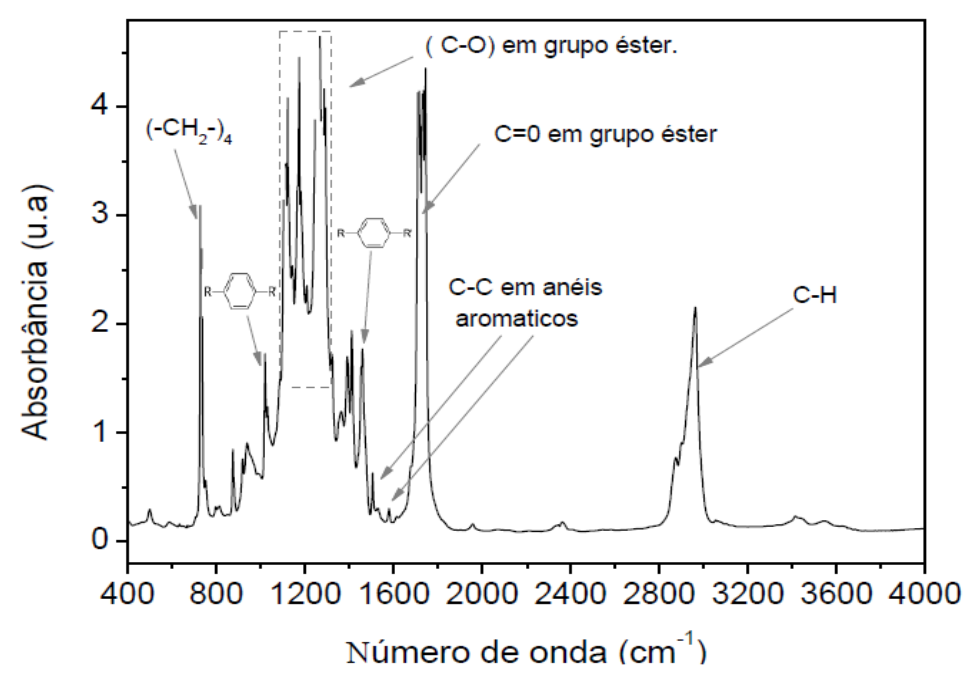

Fonte: SCHIMITBERGER, 2015.

Os picos entre $3700 \mathrm{~cm}^{-1}$ e $3500 \mathrm{~cm}^{-1}$, são responsáveis pelas ligações $\mathrm{O}-\mathrm{H}$, devido às hidroxilas presentes na estrutura do amido, glicerol e $\mathrm{OM}$ (SILVERSTEIN; WEBSTER; KIEMLE, 2005; ATROUS et al., 2015; NEMTANU; BRASOVEANU, 2017).

Assim de acordo com os estudos realizados por ATROUS e colaboradores, (2015); KUMAR e colaboradores (2017); NEMTANU e BRASOVEANU (2017), e comparando-se os espectros obtidos neste trabalho, pôde-se dizer que a radiação 
gama com dose de $25 \mathrm{kGy}$, não afetou as propriedades e a estrutura química cristalina do amido (amilose). Devido à diminuição das bandas na faixa de $1050 \mathrm{~cm}^{-1}$ das amostras comparadas pela análise dos espectros de FTIR, não se pode afirmar que a dose de $25 \mathrm{kGy}$, provocou a quebra das ligações glicosídicas representadas pela amilose nas blendas e sua interação com os demais componentes, tanto pelo processo de irradiação quanto pelo processo de extrusão reativa. 


\subsection{Microscopia eletrônica de varredura (MEV)}

Nas Figuras 46 a 49 são mostradas as micrografias em diferentes magnificações das blendas não irradiadas (NIR) e irradiadas a 25 kGy, possibilitando realizar a comparação e análise entre elas.

As demais micrografias e magnificações (25x, 27x, 30x, 200x e 500x) são mostradas no APÊNDICE A.

Figura 46 - Micrografias das blendas F0 (NIR/25 kGy) com magnificação de 200x
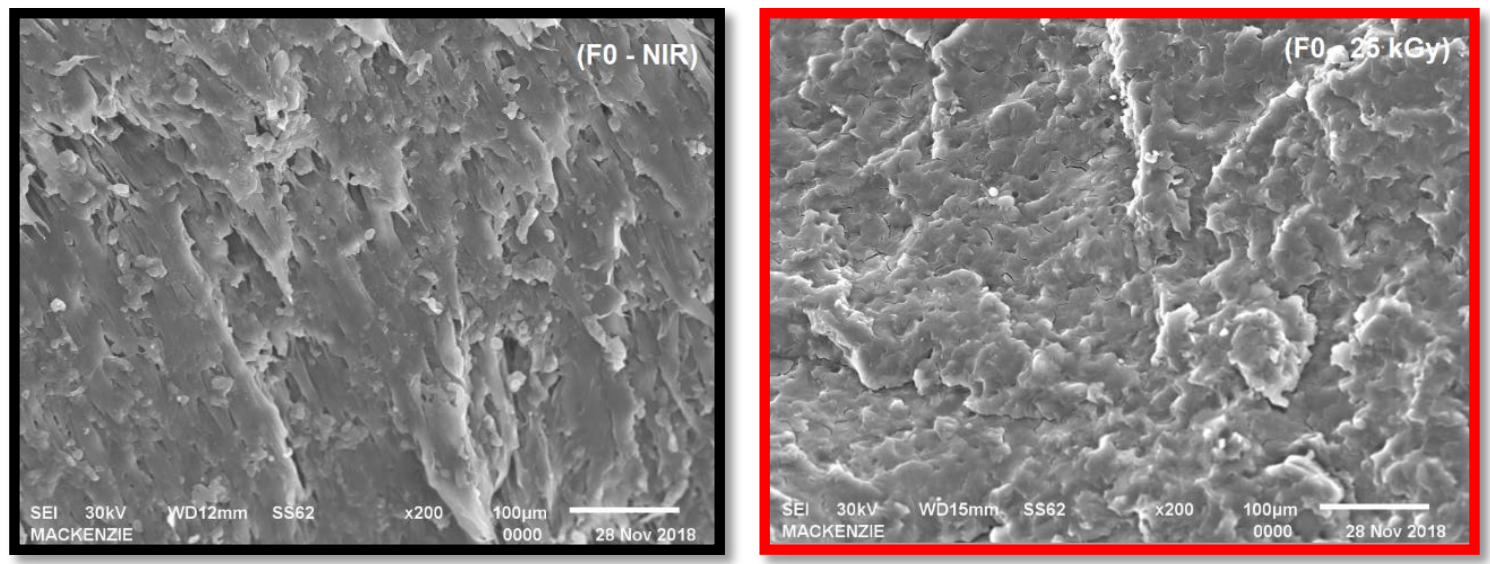

Fonte: autor da dissertação.

Figura 47 - Micrografias das blendas F1 (NIR/25 kGy) com magnificação de 200x
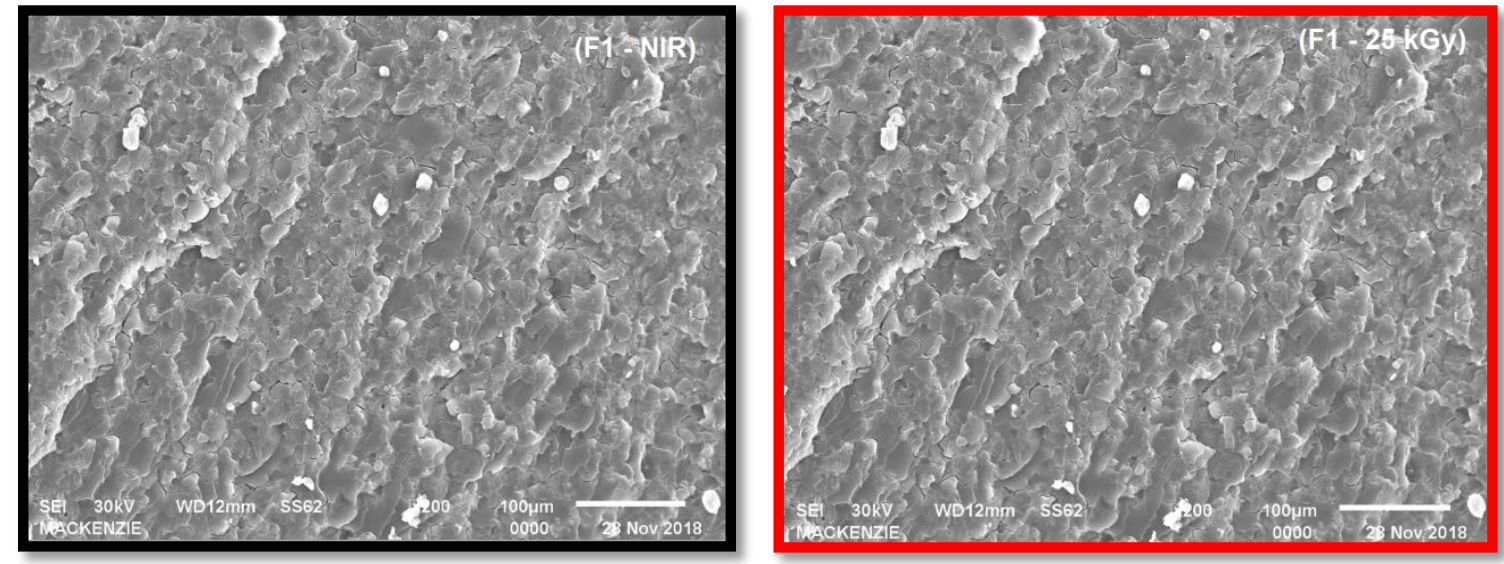

Fonte: autor da dissertação.

As micrografias obtidas das blendas mostradas nas Figuras 46 e 47, fraturadas por mecanismo frágil, apresentaram uma superfície e estrutura parcialmente homogênea onde se destaca a matriz de PBAT plastificada parcialmente com amido e glicerol, mostrando grânulos de amido remanescentes não totalmente plastificados. As blendas também apresentaram microcavidades 
durante o processo de fratura criogênica (dimples), devido ao TPS possuir duas fases distintas: a do amido in natura (não plastificado) e a fase plastificada (OLIVEIRA, 2015). Os eventos de dimples e as interações químicas entre componentes de blendas e o PBAT, também foram observadas e estudadas por MOUSTAFA, GUIZANI e DUFRESNE (2017). Entretanto, observou-se que a amostra com TWEEN ${ }^{\circledR} 80(\mathrm{~F} 1)$, teve comportamento mais homogêneo e aspecto liso em relação a amostra plastificada somente com glicerol (F0).

Assim, é possível assegurar que as blendas F0 e F1 apresentaram uma homogeneização e miscibilidade parcial e a dose de radiação de 25 kGy não interferiu visualmente nas propriedades morfológicas das blendas analisadas.

Figura 48 - Micrografias das blendas F2 (NIR/25 kGy) com magnificação de 200x
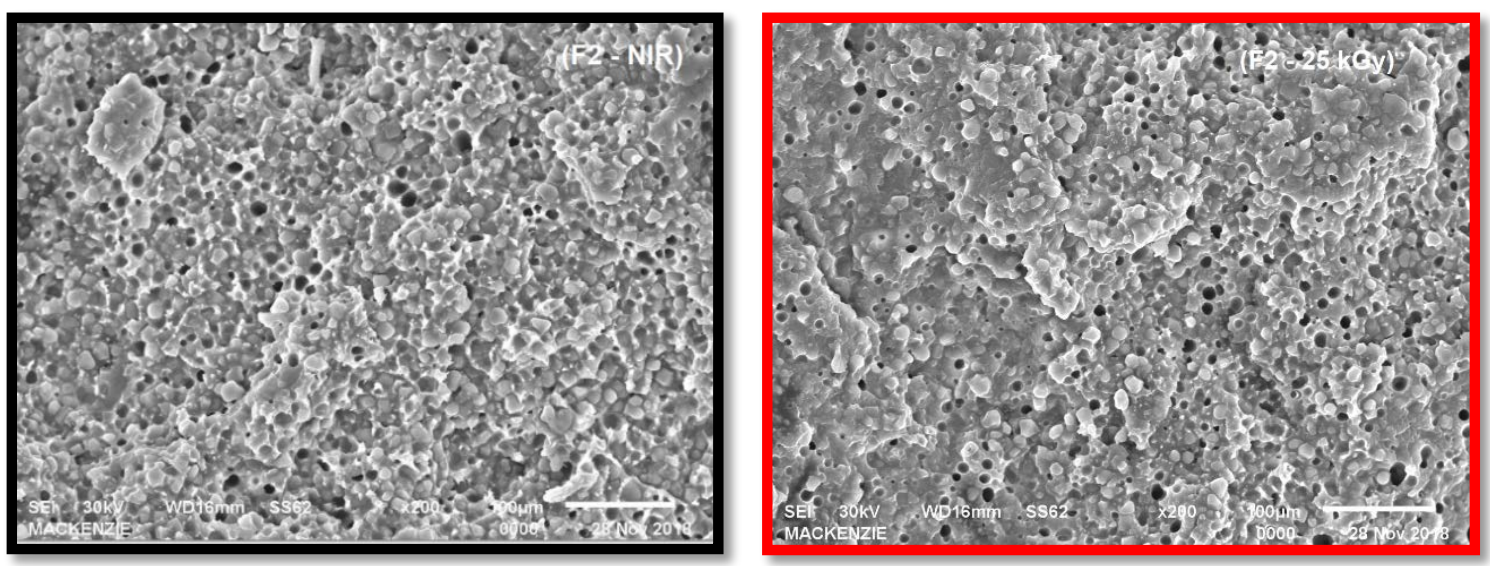

Fonte: autor da dissertação.

Figura 49 - Micrografias das blendas F3 (NIR/25 kGy) com magnificação de 200x
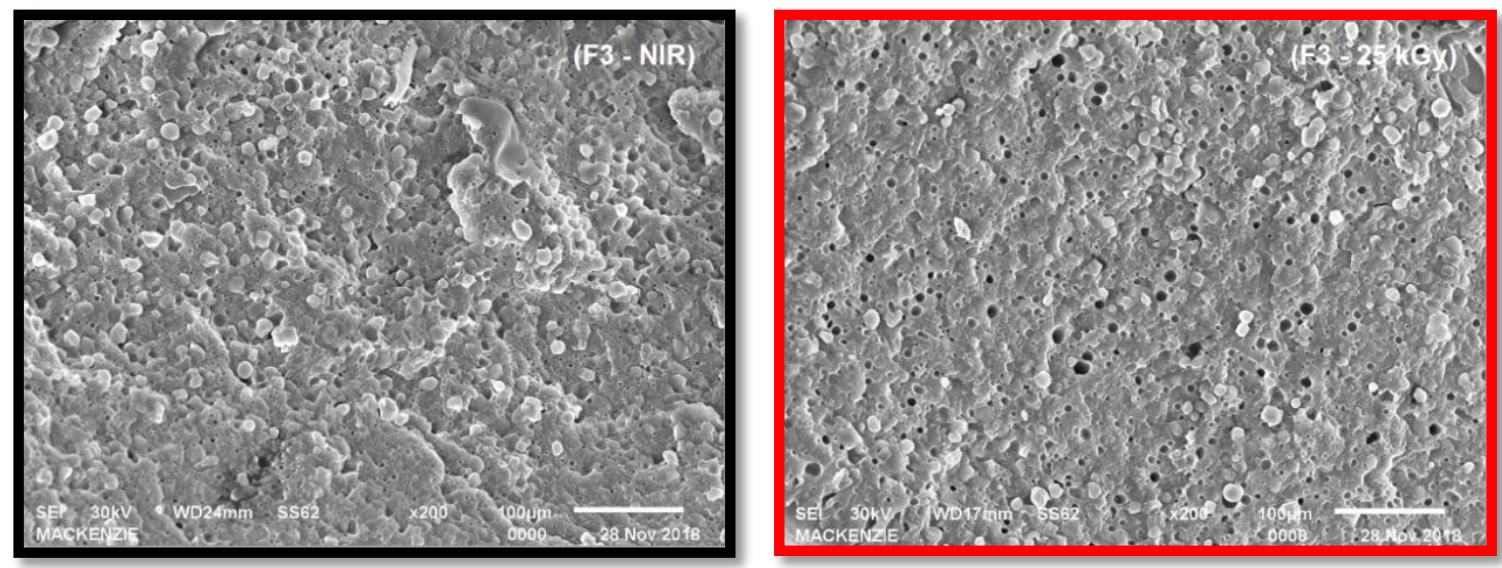

Fonte: autor da dissertação. 
Já as micrografias mostradas nas Figuras 48 e 49, plastificadas com OM e TWEEN ${ }^{\circledR}$ 80, apresentaram as mesmas singularidades das blendas F0 e F1, com presença de dimples mais acentuados e imiscibilidade do TPS com o PBAT na blenda F2 composta por OM e miscibilidade parcial pela presença de OM e TWEEN $^{\circledR} 80$ na blenda F3, com diminuição relativa dos dimples. Devido a não plastificação dos grânulos de amido presentes no TPS com o PBAT, as amostras apresentaram morfologia com fases dispersas, aspecto mais poroso $\mathrm{e}$ heterogêneo. Observou-se também que as amostras não apresentaram mudanças e alterações morfológicas visíveis com a dose de radiação de 25 kGy.

Assim as blendas F0 e F1 de TPS plastificadas com glicerol, apresentaram melhores resultados com o PBAT em relação as blendas F2 e F3, e o amido presente no TPS não sofreu alterações químicas significativas por meio da dose de radiação utilizada para modificação e estudo morfológico, conforme mostrado em estudos realizados em amido por ATROUS e colaboradores (2015); KUMAR e colaboradores (2017) e demais pesquisadores em seus estudos com blendas poliméricas e outras técnicas realizadas nesta dissertação.

\subsection{Difração de raios X (DRX)}

Nas Figuras 50 a 53, são mostradas as curvas de difração de raios $X$, das blendas não irradiadas (NIR) e irradiadas a 25 kGy, possibilitando realizar a comparação entre elas.

Na Tabela 11 são apresentados os ângulos de difração correspondentes a parte cristalina do amido utilizado neste estudo (OLIVEIRA, 2015) e do PBAT (PAN et al., 2016), com a finalidade de se ter um comparativo entre os valores $2 \theta\left(^{\circ}\right)$ encontrados na literatura, e os obtidos neste trabalho nas blendas analisadas e mostradas nas curvas das Figuras 50 a 53.

Tabela 11 - Valores de $2 \theta$ do amido tipo A e do PBAT (Ecoflex ${ }^{\circledR}$ )

\begin{tabular}{c|c|c|c|c|c|c|c|c}
\cline { 2 - 8 } & \multicolumn{7}{c}{$\mathbf{2 \theta}\left({ }^{\circ}\right)$} \\
\hline Amido - Tipo A & 11,50 & 15,10 & 17,10 & 18,09 & 20,05 & 23,05 & ----- & ----- \\
\hline PBAT & 16,00 & 17,22 & 20,12 & 23,00 & 24,72 & 28,52 & 30,95 & $\mathbf{2 0 , 5 3 *}$ \\
\hline
\end{tabular}

Fonte: adaptado de OLIVEIRA (2015) e PAN (2016). 
PAN e colaboradores (2016) ao estudar o PBAT pela técnica de DRX, observou que os ângulos de difração $2 \theta\left(^{\circ}\right)$ encontrados apresentam os seguintes planos de difração $\left(\mathrm{d}_{\mathrm{hkl}}\right): 2 \theta(0 \overline{1} 1)=16,00^{\circ} ; 2 \theta(010)=17,22^{\circ} ; 2 \theta(\overline{1} 02)=20,12^{\circ}$; $2 \theta(100)=23,00^{\circ} ; \quad 2 \theta(\overline{1} 11)=24,72^{\circ} ; \quad 2 \theta(\overline{1} \overline{1} 2,012,101)=28,52^{\circ}$; $2 \theta(1 \overline{2} 1,1 \overline{2} 0,120)=30,95^{\circ}$. Assim, foi possível correlacionar a partir das curvas de difração, os planos cristalinos das blendas analisadas com o ângulo de difração obtido na literatura.

Figura 50 - Curvas de DRX das blendas F0 (NIR/25 kGy)
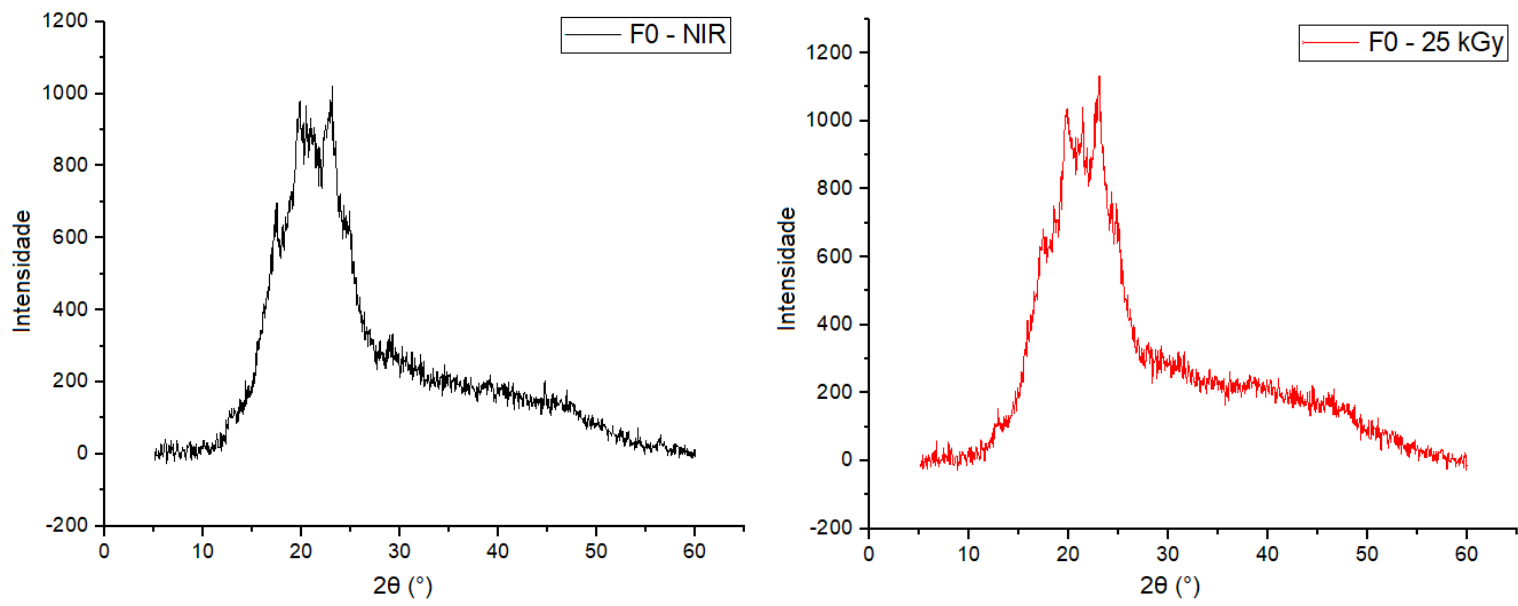

Fonte: autor da dissertação.

Figura 51 - Curvas de DRX das blendas F1 (NIR/25 kGy)
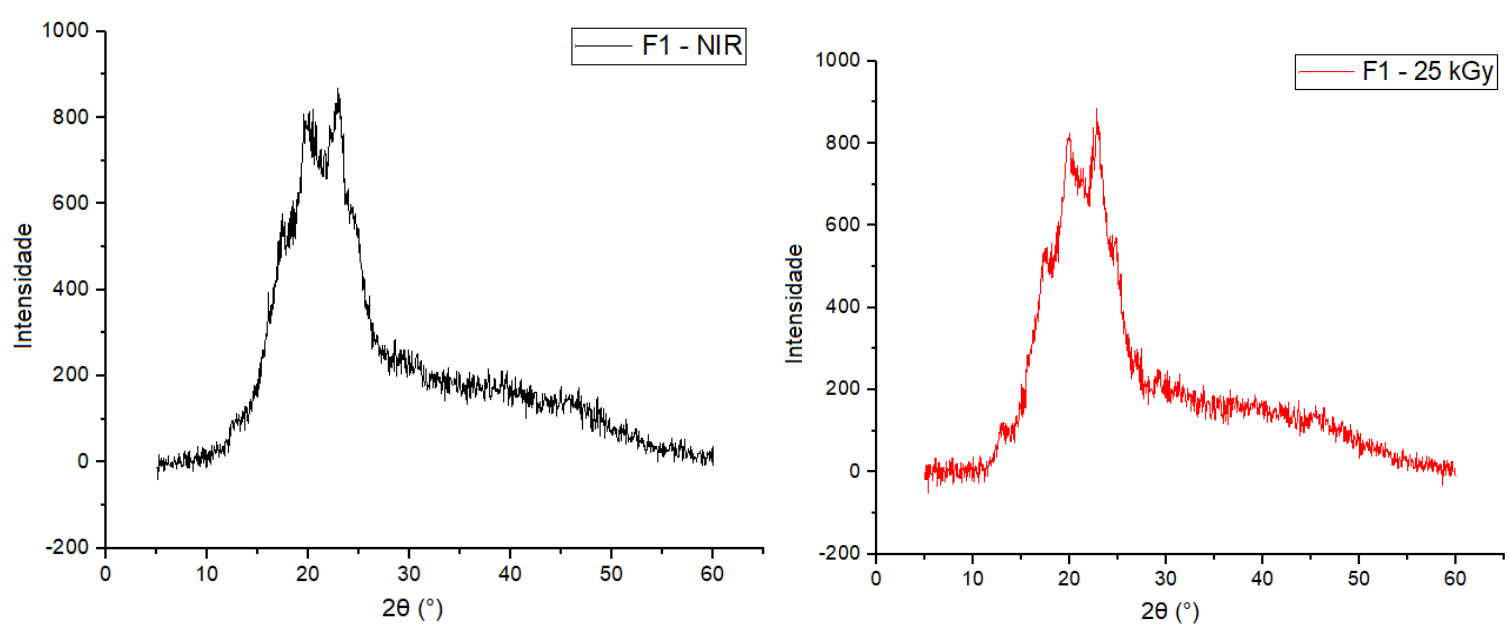

Fonte: autor da dissertação.

As curvas de difração de raios X das blendas F0 (NIR - 25 kGy) compostas por glicerol em sua composição (Figura 50), apresentaram similaridades nos picos de difração nos quais, não se observou a interação da radiação $(\gamma)$ nos componentes da blenda, bem como a interação do PBAT e amido como 
constituinte. Os picos de difração coincidiram com os do PBAT puro e do amido irradiado, e estão de acordo com os resultados obtidos por vários pesquisadores na literatura (GANI et al., 2012; ATROUS et al., 2015; PAN et al., 2016; KUMAR et al., 2017; MOUSTAFA, GUIZANI; DUFRESNE, 2017), os quais observaram 5 picos cristalinos e suas transições.

$\mathrm{Na}$ Figura 51 são mostradas as curvas de DRX das blendas F1 (NIR - 25 kGy), compostas por glicerol e TWEEN ${ }^{\circledR}$ 80, onde observou-se que não houve diferenças entre os espectros, sendo que o pico cristalino $2 \theta\left(^{\circ}\right)$ localizado a $25^{\circ}$ da blenda com TWEEN ${ }^{\circledR} 80$, teve uma leve alteração em relação a blenda NIR e o comportamento dos picos $2 \theta\left(^{\circ}\right)$ de ambas as blendas localizados entre os graus $20^{\circ}$ e $23^{\circ}$ os quais coincidiram com os resultados obtidos do PBAT e amido irradiado a 20 kGy mostrados nos estudos realizados por ATROUS e colaboradores (2015); PAN e colaboradores (2016); KUMAR e colaboradores (2017) e MOUSTAFA, GUIZANI e DUFRESNE (2017).

Assim pôde-se concluir, que as blendas semicristalinas F0 e F1, compostas por glicerol no ensaio de DRX, não apresentaram mudanças significativas de cristalinidade em sua estrutura, com ou sem a adição de TWEEN ${ }^{\circledR} 80$, tanto nas irradiadas quanto nas não irradiadas (NIR).

Figura 52 - Curvas de DRX das blendas F2 (NIR/25 kGy)
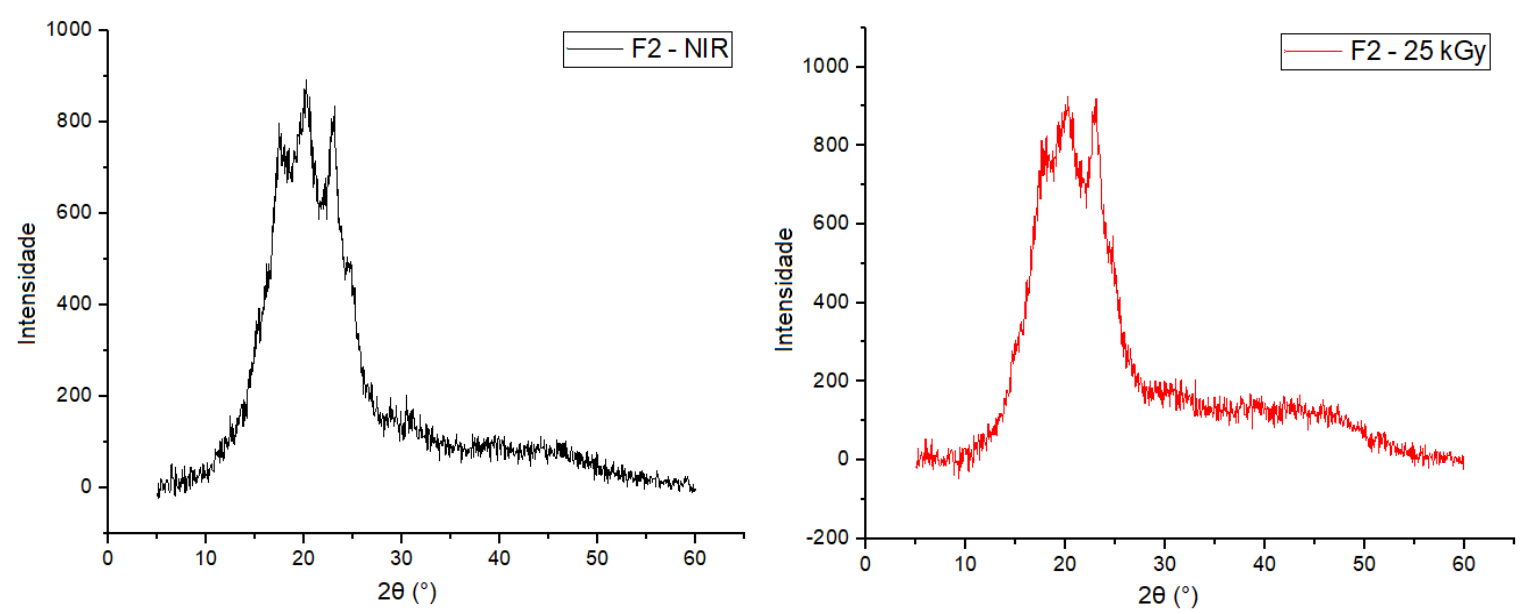

Fonte: autor da dissertação. 
Figura 53 - Curvas de DRX das blendas F3 (NIR/25 kGy)
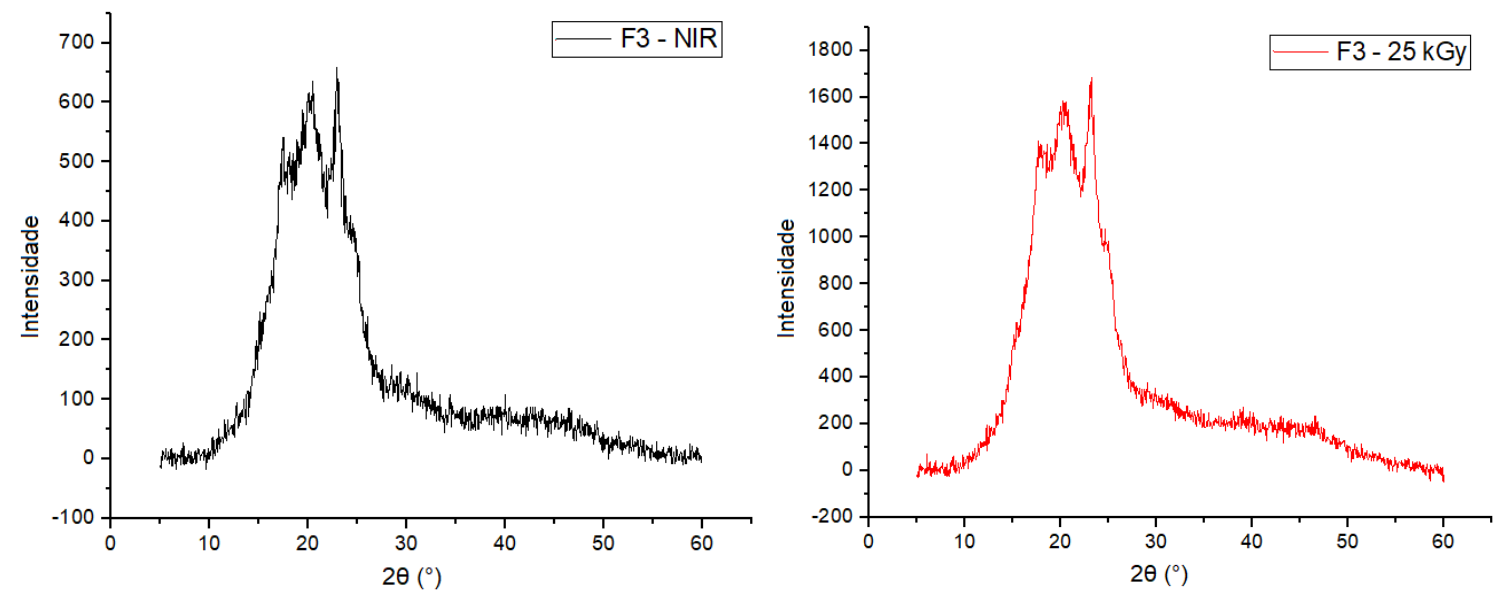

Fonte: autor da dissertação.

As curvas de difração de raios $X$ das blendas $F 2$ e F3 mostradas nas Figuras 52 e 53 , compostas por OM/TWEEN ${ }^{\circledR} 80$, apresentaram similaridades nos picos $2 \theta\left(^{\circ}\right)$ observando-se 3 picos definidos em $17^{\circ}, 20^{\circ}$ e $23^{\circ}$, que estão de acordo com os estudos realizados por GANI e colaboradores (2012); ATROUS e colaboradores (2015); PAN e colaboradores (2016); KUMAR e colaboradores (2017) e MOUSTAFA, GUIZANI e DUFRESNE (2017), sendo que na blenda F3 irradiada, os picos cristalinos apresentaram uma amplitude maior do que na blenda F3 não irradiada (NIR) composta por OM e TWEEN ${ }^{\circledR} 80$.

Assim pode-se concluir, que as blendas semicristalinas F2 e F3, compostas por OM no ensaio de DRX, não apresentaram mudanças significativas de cristalinidade em sua estrutura, com ou sem a adição de TWEEN ${ }^{\circledR} 80$, tanto nas blendas irradiadas quanto nas não irradiadas (NIR).

5.5.1 Îndice de cristalinidade (IC)

Na Tabela 12, são apresentados os índices de cristalinidade aproximados calculados por meio das curvas de DRX e da Equação 10. Os dados utilizados para o cálculo estão descritos no APÊNDICE B. 
Tabela 12 - Índices de cristalinidade (IC) das blendas, calculados por meio das curvas de DRX e da Equação 10

\begin{tabular}{|c|c|c|c|c|}
\hline Blendas & $\begin{array}{c}\text { Curva de DRX } \\
\text { (Área total) }\end{array}$ & $\begin{array}{l}\text { Área da região } \\
\text { cristalina }\end{array}$ & $\begin{array}{c}\text { Índice de } \\
\text { cristalinidade }\left(I_{c}\right) \%\end{array}$ & $\begin{array}{c}\text { Diferença de } \\
\text { cristalinidade } \\
\text { (NIR/25 kGy) \% }\end{array}$ \\
\hline FO - NIR & 11.847 & 4.262 & 36,0 & \multirow{2}{*}{0,1} \\
\hline FO - 25 kGy & 13.007 & 4.668 & 35,9 & \\
\hline F1 - NIR & 10.430 & 3.546 & 34,0 & \multirow{2}{*}{3,5} \\
\hline F1 - 25 kGy & 9.825 & 3.687 & 37,5 & \\
\hline F2 - NIR & 9.156 & 4.016 & 43,9 & \multirow{2}{*}{1,5} \\
\hline F2 - 25 kGy & 10.265 & 4.657 & 45,4 & \\
\hline F3 - NIR & 6.762 & 2.844 & 42,1 & \multirow{2}{*}{3,7} \\
\hline F3 - 25 kGy & 18.316 & 8.394 & 45,8 & \\
\hline
\end{tabular}

Fonte: autor da dissertação.

De acordo com os dados apresentados na Tabela 9, as blendas F0 não tiveram alterações no percentual de cristalinidade e entre si $(0,1 \%)$ após a irradiação; as blendas F1, tiveram alteração de cristalinidade; na amostra não irradiada e irradiada (3,5\%), e com o TWEEN ${ }^{\circledR} 80$ em relação a amostra F0 sem o surfactante obtendo a diferença de 3,4\% (36,0\% - 34,0\%) a maior entre as amostras NIR mostrando a interação química do TWEEN ${ }^{\circledR} 80$ na blenda analisada.

Entretanto, na blenda F1 irradiada obteve-se o maior percentual de cristalinidade dentre as plastificadas com glicerol com 37,5\%, mostrando a interação do TWEEN ${ }^{\circledR} 80$ na blenda analisada.

O IC das blendas pode aumentar por meio dos efeitos da radiação, pois ela degradou preferencialmente as regiões amorfas do amido constituídas pela amilopectina de acordo com estudos realizados por ATROUS e colaboradores (2015) e KUMAR e colaboradores (2017).

As intensidades das curvas de difração das blendas obtidas, são proporcionais a sua cristalinidade. Portanto, uma maior intensidade de difração resultará em um maior índice de cristalinidade.

A interação química do ácido oleico que também está presente na composição do TWEEN ${ }^{\circledR} 80$ como plastificante foi estudada por SCHLEMMER e colaboradores (2010), em que a quantidade de ácido oleico presente no óleo de buriti utilizado como plastificante, favoreceu uma melhor resistência térmica e 
estabilidade para o amido em relação ao glicerol, além de o processo de plastificação ter ocorrido mais eficientemente.

As blendas F2, por terem óleo de mamona em sua composição tiveram alterações e maiores valores médios de cristalinidade em relação as amostras F0 e F1 e entre suas respectivas composições (1,5\%); tanto as irradiadas e não irradiadas, obtendo o maior valor individual de cristalinidade calculada dentre todas as formulações. A interação química entre os componentes da blenda e o OM por esterificação, foi observada e estudada por SATHISKUMAR e MADRAS (2011); MOUSTAFA; GUIZANI e DUFRESNE (2017), e outros pesquisadores em estudos análogos citados nas seções 3.5.1; 3.5.2; 3.7 e 3.7.1.

Já as blendas F3 com OM e F3 com TWEEN ${ }^{\circledR}$ 80, tiveram mudanças significativas de percentual entre si $(3,7 \%)$ após a irradiação, sendo que a blenda F3 com TWEEN ${ }^{\circledR} 80$ teve o maior valor de cristalinidade individual $(45,8 \%)$ dentre todas as amostras analisadas. As blendas F3 também apresentaram melhores percentuais médios em relação as formulações F0 e F1, e também percentuais individuais semelhantes de cristalinidade em relação as amostras F2 plastificadas somente com OM/TWEEN ${ }^{\circledR} 80$. Concluiu-se que o percentual de cristalinidade das blendas F3, não foi significativamente alterado com a interação do TWEEN ${ }^{\circledR} 80$ e os componentes da blenda. 


\section{CONCLUSÕES}

A partir das análises de caracterizações realizadas nas blendas não irradiadas e irradiadas, concluiu-se:

Nos ensaios de TGA/DTG, as blendas compostas por óleo de mamona tiveram melhores resultados à degradação térmica em relação as compostas por glicerol devido a interação química provocada pelo processo de esterificação dos componentes pelo processo de extrusão reativa. Observou-se que as amostras constituídas por glicerol sofreram com o processo de migração de plastificantes ao longo do tempo devido as fracas ligações químicas, o que favoreceu a perda de propriedades finais. O processo de irradiação com dose de 25 kGy, não provocou mudanças significativas entre as blendas F0-F1 e F2-F3 o que ficou demonstrado nos gráficos de DTG onde se observou estágios definidos de degradação das amostras não ocorrendo distorção gráfica entre elas.

Nos ensaios de DSC, observou-se que as amostras F2-F3 apresentaram valores maiores de fluxo de calor para a degradação do que as amostras F0-F1, devido a interação química do óleo de mamona e seus constituintes, sendo que não houve variações térmicas no processo de irradiação entre as amostras F0-F1 e F2-F3.

Nos ensaios de FTIR, as blendas não sofreram alterações químicas provocadas pelo processo de irradiação, mantendo suas propriedades.

Nas análises morfológicas, observou-se a partir das micrografias que as amostras tiveram boa homogeneização, porém ambas apresentaram dimples após a fratura vítrea, decorrentes da má interação entre as fases das blendas, nas quais as amostras F0-F1 apresentaram miscibilidade parcial e as F2-F3 não tiveram fases co-contínuas e dimples mais acentuados com grânulos de amido não incorporados e dispersos presentes em sua superfície. Assim sendo, o processo de irradiação não modificou visualmente a morfologia das blendas. 
Nas curvas de DRX, observou-se que as amostras não apresentaram mudanças significativas entre si e também pela radiação gama em seus picos cristalinos, onde as constituídas pelo óleo de mamona obtiveram os melhores resultados. Nos resultados de índice de cristalinidade (IC), observou-se que houve mudança de cristalinidade de acordo com o tipo de plastificante utilizado e uso do TWEEN $^{\circledR}$ 80. As blendas F0 e F1 não tiveram alterações significativas no IC. Entretanto, houve diferença de cristalinidade entre as amostras F1-NIR/25 kGy $(3,5 \%)$ com a incorporação de TWEEN ${ }^{\circledR}$ 80. As blendas F2-F3 obtiveram os maiores índices individuais e diferença de cristalinidade após a irradiação, demonstrado pela interação química entre os componentes e o possível processo de cristalização induzida pela radiação com o OM/TWEEN ${ }^{\circledR} 80$ e o amido/PBAT após o processo de plastificação e extrusão reativa.

Por fim, concluiu-se que a substituição do glicerol pelo óleo de mamona no processo de plastificação e obtenção do TPS para composição de blendas com o PBAT, mostrou-se viável em virtude de suportar variações de temperatura, resistência à degradação térmica, interação química sem perda de plastificantes e ser facilmente esterilizada pela radiação gama sem apresentar modificações morfológicas e químicas. 


\section{SUGESTÕES DE TRABALHOS FUTUROS}

- Avaliar o comportamento mecânico das blendas por meio de ensaios biaxiais e de fluência;

- Estudar o desenvolvimento de próteses ou elementos de fixação ósseos, baseados em polímeros biodegradáveis com matrizes à base de polissacarídeos e ácidos glaxos, carregados com enzimas biodigestoras;

- Estudar a biocompatibilidade celular com blendas deste trabalho para fins ortopédicos;

- Estudar o desenvolvimento e produção de produtos biodegradáveis, processados por radiação ionizante com longo ciclo de vida. 


\section{REFERÊNCIAS BIBLIOGRÁFICAS}

ABRAMOWSKA, A.; CIEŚLA K. A.; BUCZKOWSKI, M. J.; NOWICKI, A.; GŁUSZEWSKI, W. The influence of ionizing radiation on the properties of starch-PVA films. Nukleonika, v. 60, n. 3, p. 669-677, 2015.

AGUILERA-MIGUEL, A.; LÓPEZ-GONZALEZ, E.; SADTLER, V.; DURAND, A.; MARCHAL, P.; CASTEL, C.; CHOPLIN, L. Hydrophobically modified dextrans as stabilizers for O/W highly concentrated emulsions. Comparison with commercial non-ionic polymeric stabilizers. Colloids and Surfaces aPhysicochemical and Engineering Aspects, v. 550, p. 155-166, 2018.

AKHAVAN, A.; KHOYLOU, F.; ATAEIVARJOVI, E. Preparation and characterization of gamma irradiated Starch/PVA/ZnO nanocomposite films. Radiation Physics and Chemistry, v. 138, p. 4953, 2017.

AMERICAN SOCIETY FOR TESTING AND MATERIALS. Labeling of Plastics Designed to be Aerobically Composted in Municipal or Industrial Facilities, ASTM 2012. (ASTM D 6400-12).

AMERICAN SOCIETY FOR TESTING AND MATERIALS. Standard Practice for Determination of Structural Features in Polyolefins and Polyolefin Copolymers by Infrared Spectrophotometry (FTIR), ASTM 2013. (ASTM D 5576-00(2013)).

AMERICAN SOCIETY FOR TESTING AND MATERIALS. Standard Test Method for Thermal Stability by Thermogravimetry, ASTM 2017. (ASTM E 2550-17).

ATROUS, H.; BENBETTAIEB, N.; HOSNI, F.; DANTHINE, S.; BLECKER, C.; ATTIA, H.; GHORBEL, D. Effect of gamma-radiation on free radicals formation, structural changes and functional properties of wheat starch. International Journal of Biological Macromolecules, v. 80, p. 64-76, 2015.

AVEROUS, L.; BOQUILLON, N. Biocomposites based on plasticized starch: thermal and mechanical behaviours. Carbohydrate Polymers, v. 56, n. 2, p. 111-122, 2004.

AZEVEDO, E. C.; CHIERICE, G. O.; NETO, S. C.; SOBOLL, D. S.; NASCIMENTO, E. M.; LEPIENSKI, C. M. Gamma radiation effects on mechanical properties and morphology of a polyurethane derivate from castor oil. Radiation Effects and Defects in Solids, v. 166, n. 3, p. 208-214, 2011.

AZEVEDO, E. C.; NASCIMENTO, E. M.; CHIERICE, G. O.; NETO, S. C.; LEPIENSKI, C. M. UV and Gamma Irradiation Effects on Surface Properties of Polyurethane Derivate from Castor Oil. Polimeros-Ciencia e Tecnologia, v. 23, n. 3, p. 305-311, 2013.

A. AZEVEDO IND. E COM. DE ÒLEOS LTDA. Óleo de mamona, 2017. (Laudo de análise).

BALBANI, A. P. S.; KRAWCZYK, A. L. Efeitos da exposição aos campos eletromagnéticos do telefone celular. Controvérsias \& Interfaces. Grupo Editorial Moreira Jr., p.87-96. Disponível em: < http://www.moreirajr.com.br/revistas.asp?fase=r003\&id_materia=4158> Acesso em: 23 jul. 2016. 
BASF BRASIL. Embalagens compostáveis: um futuro possível.

Produzido por BASF Brasil. Disponível em:

<https://www.basf.com/br/pt/company/news-andmedia/quimica_dia_a_dia/ecovio_pauta.html> Acesso em: 30 abr. 2018.

BAUMHARDT NETO, R. Raios X. In: CANEVAROLO JÚNIOR, S. V. (Org.) Técnicas de Caracterização de Polímeros. São Paulo: Artliber Editora Ltda., 2004. p. 41-60.

BRANDELERO, R. P. H.; GROSSMANN, M. V. E.; YAMASHITA, F. Effect of the method of production of the blends on mechanical and structural properties of biodegradable starch films produced by blown extrusion. Carbohydrate Polymers, v. 86, n. 3, p. 1344-1350, 2011.

BRANDELERO, R. P. H.; GROSSMANN, M. V.; YAMASHITA, F. Hydrophilicity of Starch and Poly(Butylene Adipate-Co-Terephthalate) (Pbat) Films Containing Tween 80 and Soybean Oil.

Polimeros-Ciencia e Tecnologia, v. 23, n. 2, p. 270-275, 2013.

BRASKEM - I'm Green, Plástico. Disponível: <http://www.braskem.com/site.aspx/plasticoverde> Acesso em: 22 mai. 2018.

BRITO, G. F.; AGRAWAL, E. M.; ARAÚJO, T.; MÉLO, J. A. Biopolímeros, Polímeros Biodegradáveis e Polímeros Verdes. Revista eletrônica de materiais e processos, v.6.2, p. 127-139, 2011. Departamento de Engenharia de Materiais - Universidade Federal de Campina Grande, Campina Grande, 2011.

CALLISTER JR., W. D.; RETHWISCH, D. G. Materials Science and Engineering: An Introduction. 8 ed., John Wiley \& Sons, INC., 2009.

CARDOSO, E. C. L. OLIVEIRA, R. R.; MACHADO, G. A. F.; MOURA, E. A. B. Study of Flexible Films Prepared from PLA/PBAT Blend and PLA E-Beam Irradiated as Compatibilizing Agent.

Characterization of Minerals, Metals, and Materials 2017, p. 121-129, 2017.

CHIU, H. T.; HUANG, S. Y.; CHEN, Y. F.; KUO, M. T.; CHIANG, T. Y.; CHANG, C. Y.; WANG, Y. H. Heat Treatment Effects on the Mechanical Properties and Morphologies of Poly (Lactic Acid)/Poly (Butylene Adipate-co-terephthalate) Blends. International Journal of Polymer Science, p. 11, 2013.

CHUNG, F. H.; SCOTT, R. W. A New Approach to the Determination of Crystallinity of Polymers by X-ray Diffraction. Journal of Applied Crystallography, v. 6, n. 3, p. 225-230, 1973.

CORRADINI, E.; TEIXEIRA, E. M.; AGNELI, J. A. M.; MATTOSO, L. H. C. Amido Termoplástico - São Carlos: Embrapa Instrumentação Agropecuária, 2007. Disponível em: < https://www.infoteca.cnptia.embrapa.br/bitstream/doc/30796/1/DOC302007.pdf> Acesso em: 25 jul. 2016.

CORREIA, C. A. Obtenção e caracterização de PLA reforçado com nanocelulose. 2015. Dissertação (Mestrado em Engenharia Metalúrgica e de Materiais) - Escola Politécnica, Universidade de São Paulo, São Paulo, 2015. Disponível em: <www.teses.usp.br>. Acesso em: 13 dez. 2018.

ESMAEILI, M.; PIRCHERAGHI, G.; BAGHERI, R.; ALTSTADT, V. The impact of morphology on thermal properties and aerobic biodegradation of physically compatibilized poly (lactic acid)/co-plasticized thermoplastic starch blends. Polymers for Advanced Technologies, v. 29, n. 12, p. 2880-2889, 2018.

FIOCRUZ. Radiação. Disponível em: <http://www.fiocruz.br/biosseguranca/Bis/lab_virtual/radiacao.html> Acesso em: 25 jul. 2016. 
FONSECA, N. B. S.; SOTO-BLANCO, B. Toxicidade da ricina presente nas sementes de mamona. Semina: Ciências Agrárias, Londrina v. 35, n. 3, p. 1415-1424, 2014.

FOOD INGREDIENTS BRASIL. Dossiê especial: Amidos. v. 17, n. 35, p. 31-39, 2015. Disponível em: < http://www.revista-fi.com/edicoes/77/\#p=1> Acesso em: 21 jul. 2016.

GANI, A.; BASHIR, M.; WANI, S. M.; MASOODI, F. M. Modification of bean starch by gammairradiation: Effect on functional and morphological properties. Lwt-Food Science and Technology, v. 49, n. 1, p. 162-169, 2012.

GARRISON, T. F.; MURAWSKI, A.; QUIRINO, R. L. Bio-Based Polymers with Potential for Biodegradability. Polymers, v. 8, n. 7, p. 22, 2016.

GILES JR., H. F.; WAGNER JR., J. R.; MOUNT III., E. M. Extrusion: The Definitive Processing Guide and Handbook, Willian Andrew Publishing, 2004.

GONÇALVES, M. DO C. Microscopia eletrônica de varredura. In: CANEVAROLO JÚNIOR, S. V. (Org.) Técnicas de Caracterização de Polímeros. São Paulo: Artliber Editora Ltda., 2004. p. 165-175.

HAN, C. Y.; BIAN, J. J.; LIU, H.; DONG, L. S. Effect of gamma-radiation on the thermal and mechanical properties of a commercial poly(butylene adipate-co-terephthalate). Polymer International, v. 58, n. 6, p. 691-696, 2009.

HWANG, I. T.; CHAN-HEE, J.; IN-CHOI, K.; JAE-HAK, C.; YOUNG-CHANG, N. Electron beam-induced crosslinking of poly(butylene adipate-co-terephthalate). Nuclear Instruments \& Methods in Physics Research Section B-Beam Interactions with Materials and Atoms, v. 268, n. 21, p. 33863389, 2010.

KAWANO, Y. Espectroscopia vibracional de absorção no infravermelho. In: CANEVAROLO JÚNIOR, S. V. (Org.) Técnicas de Caracterização de Polímeros. São Paulo: Artliber Editora Ltda., 2004. p. 17-39.

KUMAR, P.; PRAKASH, K. S.; JAN, K.; SWER , T. L.; JAN, S.; VERMA, R.; DEPPIKA, K.; DAR, M. Z. ; VERMA, K.; BASHIR, K. Effects of gamma irradiation on starch granule structure and physicochemical properties of brown rice starch. Journal of Cereal Science, v. 77, p. 194-200, 2017.

LEE, H. Y.; DANJO, T.; IWATA, T. Synthesis and characterization of dextrin derivatives by heterogeneous esterification. Journal of Polymer Research, v. 25, n. 3, p. 8, 2018.

LIMA FILHO, T.; TEIXEIRA, L. J. Q.; ROCHA, C. T. da; FERREIRA, G. A. M.; SOUZA, M. C. de. Energia ionizante na conservação de alimentos: revisão. B. CEPPA, Curitiba, v. 30, n. 2. Curitiba. 2012. Disponível em:<https://revistas.ufpr.br/alimentos/article/view/30501>. Acesso em: 27 out. 2018.

MA, X. Y.; WANG, Y. F.; WANG, J. Q.; XU, Y. N. Effect of PBAT on Property of PLA/PHB Film Used for Fruits and Vegetables. International Conference on Biomaterials, Nanomaterials and Composite Materials (CBNCM), 2016, Chengdu, Peoples R. China. E. D. P. Sciences, Nov 04-06.

MACHADO, L. D. B.; MATOS, J. DO R. Análise térmica diferencial e calorimetria exploratória diferencial. In: CANEVAROLO JÚNIOR, S. V. (Org.) Técnicas de Caracterização de Polímeros. São Paulo: Artliber Editora Ltda., 2004. p. 229-261.

MAGALHÃES, M. T.; MIRANDA, C. S.; JOSÉ, N. M. Estudo do monitoramento tecnológico de blendas poliméricas constituídas por poliésteres aromáticos alifáticos e amido - Universidade Federal da Bahia, (UFBA), v. 8, n. 1, p. 85-91, 2015. 
MALI, S.; GROSSMANN, M. V. E.; YAMASHITA, F. Filmes de amido: produção, propriedades e potencial de utilização. Semina: Ciências Agrárias, v. 31, n. 1, p. 137-156, 2010.

MARINHO, V. A. D.; PEREIRA, C. A. B.; VITORINO, M. B. C.; SILVA, A. S.; CARVALHO, L. H.; CANEDO, E. L. Degradation and recovery in poly(butylene adipate-co-terephthalate)/thermoplastic starch blends. Polymer Testing, v. 58, p. 166-172, 2017.

MATOS, J. DO R.; MACHADO, L. D. B. Análise térmica - Termogravimetria. In: CANEVAROLO JÚNIOR, S. V. (Org.) Técnicas de Caracterização de Polímeros. São Paulo: Artliber Editora Ltda., 2004. p. 209-228.

MILES, D. C.; BRISTON, J. H. Tecnologia de Polímeros, São Paulo: Editora Polígono S.A, 1975.

MORAES, A. R. F. e; POLA, C. C.; BILCK, A. P.; YAMASHITA, F.; TRONTO, J.; MEDEIROS, E. A. A.; SOARES, N. F. F. Starch, cellulose acetate and polyester biodegradable sheets: Effect of composition and processing conditions. Materials Science \& Engineering C-Materials for Biological Applications, v. 78, p. 932-941, 2017.

MOUSTAFA, H.; GUIZANI, C.; DUFRESNE, A. Sustainable biodegradable coffee grounds filler and its effect on the hydrophobicity, mechanical and thermal properties of biodegradable PBAT composites. Journal of Applied Polymer Science, v. 134, n. 8, p. 11, 2017.

NEMTANU, M. R.; BRASOVEANU, M. Degradation of amylose by ionizing radiation processing. Starch-Starke, v. 69, n. 3-4, p. 9, 2017.

NUNES, M. R. S.; MARTINELLI, M.; PEDROSO, M. M. Epoxidação do óleo de mamona e derivados empregando o sistema catalítico VO(acac) 2 /TBHP\#. Química Nova, v. 31, n. 4, p. 818-821, 2008.

OKUNO, E. Efeitos biológicos das radiações ionizantes. Acidente radiológico de Goiânia - Instituto de Física da Universidade de São Paulo (IF-USP). Estudos Avançados, v. 27, n. 77, p. 185, 2013.

OLIVEIRA, C. F. de P. Obtenção e caracterização de amido termoplástico e de suas misturas com polipropileno. 2015. Tese (Doutorado em Engenharia Metalúrgica e de Materiais) - Escola Politécnica, Universidade de São Paulo, São Paulo, 2015. Disponível em: <www.teses.usp.br>. Acesso em: 20 out. 2018.

PAN, H. W.; JU, D. D.; ZHAO, Y.; WANG, Z.; YANG, H. L.; ZHANG, H. L.; DONG, L. S. Mechanical Properties, Hydrophobic Properties and Thermal Stability of the Biodegradable Poly(butylene adipate-co-terephthalate)/Maleated Thermoplastic Starch Blown Films. Fibers and Polymers, v. 17, n. 10 , p. 1540-1549, 2016.

POLESI, L. F.; SARMENTO, S. B. S.; DE MORAES, J.; FRANCO, C. M. L.; CANNIATTI-BRAZACA, S. G. Physicochemical and structural characteristics of rice starch modified by irradiation. Food Chemistry, v. 191, p. 59-66, 2016.

POVEDA, P. N. S. Estudo do efeito de nanopartículas de carbonato de cálcio, dióxido de titânio e óxido de zinco nas propriedades dos termoplásticos polietileno de baixa densidade linear $e$ copoliéster alifático aromático, submetidos à radiação ultravioleta. 2015. Tese (Doutorado em Tecnologia Nuclear - Aplicações) - Instituto de Pesquisas Energéticas e Nucleares, Universidade de São Paulo, São Paulo, 2018. Disponível em: <www.teses.usp.br> Acesso em: 16 de jun. 2018.

PRODUCT INFORMATION: Ecoflex ${ }^{\circledR}$ F Blend C 1200 - 2013. Disponível em: <http://productfinder.basf.com/group/corporate/product-finder/en/general-info:/Brand+ecoflex> Acesso em: 13 mai. 2018. 
RABELLO, M. S. Aditivação de Polímeros, São Paulo: Artliber Editora, 2000.

ROGOVINA, S. Z. Biodegradable polymer composites based on synthetic and natural polymers of various classes. Polymer Science Series C, v. 58, n. 1, p. 62-73, 2016.

SABERI, B.; CHOCKCHAISAWASDEE, S.; GOLDING, J. B.; SCARLETT, C. J.; STATHOPOULOS, C. E. Physical and mechanical properties of a new edible film made of pea starch and guar gum as affected by glycols, sugars and polyols. International Journal of Biological Macromolecules, v. 104, p. 345-359, 2017.

SANTOS, R. A. L.; MULLER, C. M. O.; GROSSMANN, M.V.E.; MALI, S. YAMASHITA, F. Starch/poly (butylene adipate-co-terephthalate)/montmorillonite films produced by blow extrusion. Quimica Nova, v. 37, n. 6, p. 937-U23, 2014.

SATHISKUMAR, P. S.; MADRAS, G. Synthesis, characterization, degradation of biodegradable castor oil based polyesters. Polymer Degradation and Stability, v. 96, n. 9, p. 1695-1704, 2011.

SCHIMITBERGER, T. Desenvolvimento de filmes dosimétricos fotoluminescentes à base do PBAT e do MEH-PPV para aplicação em dosimetria de altas doses de radiação Gama. 2015. Tese (Doutorado) - Universidade Federal de Minas Gerais, Minas Gerais. 145p. Disponível em: < http://www.bibliotecadigital.ufmg.br/dspace/handle/1843/BUBD-A9TKW7> Acesso em: 10 jul. 2018.

SCHLEMMER, D.; SALES M. J. A.; RESCK, I. S. Preparação, caracterização e degradação de blendas PS/TPS usando glicerol e óleo de buriti como plastificantes. Polímeros: Ciência e Tecnologia, v. 20, n. 1, p. 6-13, 2010.

SIGMA ALDRICH. Glycerol G9012. Brazil, 2018. (Catálogo comercial). Disponível em:< https://www.sigmaaldrich.com/catalog> Acesso em: 28 abr. 2018.

SIGMA ALDRICH. Oleic acid. Brazil, 2018. (Catálogo comercial). Disponível em:< https://www.sigmaaldrich.com/catalog> Acesso em: 28 abr. 2018.

SIGMA ALDRICH. TWEEN 80® P1754. Brazil, 2018. (Catálogo comercial). Disponível em:< https://www.sigmaaldrich.com/catalog> Acesso em: 10 jun. 2018.

SILVERSTEIN, R. M; WEBSTER, F.X.; KIEMLE, D.J. Spectrometric Identification of Organic Compounds. 7 ed., John Wiley \& Sons, INC., 2005.

ULTRACKI, L.A. Polymer Blends Handbook. Kluwer Academic Publishers, vol.1, 2002.

VIEIRA, M. M. G. Desenvolvimento de compostos poliméricos biodegradáveis modificados com cargas e fibras naturais vegetais. 2010. Dissertação (Mestrado) - Universidade Federal de São Carlos, São Paulo. 162p.

WELLEN, R. M. R.; RABELLO, M. S.; FECHINE, G. J. M.; CANEDO, E. L. The melting behaviour of poly(3-hydroxybutyrate) by DSC. Reproducibility study. Polymer Testing, v. 32, n. 2, p. 215-220, 2013.

WOJNÁROVITS, L. Handbook of Nuclear Chemistry: Chemical Appications of Nuclear Reactions and Radiations, Kluwer Academic Publishers, vol.3, Cap. 1, 2003.

YOSHIMURA, E. M. Física das Radiações: interação da radiação com a matéria. Revista Brasileira de Física Médica, v. 3, n. 1, p. 57-67, 2009. 
ZEHETMEYER, G. Desenvolvimento e caracterização de embalagens ativas compostas de PBAT com incorporação de nisina. 2016. Tese (Doutorado) - Universidade Federal do Rio Grande do Sul, Rio Grande do Sul. 178p. Disponível em: < https://www.lume.ufrgs.br/handle/10183/143867> Acesso em: 26 ago. 2018.

ZHU, F. Impact of gamma-irradiation on structure, physicochemical properties, and applications of starch. Food Hydrocolloids, v. 52, p. 201-212, 2016.

ZUO, Y. F.; GU, J. Y.; YANG, L.; QIAO, Z. B.; ZHANG, Y. H. Study on the preparation of maleated thermoplastic starch by reactive extrusion. Journal of Thermoplastic Composite Materials, v. 29, n. 3, p. 397-409, 2016. 
APÊNDICE A - Micrografias em diferentes perspectivas e magnificações das blendas não irradiadas (NIR) e irradiadas a 25 kGy

Tabela 13 - Micrografias das blendas F0 em diferentes magnificações (25x, 27x, 200x, 500x): Não irradiadas (NIR) e irradiadas a $25 \mathrm{kGy}$

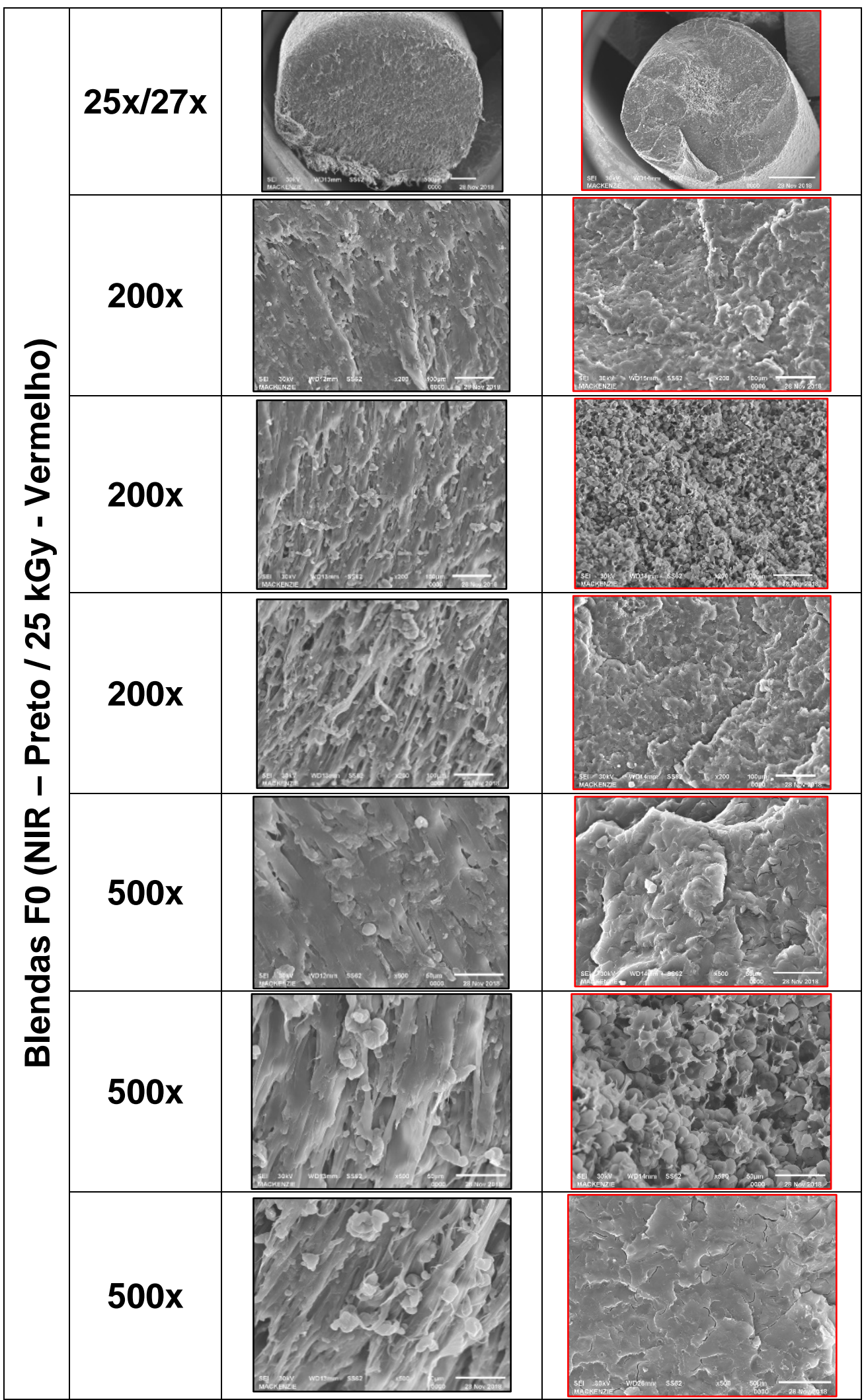

Fonte: autor da dissertação. 
Tabela 14 - Micrografias das blendas F1 em diferentes magnificações (27x, 30x, 200x, 500x): Não irradiadas (NIR) e irradiadas a $25 \mathrm{kGy}$

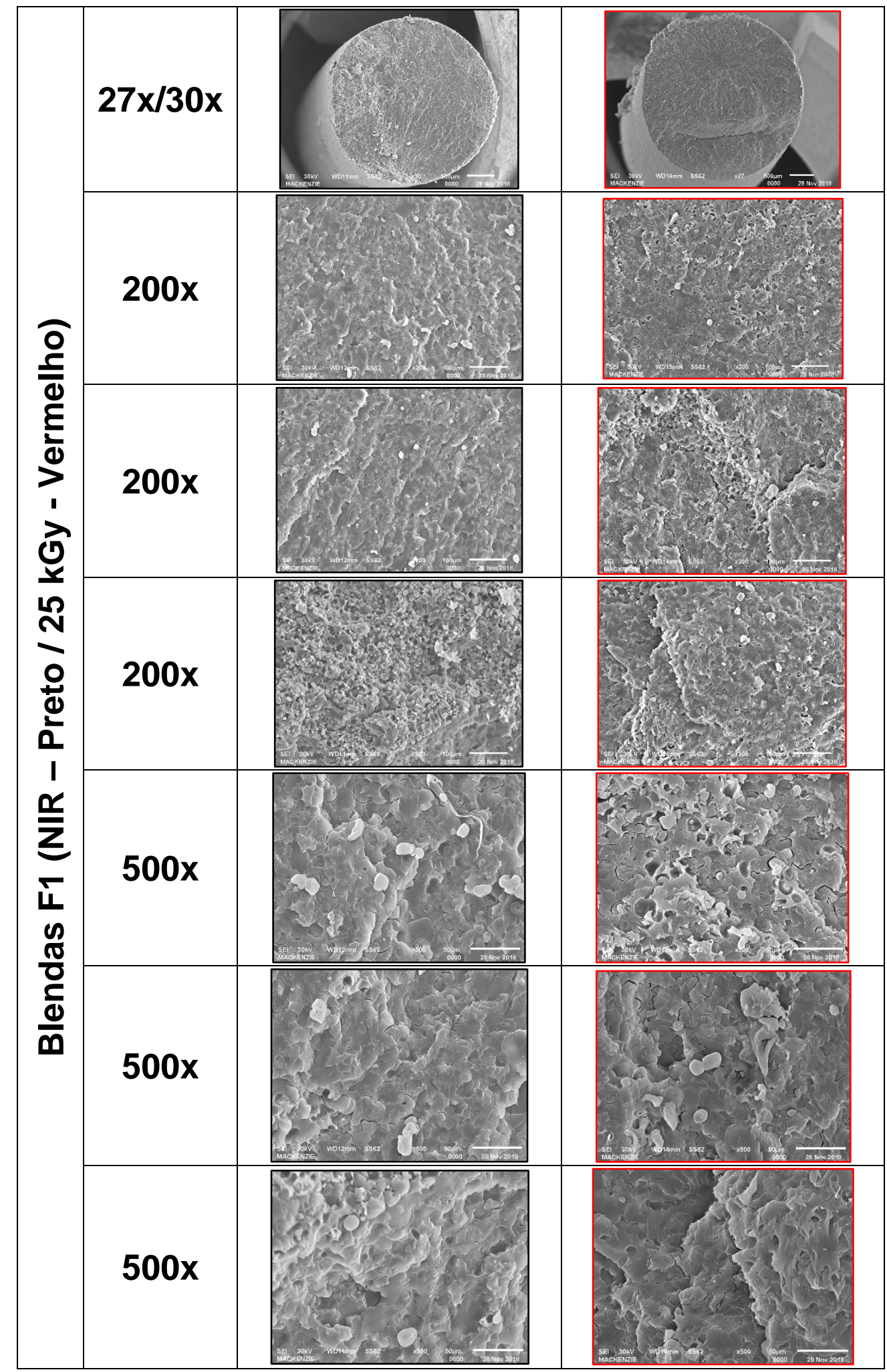

Fonte: autor da dissertação. 
Tabela 15 - Micrografias das blendas F2 em diferentes magnificações (27x, 30x, 200x, 500x): Não irradiadas (NIR) e irradiadas a $25 \mathrm{kGy}$

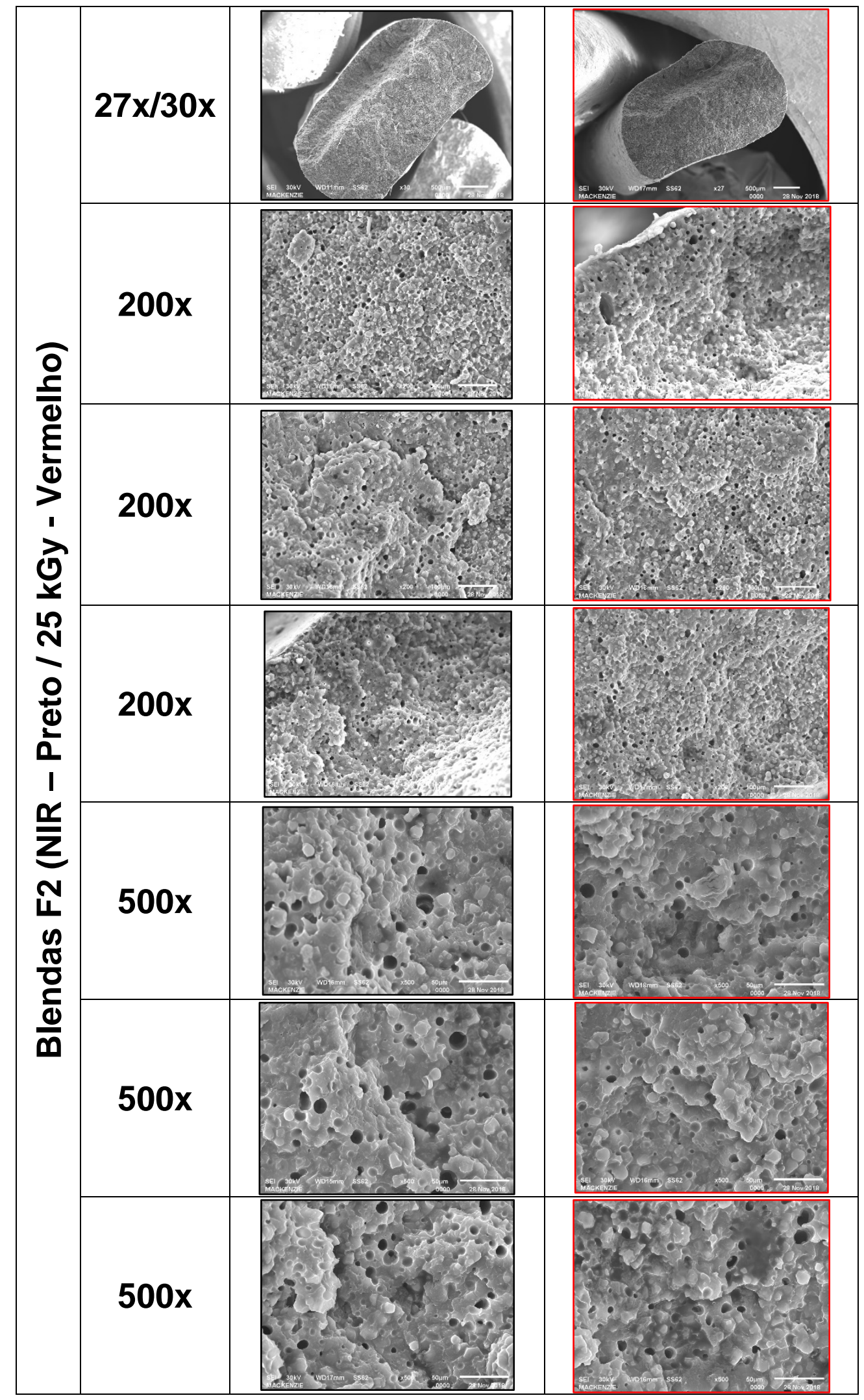

Fonte: autor da dissertação. 
Tabela 16 - Micrografias das blendas F3 em diferentes magnificações (27x, 200x, 500x): Não irradiadas (NIR) e irradiadas a 25 kGy

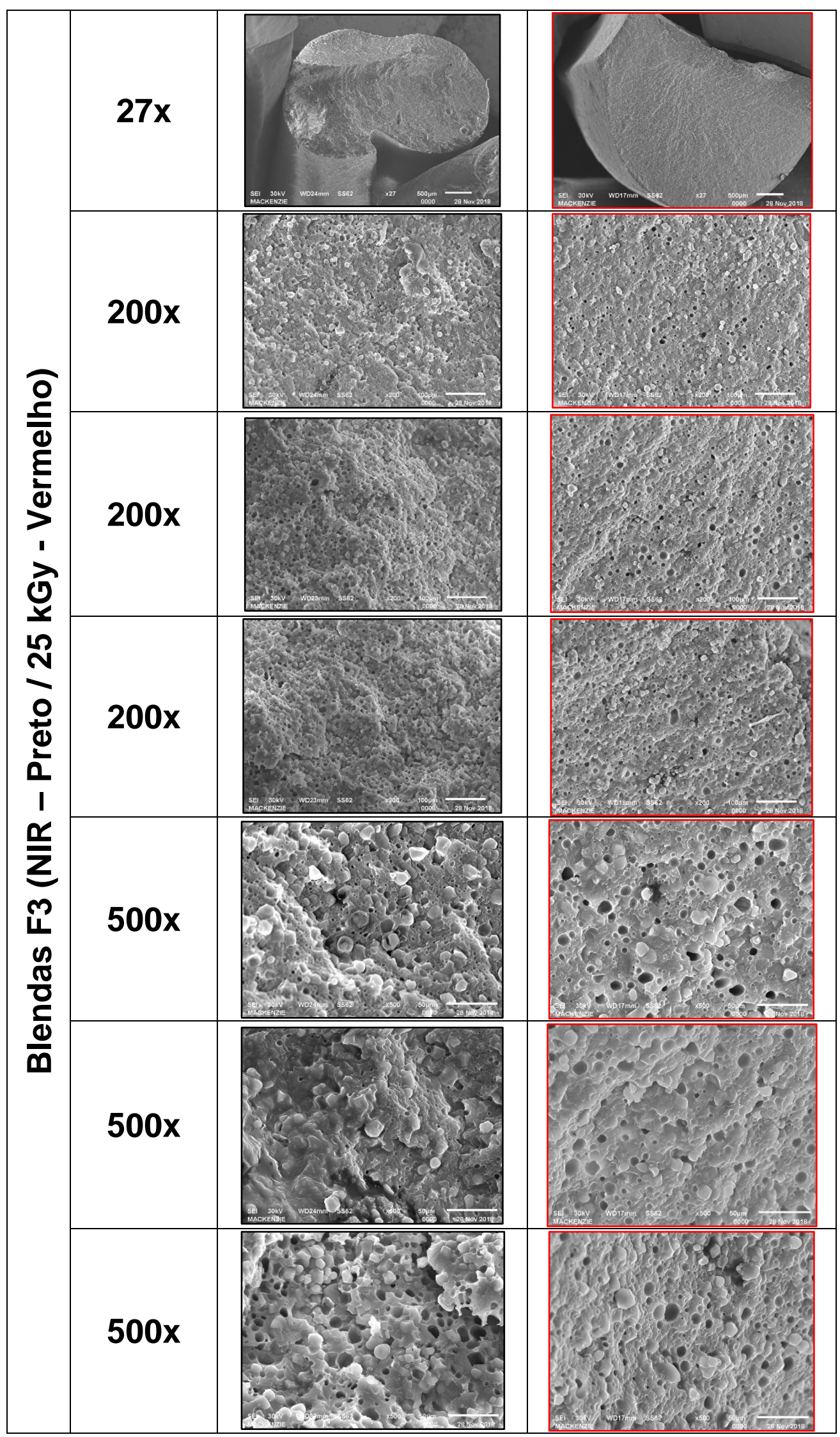

Fonte: autor da dissertação. 
APÊNDICE B - Dados utilizados para cálculo do índice de cristalinidade das blendas por meio de curvas de DRX pelo método de subtração do halo amorfo

1 - Blenda F0 - (NIR/25 kGy)

Tabela 17 - Área total de integração da curva de DRX da blenda F0 - (NIR/25 kGy)

\begin{tabular}{|c|c|c|}
\hline Blenda & Área total & Centro do pico \\
\hline F0 - NIR & 11.847 & 23,12 \\
\hline F0 - 25 kGy & 13.007 & 23,06 \\
\hline
\end{tabular}

Fonte: autor da dissertação.

Figura 54 - Área total da região cristalina da blenda F0 - (NIR/25 kGy), após a correção de linha base da curva de DRX
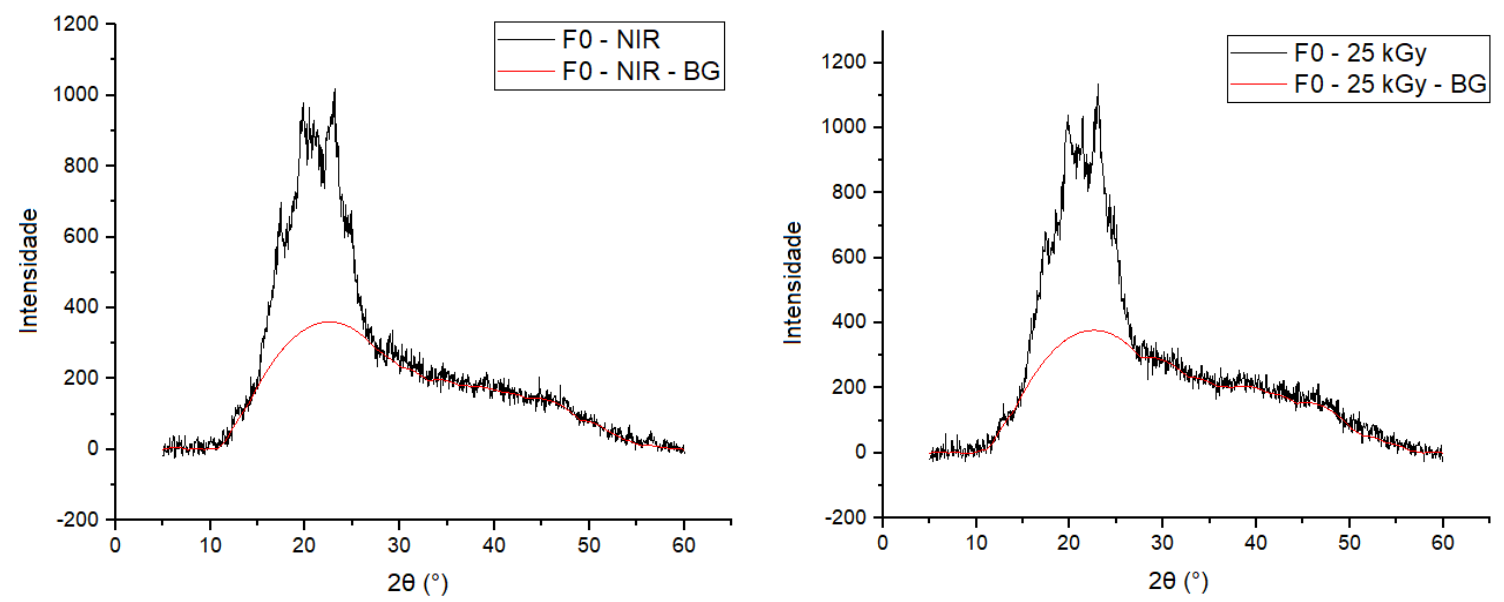

BG: Background (do inglês "linha base", linha referente à fração de amorfo)

Fonte: autor da dissertação.

Tabela 18 - Área dos picos de integração da curva de DRX da blenda F0 - (NIR/25 kGy) após correção de linha base

\begin{tabular}{c|c|c|} 
Blenda & Área cristalina & Centro do pico \\
\hline F0 - NIR & 4.262 & 23,12 \\
\hline F0 - 25 kGy & 4.668 & 23,06 \\
\hline
\end{tabular}

Fonte: autor da dissertação. 
2 - Blenda F1 - (NIR/25 kGy)

Tabela 19 - Área total de integração da curva de DRX da blenda F1 - (NIR/25 kGy)

\begin{tabular}{|c|c|c|}
\hline Blenda & Área total & Centro do pico \\
\hline F1 - NIR & 10.430 & 22,94 \\
\hline F1 - 25 kGy & 9.825 & 22,76 \\
\hline
\end{tabular}

Fonte: autor da dissertação.

Figura 55 - Área total da região cristalina da blenda F1 - (NIR/25 kGy), após a correção de linha base da curva de DRX
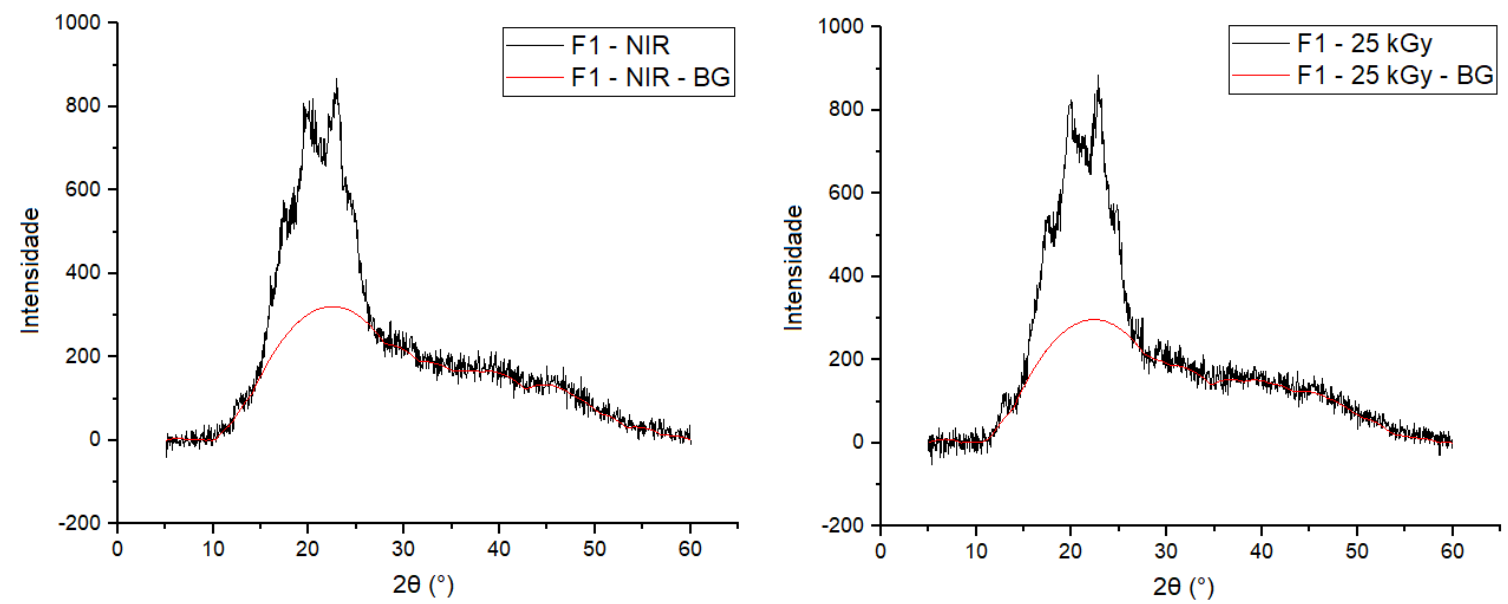

BG: Background (do inglês "linha base", linha referente à fração de amorfo)

Fonte: autor da dissertação.

Tabela 20 - Área dos picos de integração da curva de DRX da blenda F1 - (NIR/25 kGy) após correção de linha base

\begin{tabular}{c|c|c} 
Blenda & Área cristalina & Centro do pico \\
\hline F1 - NIR & 3.546 & 22,94 \\
\hline F1-25 kGy & 3.687 & 22,76 \\
\hline
\end{tabular}

Fonte: autor da dissertação. 
3 - Blenda F2 - (NIR/25 kGy)

Tabela 21 - Área total de integração da curva de DRX da blenda F2 - (NIR/25 kGy)

\begin{tabular}{c|c|c|}
\hline Blenda & Área total & Centro do pico \\
\hline F2 - NIR & 9.156 & 20,19 \\
\hline F2 - 25 kGy & 10.265 & 20,30 \\
\hline
\end{tabular}

Fonte: autor da dissertação.

Figura 56 - Área total da região cristalina da blenda F2 - (NIR/25 kGy), após a correção de linha base da curva de DRX
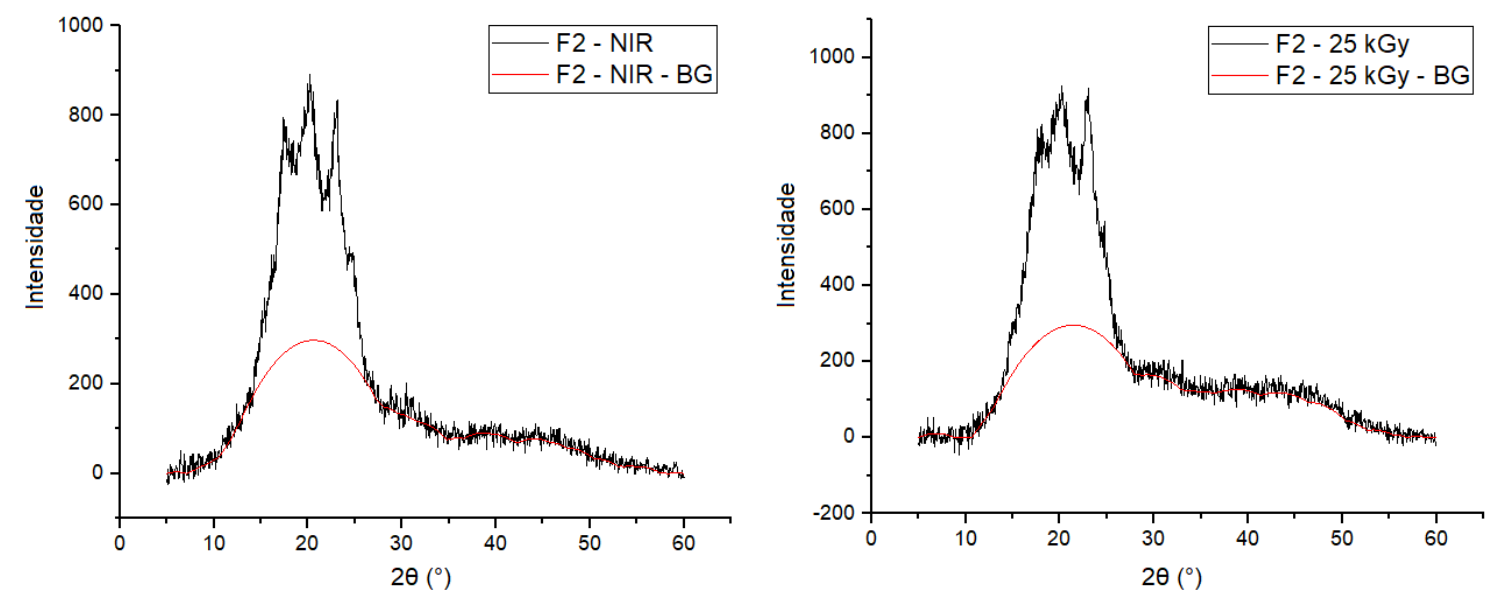

BG: Background (do inglês "linha base", linha referente à fração de amorfo)

Fonte: autor da dissertação.

Tabela 22 - Área dos picos de integração da curva de DRX da blenda F2 - (NIR/25 kGy) após correção de linha base

\begin{tabular}{c|c|c|} 
Blenda & Área cristalina & Centro do pico \\
\hline F2 - NIR & 4.016 & 20,19 \\
\hline F2 - 25 kGy & 4.657 & 20,30 \\
\hline
\end{tabular}

Fonte: autor da dissertação. 
4 - Blenda F3 - (NIR/25 kGy)

Tabela 23 - Área total de integração da curva de DRX da blenda F3 - (NIR/25 kGy)

\begin{tabular}{c|c|c|}
\hline Blenda & Área total & Centro do pico \\
\hline F3 - NIR & 6.762 & 23,06 \\
\hline F3 - 25 kGy & 18.316 & 23,06 \\
\hline
\end{tabular}

Fonte: autor da dissertação.

Figura 57 - Área total da região cristalina da blenda F3 - (NIR/25 kGy), após a correção de linha base da curva de DRX
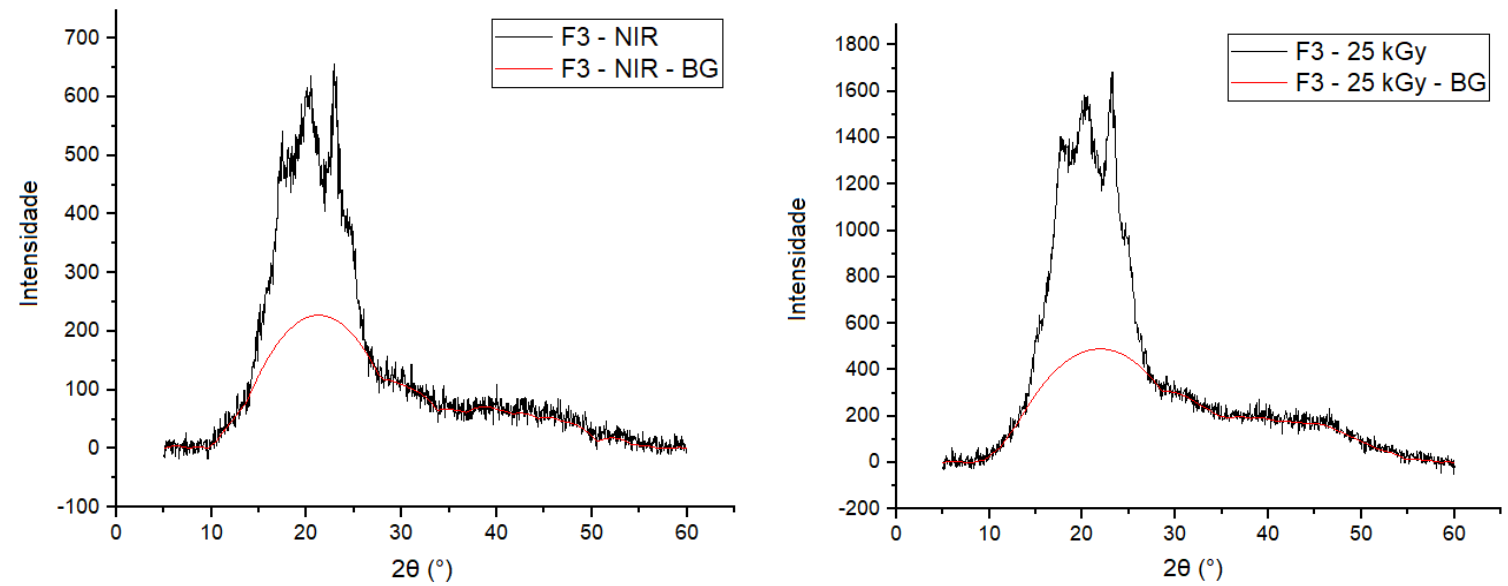

BG: Background (do inglês "linha base", linha referente à fração de amorfo)

Fonte: autor da dissertação.

Tabela 24 - Área dos picos de integração da curva de DRX da blenda F3 - (NIR/25 kGy) após correção de linha base

\begin{tabular}{c|c|c|} 
Blenda & Área cristalina & Centro do pico \\
\hline F3 - NIR & 2.844 & 23,06 \\
\hline F3 - 25 kGy & 8.394 & 23,06 \\
\hline
\end{tabular}

Fonte: autor da dissertação. 
ANEXO A - Laudo das propriedades físico-químicas do óleo de mamona

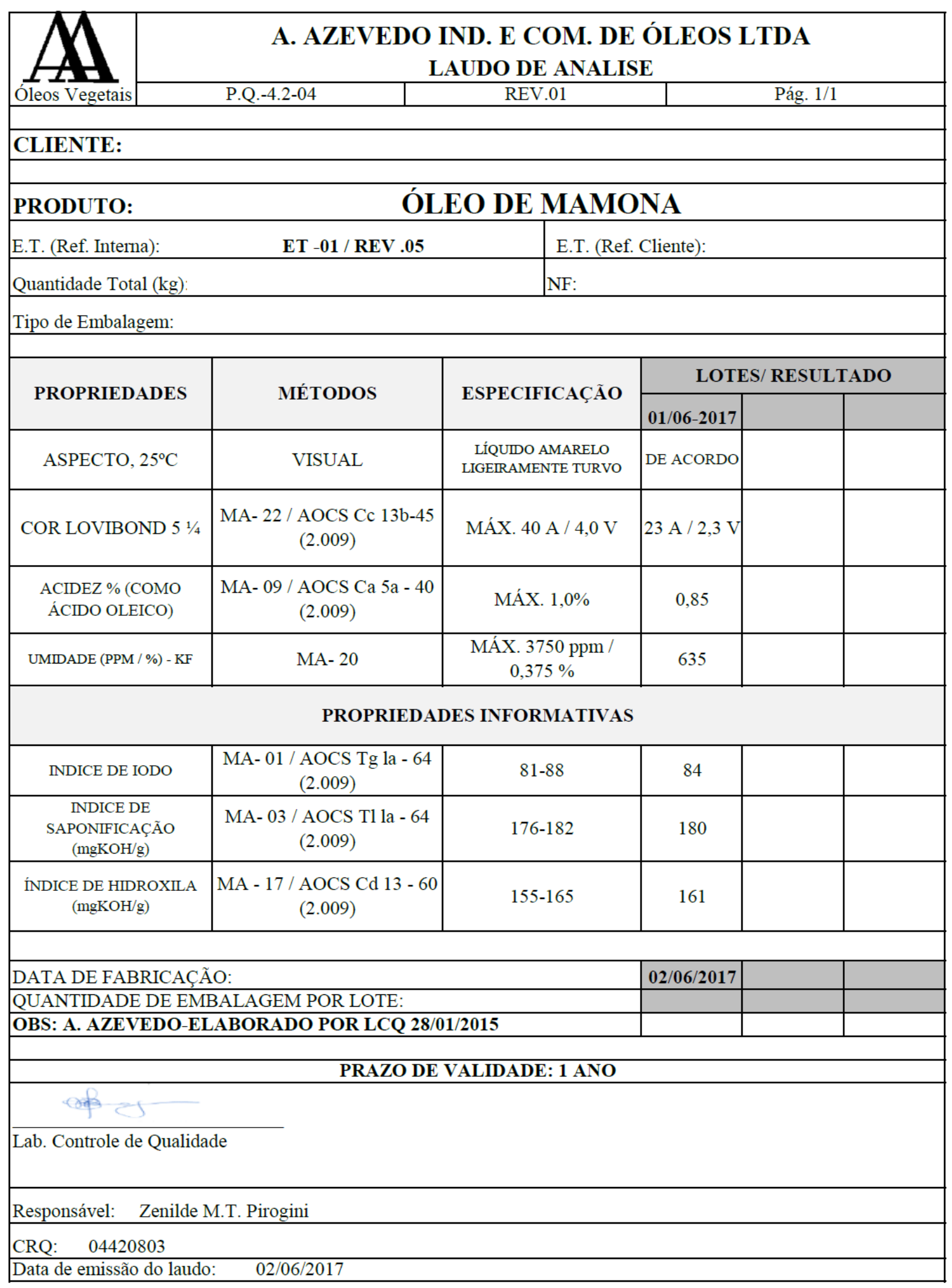


INSTITUTO DE PESQUISAS ENERGÉTICAS E NUCLEARES

Diretoria de Pesquisa, Desenvolvimento e Ensino

Av. Prof. Lineu Prestes, 2242 - Cidade Universitária CEP: 05508-000

Fone/Fax(0XX11) 3133-8908

SÃO PAULO - São Paulo - Brasil

http://www.ipen.br

O IPEN é uma Autaquia vinculada à Secretaria de Desenvolvimento, associada

à Universidade de São Paulo e gerida técnica e administrativamente pela

Comissão Nacional de Energia Nuclear, órgão do

Ministério da Ciência, Tecnologia e Inovação. 